I N T ER N ATIONAL MONETARY FUND

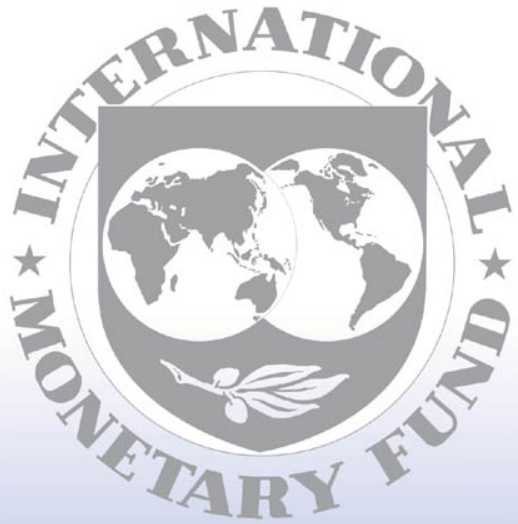

Staff

Country

Reports 


\section{Peru: Report on the Observance of Standards and Codes-Data Module, Response by the Authorities, and Detailed Assessments Using Data Quality Assessment Framework}

This Report on the Observance of Standards and Codes on Data Module for Peru was prepared by a staff team of the International Monetary Fund as background documentation for the periodic consultation with the member country. It is based on the information available at the time it was completed on October 7, 2003. The views expressed in this document are those of the staff team and do not necessarily reflect the views of the government of Peru or the Executive Board of the IMF.

The response by the Authorities on this report, and the Detailed Assessment Using the Data Quality Assessment Framework (DQAF) are also included.

The policy of publication of staff reports and other documents by the IMF allows for the deletion of market-sensitive information.

To assist the IMF in evaluating the publication policy, reader comments are invited and may be sent by e-mail to publicationpolicy@imf.org.

Copies of this report are available to the public from

International Monetary Fund • Publication Services

700 19th Street, N.W. • Washington, D.C. 20431

Telephone: (202) 6237430 • Telefax: (202) 6237201

E-mail: publications@imf.org • Internet: http://www.imf.org

Price: $\$ 15.00$ a copy

International Monetary Fund

Washington, D.C. 
This page intentionally left blank

CInternational Monetary Fund. Not for Redistribution 


\section{INTERNATIONAL MONETARY FUND}

\section{PERU}

\section{Report on the Observance of Standards and Codes (ROSC)—Data Module}

Prepared by the Statistics Department

Approved by Carol S. Carson and Anoop Singh

October 7, 2003

Contents

Acronyms......

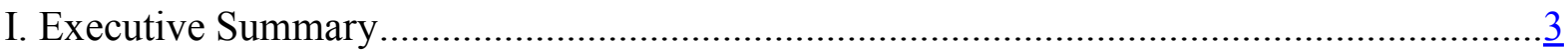

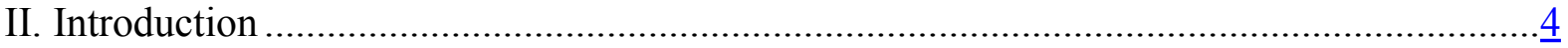

III. Data Dissemination Practices and the Special Data Dissemination Standard ...................... $\frac{5}{6}$

Data dimension: coverage, periodicity, and timeliness .....................................

Access dimension........................................................................................

Integrity dimension ....................................................................................

Quality dimension....................................................................................

Monitoring of data dissemination ...................................................................

IV. Summary Assessment of Data Quality ...................................................................

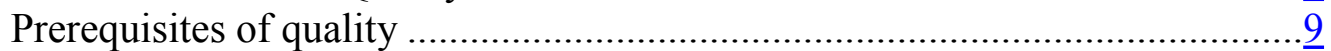

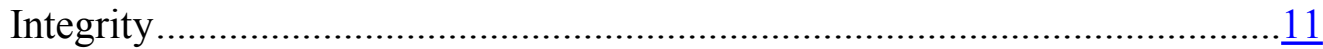

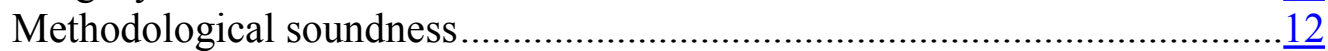

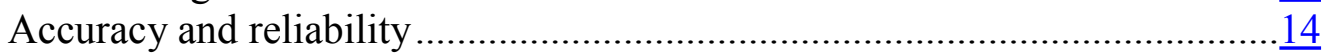

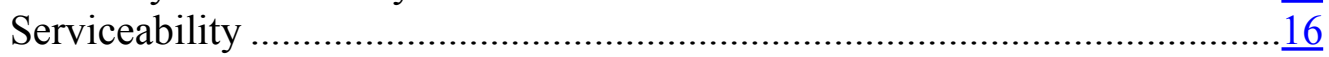

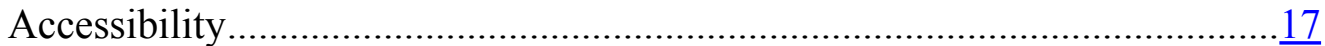

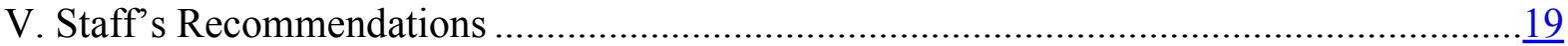

General Recommendations .....................................................................

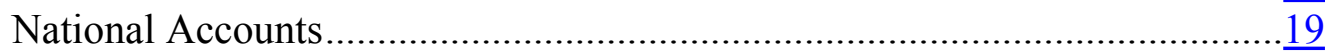

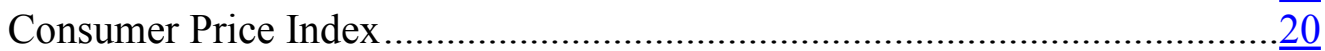

Wholesale Price Index .............................................................................

Government Finance Statistics .................................................................

Monetary Statistics..........................................................................

Balance of Payments Statistics .................................................................

Text Tables

Table 1. Overview of Current Practices Regarding Coverage, Periodicity, and Timeliness of Data Compared to the SDDS.

Table 2. Data Quality Assessment Framework - Summary Presentation of Results ...............22 


\section{ACRONYMS}

1993 SNA

BPM5

COICOP

CPI

CRBP

DQAF

DSBB

ENAPROM

GDP

GFS

GFSM 1986

GFSM 2001

ILO

IMF

ISIC

LSE

MFSM

$\mathrm{MEF}$

NIS

NISI

NSDP

PPI

ROSC

SBIC

SDDS

SUNAT

WPI
System of National Accounts 1993

Balance of Payments Manual, fifth edition

Classification of Individual Consumption by Purpose

Consumer Price Index

Central Reserve Bank of Peru

Data Quality Assessment Framework

Dissemination Standards Bulletin Board

Encuesta Nacional de Propósitos Múltiples

Gross Domestic Product

Government Finance Statistics

A Manual of Government Finance Statistics 1986

Government Finance Statistics Manual 2001

International Labor Organization

International Monetary Fund

International Standard Industrial Classification of all Economic Activities

Lima Stock Exchange

Monetary and Financial Statistics Manual

Ministry of Economy and Finance

National Institute of Statistics

National Institute of Statistics and Informatics

National Summary Data Page

Producer Price Index

Report on the Observance of Standards and Codes

Superintendency of Banks and Insurance Companies

Special Data Dissemination Standard

National Tax Superintendency

Wholesale Price Index 


\section{EXECUTIVE SUMMARY}

This Report on the Observance of Standards and Codes (ROSC) data module provides a review of Peru's data dissemination practices against the IMF's Special Data Dissemination Standard (SDDS), complemented by an in-depth assessment of the quality of the national accounts, consumer price, wholesale price, government finance, monetary, and balance of payments statistics. The agencies that compile the statistics assessed in this report are the Central Reserve Bank of Peru (CRBP) and the National Institute of Statistics and Informatics (NISI). The assessment was carried out by a mission from the IMF's Statistics Department that visited Lima, Peru during February 12-26, 2003.

The mission reached the following main conclusions:

- SDDS observance/subscription: Peru subscribes to the SDDS. It meets the SDDS specifications for coverage, periodicity, and timeliness for all data categories, with two exceptions, and for advance release calendars. For the exceptions, which are the periodicity and timeliness of the data on wage and earnings and the timeliness of the data on central government operations, ${ }^{1}$ Peru uses the two flexibility options to which it is entitled. In several instances, the Peruvian agencies could usefully update the metadata they provide for the Dissemination Standards Bulletin Board (DSBB).

- $\quad$ Prerequisites of quality: Peru has a legal and institutional framework that is broadly adequate to support the quality of official statistics. However, responsibility for compiling and disseminating government finance statistics is not clearly specified. Coordinating mechanisms among the producers of official statistics are weak, a situation that has led to some duplication of efforts. The legal framework provides a mandate for reporting and protects the confidentiality of individual respondents' data. Staff resources are under pressure in the NISI in the face of increasing statistical requirements, making additional resources a key factor for improving the national accounts and price indices. For other datasets, resources are commensurate with existing statistical programs. All agencies demonstrate awareness of quality as a cornerstone of statistical work. However, formal processes to monitor the quality of statistics need to be strengthened.

- Integrity: All institutions demonstrate professionalism and provide guidelines on ethical conduct to their staff. The terms and conditions under which statistics are collected, processed, and disseminated are available to the public. However, advance notice of major changes in methodology, source data, and statistical techniques is not always given. Some dissemination procedures, which lead to selected government authorities obtaining access to statistics prior to their release, are not made known to the public.

- Methodological soundness: The methodologies for compiling macroeconomic statistics broadly follow international standards, with the exception of the wholesale

\footnotetext{
${ }^{1}$ After the visit of the mission, the CRBP began disseminating data on central government operations with a four-week lag, in accordance with the period stipulated by the SDDS.
} 
price index. There is room for improvement in the scope, classification, sectorization, and basis for recording in all datasets.

- Accuracy and reliability: There are important shortcomings in data sources for national accounts and price statistics and, to a lesser extent, the balance of payments. Statistical techniques and assessment and validation of source and intermediate data are also weak for national accounts and, to a lesser extent, for prices and balance of payments statistics. Response rates for surveys are low, particularly for national accounts source data. Government finance statistics compiled by the CRBP are not reconciled with the relevant information from the Ministry of Economy and Finance.

- $\quad$ Serviceability: As confirmed by the results of a recent user survey, ${ }^{2}$ the needs of nongovernmental users of official statistics are not monitored, with the exception of the consumer price index. As noted above, the timeliness and periodicity of most statistical categories meet or exceed SDDS requirements. Statistics are, in general, consistent across sectors, but there are inconsistencies within the national accounts statistics. Studies and analyses of revisions to macroeconomic statistics are generally made public.

- Accessibility: In general, all datasets are accessible by the public; however, there is room for improving the presentation and dissemination of metadata for all macroeconomic statistics. Data are released simultaneously to all interested parties.

In summary, Peru's macroeconomic statistics and statistical database are, to a large extent, adequate for effective surveillance. Nevertheless, IMF staff identified important shortcomings in national accounts and price statistics that have the potential for detracting from the accurate and timely analysis of economic and financial developments and the formulation of appropriate policies.

\section{INTRODUCTION}

1. The data dissemination module of this Report on Observance of Standards and Codes (ROSC) provides a summary of Peru's practices on the coverage, periodicity, and timeliness of the Special Data Dissemination categories (SDDS). It is complemented by a detailed assessment of the quality of national accounts, consumer and producer price indices, ${ }^{3}$ government finance, monetary, and balance of payments statistics, using the Data Quality Assessment Framework (DQAF) developed by the IMF's Statistics Department. This report

\footnotetext{
${ }^{2}$ With the assistance of the authorities, an informal survey was conducted among academics, international organizations, banks, and public and private sector agencies. The results of the survey are presented in Appendix III of the accompanying Detailed Assessments document.

${ }^{3}$ Because there is no producer price index available in Peru, the mission assessed the wholesale price index that has been published since 1920 .
} 
is based on information provided prior to and during a staff mission ${ }^{4}$ from February 12-26, 2003, as well as publicly available information.

2. Section II provides an overview of the SDDS and an assessment of Peru's data dissemination practices against this standard. Section III presents a summary assessment of the quality of the principal macroeconomic datasets, based on the DQAF dataset-specific assessment frameworks. Finally, Section IV sets out recommendations to achieve further improvements in Peru's macroeconomic statistics.

\section{Data Dissemination Practices and the Special Data Dissemination STANDARD}

3. Peru subscribed to the SDDS in August 1996 and started posting its metadata on the Dissemination Standards Bulletin Board (DSBB) in September 1996. Peru is in observance of the SDDS, having met the specifications for the coverage, periodicity, and timeliness of the data, and for the dissemination of advance release calendars in July 1999. The Data Template on International Reserves and Foreign Currency Liquidity has been disseminated and hyperlinked to the DSBB since June 9, 2000. The National Summary Data Page (NSDP) has been hyperlinked to the DSBB since September 15, 1997.

4. The institutions responsible for the compilation and dissemination of the SDDS prescribed data categories are the Central Reserve Bank of Peru (CRBP), the National Institute of Statistics and Informatics (NISI), The Superintendency of Banks and Insurance Companies (SBIC), the Lima Stock Exchange (LSE), and the Ministry of Labor. The CRBP compiles and disseminates data on quarterly national accounts, general government operations, central government operations, central government debt, the analytical accounts of the banking sector, the analytical accounts of the central bank, interest rates, balance of payments, merchandise trade, international reserves and foreign currency liquidity, and the international investment position. The CRBP is also responsible for the maintenance of the NSDP and the publication of advance release calendars. The NISI compiles and disseminates data on annual national accounts, production index, consumer and wholesale prices, wages, employment, unemployment, and population; the SBIC compiles and disseminates data on interest rates and the exchange rate; the LSE compiles and disseminates statistics on the stock market; and the Ministry of Labor compiles and disseminates data on employment, and wages and earnings.

5. Peru provides access to these data through a variety of publications and the following Internet websites:

- $\quad$ CRBP website (http://www.bcrp.gob.pe/)

- $\quad$ NISI website (http://www.inei.gob.pe/)

- Ministry of Labor website (http://www.mtps.gob.pe/)

- Ministry of Economy and Finance (MEF) website (http://www.mef.gob.pe)

\footnotetext{
${ }^{4}$ The mission team was headed by Edgar Ayales and included Alberto Jiménez de Lucio, Antonio Galicia Escotto, José Carlos Moreno, Lisbeth Rivas (all STA), Dale Smith (Expert), and Mabel Hollstein (STAAdministrative Assistant).
} 
- $\quad$ Superintendencia Nacional de Administración Tributaria (SUNAT) website (http://www.sunat.gob.pe)

- $\quad$ SBIC website: (http://www.sbs.gob.pe)

- $\quad$ LSE website (http://www.bvl.com.pe)

\section{Data dimension: coverage, periodicity, and timeliness}

6. The coverage, periodicity, and timeliness for macroeconomic data in Peru are summarized and compared with SDDS specifications in Table 1. Peru meets the SDDS specifications for the data dimension for all data categories, using flexibility options for the periodicity and timeliness of the data on wage and earnings and for the timeliness of the data on central government operations. (See footnote 1.)

7. In view of the recent enhancements to the SDDS, the mission took the opportunity to discuss with the authorities the data provided under the Data Template on International Reserves and Foreign Currency Liquidity (Data Template). The mission found that liquidity requirements on foreign currency deposits held with the CRBP by resident banks are properly recorded in official reserve assets. However, the concepts and definitions of the Operational Guidelines for the Data Template on International Reserves and Foreign Currency Liquidity are not followed strictly. The CRBP includes the full amount of the liquidity requirements in the Data Template under official reserves assets, but does not register the contingent net drain, as specified in Section III of the Data Template. The basis for the recording of interest for official reserve assets does not follow the accrual principle recommended by BPM5 and the Operational Guidelines. The Data Template is compiled and disseminated with the periodicity and timeliness prescribed by the SDDS; however, Sections II and III of the Data Template on predetermined and contingent net flows are not updated for the last three weeks of the month.

\section{Access dimension}

8. Advance release calendars that meet the SDDS requirements are disseminated on the website and the Weekly Bulletin of the CRBP and are redisseminated on the IMF's DSBB (http://dsbb.imf.org/applications/web/sddsctycatarclist/?strcode=PER). Peru meets the SDDS requirements for access to data by the public. In general, data are released simultaneously to all interested parties on the website of the CRBP and on Peru's NSDP (http://www.bcrp.gob.pe/).

\section{Integrity dimension}

9. The SDDS requires the disclosure of information on terms and conditions that govern the collection, compilation, and dissemination of data, including the confidentiality of the data collected. The terms and conditions under which most official statistics are compiled and disseminated in Peru are not sufficiently publicized. Government officials' internal access to some statistics prior to public release is not made known to the public. Data released by the Peruvian statistics-producing agencies are generally not accompanied by ministerial commentary. 


\section{Quality dimension}

10. Summary methodology statements for all SDDS data categories have been provided to the IMF and have been posted on the DSBB. In addition, methodological information and explanatory notes on changes in methodology are also disseminated by the CRBP and by the NISI through publications and the Internet. Peruvian statistics-producing agencies also disseminate component details and additional data series that make possible cross-checks and checks of reasonableness for all data categories prescribed by the SDDS.

\section{Monitoring of data dissemination}

11. In accordance with the IMF Executive Board's Third Review of the SDDS, the IMF staff began monitoring performance under the SDDS beginning in July $2000 .^{5}$ Monitoring is carried out against the release dates stated in the advance release calendars and the metadata, i.e., to verify not only that the data are released according to the calendar, but also that the data disseminated correspond to the metadata posted on the DSBB. During July 2000December 2002, Peru's dissemination practices were in observance of SDDS requirements for most of the period; in some cases, there were delays in the dissemination of data on the NSDP, especially those corresponding to the labor market. Technical problems also contributed to occasional delays.

\footnotetext{
${ }^{5}$ The data dimension - coverage, periodicity, and timeliness of the data — and the advance release calendars of the access dimension have been monitored since July 2000. Other elements of the SDDS are on a self-disclosure basis by subscribers; that is, the subscribers are asked to confirm on a quarterly basis that their descriptions of their practices are accurate.
} 
Table 1. Peru: Overview of Current Practices Regarding Coverage, Periodicity, and Timeliness of Data Compared to the SDDS

\begin{tabular}{|c|c|c|c|c|c|c|}
\hline \multirow{2}{*}{$\begin{array}{c}\text { SDDS } \\
\text { Data } \\
\text { Category }\end{array}$} & \multirow{2}{*}{$\begin{array}{c}\text { Coverage } \\
\text { (meets SDDS } \\
\text { requirements) }\end{array}$} & \multicolumn{2}{|c|}{ Periodicity } & \multicolumn{2}{|c|}{ Timeliness } & \multirow{2}{*}{ Comments } \\
\hline & & SDDS & Peru $^{1}$ & SDDS & Peru $^{1}$ & \\
\hline \multicolumn{7}{|l|}{ Real Sector } \\
\hline National accounts & Yes & $\mathrm{Q}$ & Q & Q & $8 \mathrm{~W}$ & $\begin{array}{l}\text { Timeliness exceeds SDDS } \\
\text { requirements. }\end{array}$ \\
\hline $\begin{array}{l}\text { Production } \\
\text { index/indices }\end{array}$ & Yes & $\mathrm{M}$ & $\mathrm{M}$ & $\begin{array}{l}6 \mathrm{~W}(\mathrm{M} \\
\text { encouraged) }\end{array}$ & $5-6 \mathrm{~W}$ & \\
\hline \multirow{3}{*}{$\begin{array}{l}\text { Employment } \\
\text { Unemployment } \\
\text { Wages/earnings }\end{array}$} & Yes & Q & $\mathrm{M}$ & Q & $4-6 \mathrm{~W}$ & $\begin{array}{l}\text { Periodicity and timeliness exceed } \\
\text { SDDS requirements. }\end{array}$ \\
\hline & Yes & Q & $\mathrm{M}$ & Q & 15-20D & $\begin{array}{l}\text { Periodicity and timeliness exceed } \\
\text { SDDS requirements. }\end{array}$ \\
\hline & Yes & Q & $\mathrm{A}$ & Q & $1 \mathrm{Y}$ & $\begin{array}{l}\text { Flexibility option for timeliness and } \\
\text { periodicity. }\end{array}$ \\
\hline \multirow{2}{*}{$\begin{array}{l}\text { Consumer price } \\
\text { index } \\
\text { Producer price index }\end{array}$} & Yes & $\mathrm{M}$ & $\mathrm{M}$ & $1 \mathrm{M}$ & $1 \mathrm{WD}$ & $\begin{array}{l}\text { Timeliness exceeds SDDS } \\
\text { requirements. }\end{array}$ \\
\hline & Yes & $\mathrm{M}$ & $\mathrm{M}$ & $1 \mathrm{M}$ & $1 \mathrm{WD}$ & $\begin{array}{l}\text { Timeliness exceeds SDDS } \\
\text { requirements. }\end{array}$ \\
\hline \multicolumn{7}{|l|}{ Fiscal Sector } \\
\hline $\begin{array}{l}\text { General government } \\
\text { operations }\end{array}$ & Yes & $\mathrm{A}$ & Q & $2 \mathrm{Q}$ & $8 \mathrm{~W}$ & $\begin{array}{l}\text { Periodicity and timeliness exceed } \\
\text { SDDS requirements. }\end{array}$ \\
\hline $\begin{array}{l}\text { Central government } \\
\text { operations }\end{array}$ & Yes & $\mathrm{M}$ & $\mathrm{M}$ & $1 \mathrm{M}$ & $5-6 \mathrm{~W}$ & $\begin{array}{l}\text { Flexibility option utilized for } \\
\text { timeliness of the data. (See footnote } \\
\text { 1.) }\end{array}$ \\
\hline $\begin{array}{l}\text { Central government } \\
\text { debt }\end{array}$ & Yes & Q & Q & $1 \mathrm{Q}$ & $8 \mathrm{~W}$ & $\begin{array}{l}\text { Timeliness exceeds SDDS } \\
\text { requirements. }\end{array}$ \\
\hline \multicolumn{7}{|l|}{ Financial Sector } \\
\hline $\begin{array}{l}\text { Analytical accounts } \\
\text { of the banking sector }\end{array}$ & Yes & $\mathrm{M}$ & $\mathrm{W}$ & $1 \mathrm{M}$ & $3-4 \mathrm{~W}$ & $\begin{array}{l}\text { Periodicity exceeds SDDS } \\
\text { requirements. }\end{array}$ \\
\hline $\begin{array}{l}\text { Analytical accounts } \\
\text { of the central bank }\end{array}$ & Yes & $\begin{array}{c}\mathrm{M}(\mathrm{W} \\
\text { recommende } \\
\mathrm{d})\end{array}$ & $\mathrm{W}$ & $\begin{array}{l}2 \mathrm{~W}(\mathrm{~W} \\
\text { encouraged })\end{array}$ & $1 \mathrm{~W}$ & $\begin{array}{l}\text { Periodicity and timeliness exceed } \\
\text { SDDS requirements. }\end{array}$ \\
\hline Interest rates & Yes & $\mathrm{D}$ & $\mathrm{D}$ & $\mathrm{D}$ & $\mathrm{D}$ & \\
\hline Stock market & Yes & $\mathrm{D}$ & $\mathrm{D}$ & 2 & $\mathrm{D}$ & \\
\hline \multicolumn{7}{|l|}{ External Sector } \\
\hline Balance of payments & Yes & Q & Q & $1 \mathrm{Q}$ & $8 \mathrm{~W}$ & $\begin{array}{l}\text { Timeliness exceeds SDDS } \\
\text { requirements. }\end{array}$ \\
\hline International reserves & Yes & $\begin{array}{c}\mathrm{M}(\mathrm{W} \\
\text { recommende } \\
\mathrm{d})\end{array}$ & $\mathrm{D}$ & $1 \mathrm{~W}$ & $1 \mathrm{~W}$ & $\begin{array}{l}\text { Periodicity exceed SDDS } \\
\text { requirements. }\end{array}$ \\
\hline Reserves template & Yes & M & W & $1 \mathrm{M}$ & $5 \mathrm{WD}$ & $\begin{array}{l}\text { Periodicity and timeliness exceed } \\
\text { SDDS requirements. }\end{array}$ \\
\hline Merchandise trade & Yes & $\mathrm{M}$ & $\mathrm{M}$ & $\begin{array}{c}8 \mathrm{~W}(4-6 \mathrm{~W} \\
\text { encouraged })\end{array}$ & $5-6 \mathrm{~W}$ & $\begin{array}{l}\text { Timeliness exceeds SDDS } \\
\text { requirements. }\end{array}$ \\
\hline $\begin{array}{l}\text { International invest. } \\
\text { position }\end{array}$ & Yes & $\begin{array}{c}\mathrm{A}(\mathrm{Q} \\
\text { recommende } \\
\mathrm{d})\end{array}$ & Q & $\begin{array}{l}\text { 2Q (Q } \\
\text { encouraged) }\end{array}$ & $8 \mathrm{~W}$ & $\begin{array}{l}\text { Periodicity and timeliness exceed } \\
\text { SDDS requirements. }\end{array}$ \\
\hline Exchange rates & Yes & $\mathrm{D}$ & $\mathrm{D}$ & 2 & $\mathrm{D}$ & Spot exchange rate \\
\hline $\begin{array}{l}\text { Addendum: } \\
\text { Population }\end{array}$ & Yes & $\mathrm{A}$ & $\mathrm{A}$ & $\ldots$ & $2 \mathrm{Q}$ & $\begin{array}{l}\text { Projection based on national census } \\
\text { (every } 10 \text { years) and the annual } \\
\text { Health and Demographic Survey. }\end{array}$ \\
\hline
\end{tabular}

Periodicity and timeliness: (D) daily; (WD) with a lag of no more than one working day; (W) weekly or with a lag of no more than one week from the reference data or the closing of the reference week; (M) monthly or with a lag of no more than one month; (Q) quarterly or with a lag of no more than one quarter; (A) annually; and (...) not applicable.

${ }^{1}$ Refers to current practices in Peru.

${ }^{2}$ Given that the data are broadly disseminated by private means, the timeliness with which official data are disseminated is not time critical. Although dissemination is recommended via recorded telephone messages or by fax, the dissemination of these data may form part of other dissemination mechanisms (preferably, high frequency). 


\section{Summary Assessment of Data Quality}

12. Interest in assessing the quality of data derives from the objectives of complementing the SDDS with a consideration of the quality of the data being disseminated and of focusing more closely on the quality of the data that underpin surveillance of countries' economic policies. ${ }^{6}$ Against this background, the Statistics Department of the IMF has developed a tool to provide a structure and a common language to assess data quality. The DQAF comprises a generic framework and a set of dataset-specific frameworks. The frameworks cover five dimensions of data quality — integrity, methodological soundness, accuracy and reliability, serviceability, and accessibility—and a set of prerequisites. ${ }^{7}$

13. An assessment of six macroeconomic datasets (national accounts, consumer price, wholesale price, government finance, monetary, and balance of payments statistics) was conducted using the frame of reference provided by the dataset-specific DQAF. The information resulting from the application of this framework to the Peruvian statistical system is presented below, following the structure of the DQAF. Conclusions are presented in standardized summary tables that assess data practices on a qualitative basis, using a fourpart scale (Table 2 in this report and Tables 1-6 in the accompanying Detailed Assessments document).

\section{Prerequisites of quality}

This category in the DQAF identifies conditions within the agency in charge of producing statistics that have an impact on data quality. The elements within the category refer to the legal and institutional environment, resources, and quality awareness.

14. A series of laws and legislative decrees define the legal and institutional environment for the compilation of national accounts statistics, the consumer price index (CPI), and the wholesale price index (WPI). In 1969, the Legal Decree No. 17532 established the National Office of Statistics and Census under the Ministry of Finance as the office responsible for national accounts statistics and price indices. In December 1975, the National Office of Statistics and Census was transformed into the National Institute of Statistics (NIS), placed directly under the Prime Minister. The responsibilities of the NIS were expanded in April 1990 to include informatics. In general, the legal and institutional environment for the NISI is adequate for producing national accounts and price statistics. However, the information required for updating and maintaining the business register is available at the tax authority, but not accessible to the NISI due to legal restrictions regarding confidentiality. The institutional organization for compiling national accounts statistics is highly decentralized, and formal mechanisms for inter-agency coordination are weak, which has led to some duplication of efforts. The laws protect the confidentiality of individual respondent's data and provide a legal mandate for reporting.

15. The scarcity of computing and human resources in NISI has lead to inefficiencies in the collection, processing, and dissemination of data. Even though the staff is working at full

\footnotetext{
${ }^{6}$ Information on data quality can be found at the IMF website "Data Quality Reference Site" (http://dsbb.imf.org/dqrsindex.htm).

${ }^{7}$ See also the Generic Framework set out in Appendix II of the accompanying Detailed Assessments document to this report.
} 
capacity, resources are insufficient for making needed improvements in the national accounts and price statistics, particularly with regard to adopting the System of National Accounts 1993 (1993 SNA) fully, updating weights for price indices, and replacing the WPI with a producer price index (PPI). Although access to training in statistical methodologies is limited, extensive technical assistance from bilateral donors has been received in recent years.

16. Although the NISI has not established an official program of quality awareness, e.g., total quality management, many elements of such a program are already in place, especially for monitoring data collection, processing, and dissemination of the CPI and national accounts statistics. Monthly quality assurance visits by central office staff to the field have been implemented for the CPI but not as yet for the WPI. Even though the National Statistical Policy for 2002-2006 places strong emphasis on data quality, regular procedures to obtain feedback from users and formal mechanisms for assessing and improving the quality of the WPI and the national accounts statistics need to be strengthened.

17. The Constitution of the Republic, the Charter of the CRBP, the CRBP Internal Regulations, and the CRBP Regulations on Institutional Representation, Confidentiality and Interest Conflict provide the CRBP with a solid legal and institutional environment for the collection, processing, and dissemination of monetary and balance of payments statistics and, to a lesser extent, government finance statistics (GFS). This legal framework supports the confidentiality of the respondent's data and their exclusive use for statistical purposes, and provides a clear mandate to ensure statistical reporting. However, the coordination between the CRBP and the Superintendency of Banks and Insurance Companies (SBIC) could be enhanced to avoid duplication of effort in the validation of balance sheet data and to collaborate on future improvements to the plan of accounts for commercial banks. Although the laws require that the CRBP report regularly on the state of the nation's finances, they do not explicitly assign the responsibility for compiling and disseminating GFS to the CRBP. As a result of recent legislation aimed at promoting fiscal transparency and widespread availability of fiscal statistics, over the past two years the MEF has begun to compile and disseminate some fiscal statistics and has plans to expand this activity to cover the entire range of GFS. However, the legislation does not clearly assign the responsibility to compile GFS to the MEF. The lack of coordination between the CRBP and the MEF concerning the fiscal statistics leads to duplication of effort and confusion among users.

18. The human, financial, and computing resources allocated to the existing program of statistics at the CRBP are adequate and are used efficiently. Staff have solid academic backgrounds and significant experience. The CRBP has well-established recruitment and training programs, and the salaries are competitive compared with the private sector. Systems and programs for compiling and analyzing the statistics are updated regularly. Although no cost is imputed to the generation of individual statistics, over the years the CRBP has been able to streamline the structure and resources allocated to statistical activities. Efforts are being made to upgrade the computer systems, including the recent acquisition and implementation of new software to manage the macroeconomic databases.

19. Although the CRBP does not have a mission statement for its statistical work, the authorities promote quality awareness as a key factor for maintaining public confidence and trust in the statistics. This is evidenced by the existence of procedures for quality control at 
every stage of data production and dissemination. Even though no formal surveys on data quality are undertaken, feedback is sought through regular contacts with users.

\section{Integrity}

Integrity identifies features that support firm adherence to objectivity in the collection, compilation, and dissemination of statistics so as to maintain users' confidence. Elements refer to the professionalism and ethical standards that should guide policies and practices, which should be reinforced by their transparency.

20. NISI has a tradition of professionalism. The Regulations, Organization, and Functions of NISI specify standards of conduct for employees with regard to confidentiality, management of statistical data, and avoidance of influence of third parties. Also, sanctions are specified for abuse of official data and violation of confidentiality. In addition, there are specific standards set within NISI with regard to professional behavior, courtesy toward respondents, integrity, impartiality in hiring, execution of official duties, and the avoidance of influence by third parties. Staff participate in conferences and meetings with other professional groups. Choices of sources and statistical techniques are made solely on the basis of statistical considerations. NISI comments on inaccurate interpretation and misuse of published data. Furthermore, NISI makes every effort to provide to its users in-depth explanations of statistical series and their proper use in analysis. NISI has established an office of information and institutional image.

21. With regard to transparency, the terms and conditions under which NISI compiles and disseminates statistics are available to the public in NISI publications and its website. However, dissemination procedures that lead to selected government agencies obtaining access to statistics prior to their release are not made known to the public. Although NISI indicates that the approval process for published index series is entirely internal, a number of high level government officials have embargoed access to these series on the day before they are released publicly. The list of individuals receiving privileged access is not publicized. Statistical outputs of the NISI are clearly identified as such; however, the CRBP does not clearly identify NISI as the source of monthly GDP, annual national accounts, and price statistics in its website and Weekly Bulletin. ${ }^{8}$ Advance notice of important changes in source data, methodology, and statistical techniques for price indices is given to users; however, for national accounts statistics, advance notice is only given in the case of implementing a program for changing the base year. The legal framework provides guidelines on ethical standards, which are made known to the staff.

22. The statutory provisions under which the CRBP compiles statistics support the highest standards of professionalism. The legal framework is adequate for ensuring the autonomy of the units in charge of compiling statistics, and professional competence is a key requirement for hiring new staff, as well as for promotions within the institution. The statistics in the CRBP are compiled on an impartial basis, and the selection of data sources is dictated purely by statistical considerations. Although the CRBP does not actively pursue

\footnotetext{
${ }^{8}$ After the visit of the mission, the CRBP updated its website, the Weekly Bulletin, and the DSBB to identify the NISI as the source of annual national accounts.
} 
clarification of erroneous interpretations and misuse of statistics, it is entitled to clarify interpretations and provides users with explanatory material.

23. Regarding transparency, the terms and conditions under which statistics are compiled and disseminated are available to the public on the website of the CRBP. No government agency outside the CRBP has access to the statistics before their release to the public, and no ministerial commentary is attached to the release of the data. The CRBP is clearly identified as the source of fiscal, monetary, and balance of payments statistics in its publications and website. Major changes in source data, data classification, and statistical techniques are announced only with the release of data. Guidelines on ethical standards for CRBP staff are in place and are made known to the staff.

\section{Methodological soundness}

Methodological soundness refers to the application of international standards, guidelines, and agreed practices. Application of such standards, which are specific to the dataset, is indicative of the soundness of the data and fosters international comparability. Elements refer to the basic building blocks of concepts and definitions, scope, classification and sectorization, and basis for recording.

24. The national accounts statistics partially follow the concepts and definitions of the $1993 S N A$. In terms of scope, the complete sequence of accounts for the total economy is not compiled. Peru does not publish input-output tables or detailed supply and use tables on a regular basis. The most recent input-output table has a base year of 1994. Measures of quarterly GDP by the production and expenditure approaches are compiled on a regular basis, based on the NISI's monthly production index, measured through output volume indicators with incomplete coverage. The production and assets boundaries are not fully in accordance with the $1993 S N A$. Production of manufactured goods for own final consumption, production of computer software, intellectual production, and illegal output sold are not covered; valuables and historical monuments, patented entities, systems and data bases are not included in the assets boundary. The coverage of informal activities is limited. Classification and sectorization systems broadly follow international standards. However, there are a few exceptions, such as the lack of a functional classification of government final consumption expenditures and the erroneous classification of auxiliary financial services as services to enterprises. The basis for recording is broadly in accordance with the $1993 \mathrm{SNA}$, except for government revenues and external transactions other than goods, which are recorded on a cash basis. Work in progress is only recorded for permanent crops, and agricultural output is not adjusted from crop year to calendar year. Grossing and netting procedures are adhered to insofar as the source data permit.

25. In general, the $\mathbf{C P I}$ is based on internationally accepted concepts, definitions, practices, and standards. With regard to scope, separate indices are calculated for metropolitan Lima and 24 departmental-capital cities. These indices are combined to produce a national-level index that represents the entire urban population of Peru. The index weights reflect all types of expenditure relating to personal consumption. However, imputed rent for owner-occupied housing is not included in the weighing structure of the index for Metropolitan Lima. Although the classification system has not yet been updated to the Classification of Individual Consumption by Purpose (COICOP), a comprehensive concordance has been constructed for conversion from the current system to the latest 
version of COICOP. The basis for recording meets international standards, with the exception of the recording of automobile sales, which are not netted out from purchases for the CPI weights.

26. The WPI covers domestic production and imports. There is a mixture of price concepts as both producer and wholesale prices are used for its compilation. In terms of scope, the WPI includes only agricultural production, fishing, and manufacturing. Mining and oil extraction activities, electricity and water production, and public transportation and communications are excluded from the index. All classifications for the WPI are based on ISIC Rev. 3. The basis for recording of stocks and flows for both the calculation of weights and for the prices used in the index is in accordance with international standards. Market prices are used for determining values, recording is on an accrual basis, and proper grossing/netting procedures are employed.

27. The concepts and definitions used in the compilation and dissemination of GFS by the CRBP follow the recommendations of A Manual on Government Finance Statistics 1986 (GFSM 1986). The authorities will evaluate, in due course, the timing and possible method of migration to the Government Finance Statistics Manual 2001 (GFSM 2001). Regarding the scope, GFS are compiled and disseminated for the budgetary central government, extrabudgetary accounts (rest of the central government), consolidated central government, local governments, nonfinancial public enterprises, and the nonfinancial public sector. Published data do not follow the breakdown recommended by the GFSM 1986 in some aspects, mainly because (i) there is no functional classification of expenditure, (ii) the financing and debt tables have a combined presentation using partial data by type of debt holder and by type of instrument, and (iii) limited detail is provided for most aggregates. Compilation is based on full data coverage in most cases. Classification and sectorization for revenue and expenditure, though not for financing transactions, follow the recommendations of the GFSM 1986. GFS data are provided separately for each level of government. The basis for recording the GFS follow, to a large extent, international guidelines.

28. Although the analytical framework for monetary statistics reflects concepts and definitions that broadly follow the Monetary and Financial Statistics Manual (MFSM), the full adoption of the MFSM methodology has not been completed. The scope of the depository corporations survey is currently limited to the CRBP and commercial banks, and excludes nonbank deposit-taking institutions and money market funds. However, all depository corporations are included in the financial survey. The classification of financial instruments and the sectorization of institutional units do not always follow the recommendations of the MFSM; in particular, the definition of the nonfinancial private sector in the depository corporations survey erroneously includes some depository corporations and other financial intermediaries. The basis for recording flows and stocks is largely consistent with the MFSM, although some asset and liability positions are valued at historical costs rather than market prices. Accrued interest is not included in the outstanding value of financial instruments.

29. The concepts and definitions of balance of payments statistics largely follow the methodology described in the fifth edition of the Balance of Payments Manual (BPM5). The few exceptions are assessed on a regular basis and, where possible, data supplied to international organizations are adjusted to standard concepts. The scope is in accordance with the BPM5, except for the exclusion of assets held abroad and land acquisition abroad by 
residents. The classification of the financial account in the balance of payments does not fully conform with BPM5 recommendations. The classification of direct investment subitems also departs from the BPM5 in that liabilities to affiliated enterprises are not separately identified. Regarding the basis for recording, most transactions are recorded at market prices and are converted to U.S. dollars at the exchange rate prevailing on the day of the transaction or, when appropriate, at the average exchange rate for the reference period. Transactions are generally valued on an accrual basis; however, services, interest, and external debt transactions are recorded on a cash basis.

\section{Accuracy and reliability}

Accuracy and reliability identifies features that contribute to the goal that data portray reality. Elements refer to identified features of the source data, statistical techniques, and supporting assessments and validation.

30. Except for mining, electricity, and financial and governmental services, the availability of source data for the national accounts statistics is rather limited, due to the lack of an adequate business register and insufficient resources to visit establishments. Also, response rates for some surveys are low due, in part, to collection methods based on voluntary response to announcements in the press. The available source data are generally consistent with the definitions, scope, and classifications needed for national accounts statistics, except for the inadequate ISIC classification of data from National Tax Superintendency (SUNAT). In addition, data are not available on a timely basis for annual estimates. Even though the quarterly accounts have benefited from some improvements in the timeliness of short-term indices, the coverage is very limited. Improved short-term statistics on wages, prices, government employment, production of services, changes in inventories, and household final consumption expenditures are needed. Peru had a comprehensive range of economic statistics as of 1994, the base year for present GDP estimates. However, since 1994, the statistical techniques have been largely based on extrapolation. Intermediate consumption is usually compiled as a fixed proportion of output, and the single indicator method is used to estimate GDP at constant prices. Estimates for informal, hidden, and uncovered activities are indirectly made through employment data and upward adjustments for these activities are introduced. Also, allocation of harvests over time is inaccurate. Assessment and validation of source and intermediate data and statistical products are hampered by the lack of a business register, which limits the representativeness of samples, and by the lack of detailed supply and use tables for investigating discrepancies in the statistical output. Changes in inventories are mainly determined as a residual. The magnitude of revisions in the preliminary data is investigated, but no formal studies are prepared.

31. Source data for both weights and prices in the CPI are based on comprehensive surveys. The weight structure is rather old; it is derived from the 1993-94 "Encuesta Nacional de Propósitos Multiples" (ENAPROM). A three-stage stratified sampling procedure was used to select approximately 40,000 urban households that are interviewed for the survey. Approximately 75,000 monthly price quotations are collected in Metropolitan Lima and 24 other departmental-capital cities. Except for the household expenditure data, source data are timely and consistent with the technical requirements for producing the index. Although NISI employs sound statistical techniques for data collection, processing, and monthly index calculation, the new market basket weights are based on nine-year-old 
expenditure data that have not been updated for price changes. In addition, the coverage of owner-occupied housing was eliminated from the Metropolitan Lima index through the exclusion of imputed rent, a deviation from international practices. Imputed rent is included in the indices of the other 24 cities. Thus, the national index is a weighted average of indices that have different coverage. While the assessment and validation of monthly price survey data is sound and comprehensive, a serious problem was detected by NISI with regard to the market basket weights. Test tabulations using the original 1993-94 expenditure data and similar aggregation procedures were unable to closely approximate the original results. On the basis of this revision study, NISI decided to calculate new market basket weights for the index. In addition to incorporating a number of other improvements in tabulation procedures, the new weights reflect data for high and low income households, as well as for single-person households, all of which were excluded from the original tabulations.

32. The weights for the WPI are obtained from the 1994 input-output table, reports of the SUNAT, and publications of relevant ministries. Although annual and monthly economic surveys are available, there has not been a comprehensive economic census since 1994. An updated business register does not exist, and NISI has had difficulty in obtaining measure-ofsize data for a new establishment sample. The source data for prices are obtained from a national survey of 520 establishments. Approximately 3,900 price quotations covering approximately 350 products are collected each month. With the exception of the outdated weights, statistical techniques employed follow generally accepted international standards. The assessment and validation of both source data and price index data are generally well handled. Revisions are investigated and the results are used to update the establishment sample and product specifications.

33. Source data covering the full range of economic stocks and flows are available for the central government, local government, and nonfinancial public enterprises. The data for compiling consolidated GFS for the various levels of government are also available. There is no system for automatic derivation of GFS from budget items, but compilers are familiar with the procedures for moving from primary sources to the concepts in the GFSM 1986 and use electronic spreadsheets to derive GFS tables. The main data for GFS are cross-checked with other accounting or administrative records that allow for verification of their accuracy. Preliminary GFS are compiled using the most up-to-date data; however, they are not reconciled with fiscal data for central government published by the MEF (though with different institutional coverage). Significant discrepancies in intermediate data and statistical outputs are investigated, and the data series are adjusted, as needed. Revisions incorporate significant data changes, and the reasons for the changes are explained. The revisions are studied to improve the quality of the GFS compilation process.

34. The data sources for monetary statistics are generally adequate. The plan of accounts for commercial banks follows international accounting standards and provides sufficient instrument and sectoral disaggregation. The accounts of the CRBP provide sufficient detail to approximate the classification of accounts recommended in the MFSM. The use of statistical techniques is adequate, being confined to automated checks to identify processing errors in the CRBP monetary database. The assessment and validation of source data is also adequate, consisting of checks of reported balance sheet data against secondary sources. Preliminary weekly data are reconciled with final monthly data. Revisions are always investigated, and the reasons for revisions are documented through the maintenance of two datasets: the original data set and the revised, final data set. 
35. The primary and secondary data sources are broadly sufficient to compile major items of the balance of payments statistics. Nevertheless, there are limitations in the sources used to compile data on short-term assets of nonfinancial resident units and loans in foreign direct investment. Statistical techniques are sound and consistent with international practices, although no current account adjustments are made for unrecorded trade. Data are assessed and validated against other data, and statistical discrepancies are identified and investigated. Data revisions are made as needed, based on more accurate data and on the larger sample survey at the end of the year. Revisions are investigated and the results used to inform procedures.

\section{Serviceability}

Serviceability focuses on practical aspects of how well a dataset meets users' needs. Elements refer to the extent to which data are relevant, produced, and disseminated in a timely fashion with appropriate periodicity, are consistent internally and with other datasets, and follow a predictable revisions policy.

36. The NISI and the CRBP monitor the relevance of national accounts statistics for governmental purposes. However, there are no regular procedures to assess the relevance of data to users outside the government sector. The timeliness with which the provisional estimates of the quarterly accounts are published meets the SDDS prescriptions. Consistent time series are available in limited detail from 1991 onward. However, the lack of a proper reconciliation framework hampers the consistency between quarterly and annual data, and also between the production and expenditure data for GDP. Data on government operations and external transactions can be reconciled with public finance and balance of payments statistics, respectively. Major revisions do not follow a predetermined cycle. Publications identify provisional data, and revised data are disseminated with the same level of detail as preliminary data.

37. Whereas the CPI generally meets users' needs, the WPI has a number of deficiencies with regard to coverage and relevance. Over the past several years, the CPI has been the focus of advisory groups and outside experts associated with a project to revise the market basket weights, improve index calculation methodology, and produce a national-level index. However, no efforts have been made to improve the analytical usefulness of the WPI. Preliminary plans have been made for the preparation of a producer price index. The two official indices meet the SDDS requirements for timeliness and periodicity, and both are consistent with regard to aggregations within each data set, historical comparisons, and reconciliation with other independent data sets. There is no set revision policy for updating the base-period weights for either index. However, the outlet sample for the CPI and the establishment sample for the WPI are reviewed and updated on an annual basis. The lists of products and specifications are updated on a bi-annual basis for such series.

38. The GFS release schedule is aligned with the budget cycle. Budget preparation begins in April, when preliminary GFS data for the previous year become available. GFS are used for monitoring the budget and fiscal performance under the program with the IMF and for making the projections and assessments associated with the Macroeconomic Multiannual Framework. The level of detail and timeliness of the GFS enables users to assess fiscal policy. The statistics are considered relevant by users in the government sector. Feedback from other users is not sought on a regular basis. The timeliness and periodicity of GFS meet 
or exceed SDDS requirements, except for the timeliness of statistics on central government operations (for which a flexibility option is taken). (See footnote 1.) GFS are consistent within the dataset, over time, and with statistics obtained from other data sources and statistical frameworks. Data revisions follow a regular cycle that is known to users, and preliminary data are clearly identified. Revised data are disseminated in the same format as original data and preliminary data are coherent with final data. However, analyses of revisions are not made public.

39. Formal procedures for consultation with users to obtain feedback on the relevance of monetary statistics could be strengthened, for example, by conducting user surveys and periodic meetings with users. The timeliness and periodicity of published data exceed the SDDS requirements, and the data are consistent internally and over time. Consistency checks between monetary, government finance, and balance of payments statistics are conducted regularly. Revisions follow a regular and transparent schedule. Analyses of revisions are not made public because revisions are generally not significant in amount. Significant revisions are footnoted in the statistical publications.

40. Users are not actively and systematically consulted to monitor the relevance and practical usefulness of balance of payments statistics. Quarterly balance of payments and international investment position statistics meet or exceed the timeliness and periodicity prescribed by the SDDS. Data show consistency over time and among the various external sector accounts, as well as with monetary and GFS. However, there are some discrepancies with the national accounts statistics. Revisions follow a regular schedule that is made known to the public in the publications.

\section{Accessibility}

Accessibility deals with the availability of information to users. Elements refer to the extent to which data and metadata are clear and easily available and the extent to which assistance to the users is adequate to help them find and use the data.

41. National accounts statistics are readily accessible on the NISI and CRBP websites. The annual estimates are presented clearly, and charts, tables, and analysis of recent developments are disseminated with the data. However, household and government final consumption expenditures are published only at an aggregate level. Analyses of the developments of the quarterly GDP by the expenditure approach are not published. Nevertheless, a brief analysis of the developments of the monthly GDP index is included in some issues of the Weekly Bulletin. Data are also disseminated through press releases, which are available on the NISI website and in hard copy, CD, or diskette upon request. An electronic version of the annual hard-copy publication on national accounts statistics is available on the NISI website. Quarterly national accounts statistics are released simultaneously to all interested users in accordance with an advance release calendar that is disseminated in the Weekly Bulletin and the CRBP website. However, a preannounced schedule for annual national accounts releases does not exist. Nonpublished, but nonconfidential, subaggregates are made available to users upon request. The annual publication provides detailed metadata, which are also available on the NISI website. Summarized metadata for quarterly national accounts statistics are available on the DSBB and the CRBP website. Extensive documentation of concepts and methods is published whenever the base year for the national accounts is changed. NISI and CRBP's assistance to 
users of national accounts statistics is adequate; contact information is provided at the NISI and CRBP websites and in the Weekly Bulletin.

42. Both the CPI and the WPI are disseminated simultaneously to all interested users according to pre-announced schedules on the NISI website and through other media. The formats are accessible to users and include adequate detail, relevant aggregates, and helpful charts and graphs. Although metadata for both indices are available on the website and in published bulletins, there are some deficiencies in these sources. The WPI documentation on the website is not completely up-to-date, and the CPI metadata do not indicate that the current market basket weights were not updated for price changes between the base period and the reference period. The published bulletins and press releases for both series include telephone numbers and/or the NISI website address for assistance to users. A catalog of publications is available to the public.

43. GFS are accessible in a format that facilitates proper interpretation and meaningful comparisons; the format for different sectors and subsectors is similar, major aggregates are clearly identified, statistics are shown in nominal terms and as a percentage of GDP, and time series are provided. There are GFS sections in CRBP publications, and monthly/quarterly GFS are published in subannual statistical publications. Statistics are released according to a preannounced schedule and are made available to all users simultaneously. Nonpublished data are made available upon request, but their availability is not publicized. Metadata on concepts, sources, and methods are limited, and methodological notes are published only on the DSBB. Methodological changes are described in CRBP publications. A methodological guide for all statistics published by the CRBP is being prepared and will be available by mid 2003. Assistance to users is adequate; a contact person for GFS is publicized in the CRBP website, prompt and expert support is provided to users, and a catalog of publications and services is widely available.

44. The presentation of monetary statistics in CRBP publications generally meets user needs for data accessibility. Weekly and monthly data are released simultaneously to all interested users electronically on the CRBP website and in the Weekly Bulletin.

Nonconfidential unpublished data are made available upon request, although the availability and the terms and conditions of this service are not made public. The dissemination format on the website is user friendly. There is a preannounced schedule of publication release dates. Comprehensive metadata that complement those on the DSBB are not updated regularly. In order to assist users, contact information is provided at the CRBP website and in the Weekly Bulletin. A catalog of publications is available to the public at the CRBP website.

45. Data accessibility is adequate for balance of payments statistics. Dissemination formats include statistical tables, analytical notes, and the CRBP annual report, all of which are posted at the CRBP website. Detailed and summary quarterly balance of payments statistics are released simultaneously to all interested parties on the CRBP website and in hardcopy publications. There is a preannounced schedule of publication release dates. 
Metadata accessibility is largely achieved, given that documentation on concepts, scope, classifications, and data sources are disseminated on the CRBP website, which includes a Spanish version of the SDDS metadata on the DSBB. However, methodological notes are rather limited. Assistance to users is adequate, and a catalogue of publications and documents is available on the CRBP website.

\section{STAFF's RECOMMENDATIONS}

46. Based on the results of the data quality assessment, discussions with the Peruvian authorities in the statistics-compiling agencies, and responses from data users, the following measures are proposed to increase Peru's adherence to international statistical standards. In the IMF staff's view, the high priority recommendations regarding national accounts and price statistics should be addressed with particular urgency.

\section{General Recommendations}

\section{High priority}

- Improve the coordination among the agencies that compile official statistics to avoid duplication of efforts and confusion among users.

- $\quad$ Release price and national accounts data simultaneously to all interested users, without giving privileged access to selected government officials.

- Increase staff and other resources, including an upgrade of the computers for national accounts and price statistics.

- $\quad$ Establish regular mechanisms to obtain feedback from users on the quality of statistics.

- Implement a regular calendar of censuses and surveys in agriculture, manufacturing, services, and household income and expenditure to strengthen source data for national accounts and price statistics.

\section{Other key recommendations}

- $\quad$ Clarify on the CRBP website and in some tables of the Weekly Bulletin that the NISI is the source for monthly and annual GDP estimates and price statistics.

\section{National Accounts}

\section{High priority}

- Sign an agreement with the SUNAT to obtain the list of contributing enterprises by economic activity, number of employees, and amount of sales for the most recent period, to assist in establishing a business register that provides the basis for sample surveys.

- Investigate and implement ways to improve the response rates for NISI's mandatory enterprise surveys.

- Implement a new benchmark and base year for GDP.

- Adopt the methodology used for annual GDP to compile quarterly GDP estimates, at a more aggregated level, and adopt appropriate methods for reconciling both estimates.

\section{Other key recommendations}

- Increase the detail of data on goods and services by improving the IV Quarter Household Survey; conduct the survey on a quarterly basis for a selected year every five years.

- As far as the current price data permits implement the double deflation method to calculate GDP by using the annual survey data available on cost structures. Otherwise, use fixed input-output ratios at a detailed level until better price data become available. 
- Improve the estimates of informal activities by using the results of the survey on sales and cost structures for the most important informal activities.

- Implement the complete set of institutional accounts recommended in the $1993 \mathrm{SNA}$.

\section{Consumer Price Index}

\section{High priority}

- Reintroduce the weight for imputed rent for owner-occupied housing into the Metropolitan Lima Index.

- Update the classification system to the latest version of COICOP.

- Establish a fixed calendar for weight revisions.

\section{Wholesale Price Index}

\section{High priority}

- Increase the coverage of the index to include mining, oil and gas extraction, electricity and water, and public transportation and communication.

- Investigate the possibility of obtaining improved data on number of employees and value of production from SUNAT.

\section{Other key recommendations}

- Initiate a project for replacing the WPI with a producer price index. Implement a pilot project using a subset of data from the wholesale price index.

- Establish a fixed calendar for weight revisions.

\section{Government Finance Statistics}

\section{High priority}

- Assign the responsibility for compiling and disseminating GFS to a single agency.

- Reconcile GFS published by the CRBP with the fiscal statistics published by the MEF and the Accountant General's Office.

\section{Other key recommendations}

- Meet SDDS requirements for timeliness of data on central government operations.

- Publish revenue, expenditure, and financing data for all levels of government at a more detailed level.

- Publish debt tables for central government, general government, and nonfinancial public sector, disaggregated by type of sector of debt holder and instrument.

- Develop a migration path to GFSM 2001.

\section{Monetary Statistics}

\section{High priority}

- Include all depository corporations in the depository corporations survey.

- Expand the sectoral breakdown of the depository corporations and financial surveys in accordance with the MFSM methodology.

- Enhance the coordination between CRBP and SBIC to avoid duplication of efforts in the validation of balance sheet data and to collaborate on improvements in the plan of accounts for commercial banks.

- Develop a plan for the full adoption of the MFSM methodology, especially with respect to the (i) compilation of a comprehensive sectoral balance sheet for the other depository corporations sector; (ii) sectorization and classification of accounts; (iii) valuation of financial assets and liabilities; and (iv) treatment of accrued interest. 


\section{Balance of Payments Statistics}

\section{High priority}

- Improve the scope of data sources for compiling financial flows of individual residents.

- Make the Data Template on International Reserves and Foreign Currency Liquidity consistent with the format prescribed in the Operational Guidelines.

- Compile data on public and private external debt on an accrual basis. 
Table 2. Peru: Data Quality Assessment Framework-Summary Presentation of Results

\begin{tabular}{|c|c|c|c|c|c|c|c|}
\hline Element & $\begin{array}{l}\text { National } \\
\text { Accounts }\end{array}$ & $\begin{array}{l}\text { Con- } \\
\text { sumer } \\
\text { Price } \\
\text { Index }\end{array}$ & $\begin{array}{l}\text { Whole- } \\
\text { sale } \\
\text { Price } \\
\text { Index } \\
\end{array}$ & $\begin{array}{l}\text { Govern- } \\
\text { ment } \\
\text { Finance } \\
\text { Statistics }\end{array}$ & $\begin{array}{c}\text { Mone- } \\
\text { tary } \\
\text { Statistics }\end{array}$ & $\begin{array}{c}\text { Balance } \\
\text { of Pay- } \\
\text { ments } \\
\text { Statistics }\end{array}$ & Comments \\
\hline \multicolumn{8}{|l|}{ 0. $\quad$ Prerequisites of quality } \\
\hline 0.1 Legal and institutional environment & LO & $\mathrm{O}$ & LO & LO & LO & $\mathrm{O}$ & See paragraphs 14,17 \\
\hline 0.2 Resources & LNO & LO & LNO & $\mathrm{O}$ & $\mathrm{O}$ & $\mathrm{O}$ & See paragraph 15 \\
\hline 0.3 Quality awareness & LO & LO & LNO & $\mathrm{O}$ & $\mathrm{O}$ & $\mathrm{O}$ & See paragraph 16 \\
\hline \multicolumn{8}{|l|}{ 1. Integrity } \\
\hline 1.1 Professionalism & $\mathrm{O}$ & $\mathrm{O}$ & $\mathrm{O}$ & $\mathrm{O}$ & $\mathrm{O}$ & $\mathrm{O}$ & \\
\hline 1.2 Transparency & LNO & LNO & LNO & $\mathrm{O}$ & $\mathrm{O}$ & $\mathrm{O}$ & See paragraph 21 \\
\hline 1.3 Ethical standards & $\mathrm{O}$ & $\mathrm{O}$ & $\mathrm{O}$ & $\mathrm{O}$ & $\mathrm{O}$ & $\mathrm{O}$ & \\
\hline \multicolumn{8}{|l|}{ 2. $\quad$ Methodological soundness } \\
\hline 2.1 Concepts and definitions & LO & $\mathrm{O}$ & LNO & $\mathrm{O}$ & $\mathrm{O}$ & $\mathrm{O}$ & See paragraphs 24,26 \\
\hline 2.2 Scope & LO & LO & LO & LO & LO & LO & See paragraphs 24 to 29 \\
\hline 2.3 Classification/sectorization & LO & LO & $\mathrm{O}$ & $\mathrm{O}$ & LO & $\mathrm{LO}$ & See paragraphs $24,25,28,29$ \\
\hline 2.4 Basis for recording & LO & LO & $\mathrm{O}$ & $\mathrm{O}$ & LO & $\mathrm{LO}$ & See paragraphs $24,25,28,29$ \\
\hline \multicolumn{8}{|l|}{ 3. Accuracy and reliability } \\
\hline 3.1 Source data & LNO & LO & LO & $\mathrm{O}$ & $\mathrm{O}$ & LO & See paragraphs $30,31,32,35$ \\
\hline 3.2 Statistical techniques & LNO & LO & LO & $\mathrm{O}$ & $\mathrm{O}$ & LO & See paragraphs $30,31,32,35$ \\
\hline 3.3 Assessment and validation of source data & LNO & $\mathrm{O}$ & $\mathrm{O}$ & $\mathrm{O}$ & $\mathrm{O}$ & $\mathrm{O}$ & See paragraph 30 \\
\hline $\begin{array}{l}\text { 3.4 Assessment and validation of intermediate data and } \\
\text { statistical outputs }\end{array}$ & LO & $\mathrm{O}$ & $\mathrm{O}$ & LO & $\mathrm{O}$ & $\mathrm{O}$ & See paragraphs 30,33 \\
\hline 3.5 Revision studies & LO & $\mathrm{O}$ & $\mathrm{O}$ & $\mathrm{O}$ & $\mathrm{O}$ & $\mathrm{O}$ & See paragraph 30 \\
\hline \multicolumn{8}{|l|}{ 4. $\quad$ Serviceability } \\
\hline 4.1 Relevance & LO & $\mathrm{O}$ & LNO & LO & LO & LO & See paragraphs 36 to 40 \\
\hline 4.2 Timeliness and periodicity & LO & $\mathrm{O}$ & $\mathrm{O}$ & LO & $\mathrm{O}$ & $\mathrm{O}$ & See paragraphs 36,38 \\
\hline 4.3 Consistency & LO & $\mathrm{O}$ & $\mathrm{O}$ & $\mathrm{O}$ & $\mathrm{O}$ & $\mathrm{O}$ & See paragraph 36 \\
\hline 4.4 Revision policy and practice & LO & LO & LO & $\mathrm{O}$ & $\mathrm{O}$ & $\mathrm{O}$ & See paragraphs 36,37 \\
\hline \multicolumn{8}{|l|}{ 5. Accessibility } \\
\hline 5.1 Data accessibility & $\mathrm{O}$ & $\mathrm{O}$ & $\mathrm{O}$ & $\mathrm{O}$ & $\mathrm{O}$ & $\mathrm{O}$ & \\
\hline 5.2 Metadata accessibility & LO & LO & LO & LO & LO & LO & See paragraphs 41 to 45 \\
\hline 5.3 Assistance to users & $\mathrm{O}$ & $\mathrm{O}$ & $\mathrm{O}$ & $\mathrm{O}$ & $\mathrm{O}$ & $\mathrm{O}$ & \\
\hline
\end{tabular}

Key to symbols: NA = Not Applicable; $\mathrm{O}=$ Practice Observed; LO = Practice Largely Observed; LNO =Practice Largely Not Observed; NO = Practice Not Observed 


\section{INTERNATIONAL MONETARY FUND}

PERU

\section{Report on the Observance of Standards and Codes (ROSC)—Data Module}

\section{Response by the Authorities}

October 7, 2003

Contents

I. Central Reserve Bank of Peru.

II. Ministry of Economy and Finance

A. Government Finance Statistics

III. National Institute of Statistics and Informatics $\underline{6}$

A. National Accounts. 


\section{Central Reserve Bank of Peru}

1. We agree with the main findings of the Report on the Observance of Standards and Codes (ROSC)-Data Module of the Central Reserve Bank of Peru (CRBP)'s data, in particular with respect to the following:

- The legal and institutional environment is adequate as a prerequisite for data quality.

- $\quad$ The methodologies for compiling macroeconomic statistics are broadly aligned with international standards.

- The terms and conditions under which the statistics are collected, processed, and disseminated are available to the public, which has access to the databases.

- All the institutions connected with the compilation of data, including the CRBP, demonstrate professionalism and provide ethical guidelines to their staff.

2. We set out below our comments on the observations referring to the data processed and disseminated by the CRBP.

\section{A. Balance of Payments}

- $\quad$ The value of marine resources taken by nonresident vessels has now been excluded from exports.

- With respect to the coverage of imports, it is worth noting that the current statistics include transactions in the Tacna Special Processing Area, which, according to private sector estimates, accounts for a high percentage of the transactions that are not recorded by Customs.

- For information, the items included under the "Services" heading of the balance of payments are accounted for on an accrued basis.

- $\quad$ From the first quarter of this year, the quarterly survey has included a specific question to confirm that private debt interest and amortization are recorded on an accrued basis.

- In the case of public debt interest, coordination efforts are under way with the Ministry of Economy and Finance to make accrued figures available for this heading.

- $\quad$ The private sector enterprise surveys now include more precise questions to determine the source of financing and to achieve better classification into foreign direct investment and foreign loans. The result of this work can be seen in the CRBP's latest annual report. 
- We are open to suggestions as to how to improve coverage for compiling financial flows of residents.

- With regard to the comment on the need to separate price and exchange rate effects in the assets and liabilities of the International Investment Position, efforts are under way to determine the exchange rate effect, allowing a longer timeframe to assess the price effect.

- Concerning the dissemination of the balance of payments methodology, it is worth noting that there is a detailed version of this on the IMF website.

- In considering the recommendations on the "Data Template" report on International Reserves and Foreign Currency Liquidity, which the CRBP sent to the IMF, in our view it is not appropriate to classify foreign currency reserve deposits as contingent items. By contrast, the data on public debt service payments in dollars are only available monthly and not on a weekly basis, and therefore the corresponding records are updated at those intervals.

\section{B. Monetary Statistics}

- $\quad$ On the recommendation to include interest receivable and payable as part of net international reserve assets and liabilities, we consider it advisable to maintain our current conservative practice of not overvaluing this indicator. To this end, and in line with the recommendations of a 1993 mission from the IMF's Statistics Department, the practice of not including unrealized income as assets and liabilities will be continued.

- $\quad$ For the same reasons as those outlined above, we shall continue to use the conservative basis of the lower of cost and market for recording the assets that form part of net international reserves.

- $\quad$ The recommendation that the CRBP prepare its financial accounts from statements prepared and reviewed in advance by the Superintendency of Banking and Insurance is neither practical nor appropriate. The CRBP needs timely information not merely for statistical purposes, but above all to formulate and execute monetary policy, and to prevent payment systems problems.

- The proposal for all financial investment made by depository corporations to be valued at market would not have a particularly big impact, as only those securities held to maturity in the portfolio are valued at the lower of nominal value and market.

- In addition to the publication of the aggregate financial accounts for the financial and banking systems, from this year accounts have started to be released for deposittaking institutions (depository corporations). Similarly, the recommendation that the scope of the financial accounts of all deposit-taking institutions include the private 
sector, defined as enterprises, households, and nongovernmental organizations, and that this definition exclude nonbank financial institution deposits, has been met.

- $\quad$ The breakdown of the private sector category into households and nonfinancial private enterprises would entail a significant change in the preparation of the financial institution information reports by which its implementation will be assessed.

\section{Government Finance Statistics}

- The mission states that the responsibility for compiling government statistics is not clearly assigned and that this responsibility must be given to one single institution. In this respect it should be noted that the Political Constitution mandates the Central Bank of Peru to report on the state of the nation's finances.

- Turning to the recommendation to reconcile the CRBP's statistics with those of the Ministry of Economy and Finance, and with the Republic's General Account, we must point out that as the source of the information is common to all three, there should be no differences except for those caused by revisions to the information.

- $\quad$ Concerning the recommendation to meet the requirements with respect to timeliness of publication of data on the central government operations, we can report that since end-February these have been released with a four-week time lag.

- With regard to the recommendation to publish detailed information on income, expenditure, and financing, it must be pointed out that this has been published since end-February.

- With respect to the recommendation to disseminate disaggregated public debt information, this information can be found in the quarterly tables published in the Weekly Note, and it should be explained that to date only the central government has issued debt.

\section{National Accounts}

- With respect to the comments on the real sector statistics it is worth noting that these statistics are the responsibility of the National Institute of Statistics and Informatics. However, as regards the absence of a quarterly domestic demand indicator and its components, the CRBP is in the process of constructing and disseminating this information. Reports are also being prepared on this topic. 


\section{Ministry of Economy AND FinAnCE}

\section{A. Government Finance Statistics}

3. Following are the comments from the MEF with respect of the main recommendations of the data ROSC in the area of government finance statistics: (the ROSC recommendations are shown in italics, followed by the comments from MEF)

\section{Recommendations:}

- $\quad$ Assign the responsibility of compiling and disseminating government finance statistics to one single institution.

- $\quad$ Reconcile the government finance statistics published by the Central Bank of Peru (CRBP) with those published by the Ministry of Economy and Finance (MEF) and the General Accounting Office (Contaduría General de la República).

4. Turning first to the fiscal statistics compiled and published by the MEF, these refer exclusively to the fiscal statistics produced to comply with the former Law on Fiscal Prudence and Transparency (LPTF), Law 27245. As mentioned in the report, the abovereferenced law (now partially repealed) defined certain classifiers of the components of the public sector that were not in line with international standards. However, one of the changes brought about by the law amending the LPTF (Law 27985) is to lay down a standard method of accounting for government finances that is totally compatible with international standards. We consider that this is an important point that should be given emphasis in the report.

5. It is clear from this that, as the MEF is the primary source of information on fiscal accounting, any discrepancy between the statistics published by the MEF (Fiscal Transparency Bulletin) and the CRBP (Weekly Note) must be entirely due to methodological discrepancies that it is hoped will be reconciled in the future, or to ad hoc adjustments carried out by the BCRP, and hence the Nonfinancial Public Sector coverage is now standardized.

6. As to reconciling government finance statistics, meetings were held bringing together the officials responsible for these statistics at the CRBP and at the MEF. Following the respective coordination efforts with the CRBP, the two institutions are trying to standardize the concepts and methodologies used in the various public accounts.

7. With respect to the legal requirement to publish the Fiscal Transparency Bulletin (BTF), although there is no legal obligation, there is some background in that item 12 of the letter of intent of February 2001 states that "the MEF will begin to publish a monthly fiscal bulletin in the second quarter of 2001 that will contain detailed information on revenue and spending (...) performance of budgetary units that will allow the general public to monitor closely the use of public resources and fiscal developments." 


\section{Recommendation:}

- $\quad$ Comply with the requirements of the SDDS with regard to timeliness in publishing the data on central government operations.

8. The Integrated Financial Management Information System (SIAF), a system used by the various entities to prepare government finance statistics, provides real-time data and consequently the statistics can be ready within the required timeframe (one month as required in the SDDS) as it is published in the BTF.

9. Similarly, following the IMF mission to Peru, the CRBP began to publish data on central government operations with only a four week time lag, as stipulated by the SDDS.

\section{Recommendation:}

- $\quad$ Publish statistics on revenues, expenditures, and financing requirements of the various tiers of government in greater detail.

10. In the case of the regional governments, information is available from the Integrated Public Sector Financial Management Information System (SIAF-SP). It should be noted that the draft law on Fiscal Decentralization, which has already been submitted by the executive branch to the Congress of the Republic, proposes that the regional governments be obliged to prepare economic and financial management reports. These reports will be used to improve the information on the public sector prepared both by the MEF and by the BCRP. The MEF will publish these reports on its web page as required by the Law on Transparency and Access to Public Information and Article 17 of the Basic Decentralization Law.

11. Similarly, it is hoped that the SIAF for local governments will be in operation in the medium term and so enable them to comply with the requirement to publish their statistics. It is important to mention that with effect from Law 27978, published on May 29, 2003, a supplementary credit is authorized in the public sector budget in favor of the MEF (derived from the foreign borrowing operations with the Andean Development Corporation (ADC)), which is intended to finance this project.

\section{NATIONAL INSTITUTE OF STATISTICS AND INFORMATICS}

\section{A. National Accounts}

12. The peculiar situation of having a monthly GDP not only from the supply side but also from the demand side has to be addressed straightforwardly. In this sense, it is necessary to have a table about this monthly measure of value added with the same structure as for annual and quarterly measurements.

13. It is clear for NISI that Peru does not have a monthly GDP in any version. The quarterly GDP from the supply side is the sum of monthly GDP data. Therefore, since there 
is no methodological improvement from monthly to quarterly, NISI concludes that there is not a quarterly GDP from supply side.

14. Finally, it is important to stress the fact that NISI made public the mathematical formulas for estimating the monthly GDP in order to have transparency in the eyes of the public opinion and other public institutions. 


\section{INTERNATIONAL MONETARY FUND}

PERU

\section{Detailed Assessments Using the Data Quality Assessment Framework (DQAF) \\ Prepared by the Statistics Department \\ Approved by Carol S. Carson and Anoop Singh}

October 7, 2003

This document contains a detailed assessment by dataset of the elements and indicators that underlie the data quality dimensions discussed in Peru's Report on the Observance of Standards and Codes (ROSC) — Data Module. It also includes as appendices a summary of the Special Data Dissemination Standard, the DQAF generic framework, and the results of the users' survey. 


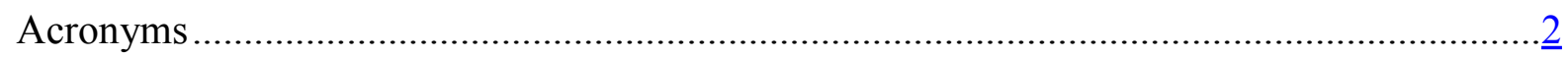

I. National Accounts ............................................................................................ 4

II. Consumer Price Index .....................................................................................

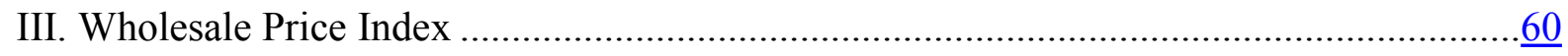

IV. Government Finance Statistics …..................................................................

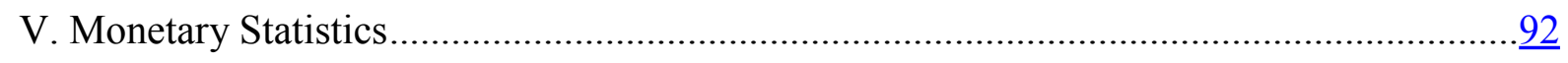

VI. Balance of Payments Statistics ...................................................................... 111

Text Tables

1. DQAF - Summary of Results for National Accounts ............................................ 41

2. DQAF - Summary of Results for Consumer Price Index............................................ $\frac{58}{72}$

3. DQAF - Summary of Results for Wholesale Price Index ............................................. $\frac{72}{72}$

4. DQAF - Summary of Results for Government Finance Statistics ................................. $\frac{90}{10}$

5. DQAF - Summary of Results for Monetary Statistics .............................................. 110

6. DQAF - Summary of Results for Balance of Payments Statistics .................................132

Appendices

I. Summary of the Special Data Dissemination Standard............................................134

II. Data Quality Assessment Framework - Generic Framework ....................................136

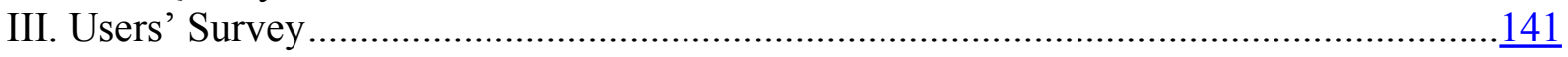




\section{ACRONYMS}

1993 SNA

AES

ASD

BIS

BOPD

BPM5

CEMLA

CFRD

COFIDE

COFOG

COICOP

CONASEV

CPC

CPI

CRBP

DEI

DQAF

DSBB

ECLAC

EDD

EDPYMES

ENAHO

ENAPOVE

ENAPROM

ENNIV

ESD

ESRD

ESU

FONAFE

GAU

GDP

GED

GFS

GFSM 1986

GFSM 2001

GFSY

HICES

HBS

IAS

ICCSI

ICSC

ILO

IMF

IOD

ISFA
System of National Accounts 1993

Annual Economic Survey

Accounting and Supervision Department, CRBP

Bank for International Settlements

Balance of Payments Department, CRBP

Balance of Payments Manual, fifth edition

Center for Latin American Monetary Studies

Credit and Financial Regulation Department, CRBP

Financial Corporation for Development

Functional Classification of Government Expenditures

Classification of Individual Consumption by Purpose

National Commission of Enterprises and Securities

Central Product Classification

Consumer Price Index

Central Reserve Bank of Peru

Directorate of Economic Indicators, NISI

Data Quality Assessment Framework

Data Standards Bulletin Board

Economic Commission for Latin America

External Debt Department, CRBP

Development Institution for the Small and Medium Enterprises

National Household Survey

National Survey of Production and Sales

Encuesta Nacional de Propósitos Múltiples

National Survey to Measure the Standard of Living

Economic Studies Division, CRBP

Economic Situation Research Department, CRBP

External Sector Unit, CRBP

National Fund for the Financing of the State Entrepreneurial Activity

Global Analysis Unit, CRBP

Gross Domestic Product

Government Entities Department, CRBP

Government Finance Statistics

A Manual of Government Finance Statistics 1986

Government Finance Statistics Manual 2001

Government Finance Statistics Yearbook

Households Income and Consumption Expenditure Survey

Households Budget Survey

International Accounting Standards

Institutional Coordinating Committee of Statistics and Informatics

Inter-institutional Committee of Statistical Coordination

International Labor Organization

International Monetary Fund

International Operations Department

Integrated System for Financial Administration 


\begin{tabular}{|c|c|}
\hline ISIC & International Standard Industrial Classification of all Economic Activities \\
\hline ISWGNA & Inter-secretarial Working Group on National Accounts \\
\hline ITRS & Internal Transactions Reporting System \\
\hline$M F S M$ & Monetary and Financial Statistics Manual \\
\hline MEF & Ministry of Economy and Finance \\
\hline MP & Ministry of Production \\
\hline MSD & Monetary Sector Division, CRBP \\
\hline NANDINA & $\begin{array}{l}\text { Common Tariff Nomenclature of Member Countries of the Cartagena } \\
\text { Agreement }\end{array}$ \\
\hline NCSI & National Council of Statistics and Informatics \\
\hline NDNA & National Directorate of National Accounts, NISI \\
\hline NDCS & National Directorate of Census and Surveys, NISI \\
\hline NDSC & National Directorate of Statistics and Census \\
\hline NIP & National Institute of Planning \\
\hline NIS & National Institute of Statistics \\
\hline NISI & National Institute of Statistics and Informatics \\
\hline NOSC & National Office of Statistics and Census \\
\hline NSDP & National Summary Data Page \\
\hline NSS & National Statistical System \\
\hline NSSI & National System of Statistics and Informatics \\
\hline ODCs & Other Depository Corporations \\
\hline PCGD & Public Credit General Department, CRBP \\
\hline PED & Public Enterprises Department, CRBP \\
\hline PID & Production Indicators Department, CRBP \\
\hline PPI & Producer Price Index \\
\hline PSAD & Public Sector Analysis Department, CRBP \\
\hline PSU & Public Sector Unit, CRBP \\
\hline QFIED & Quarterly Services, Foreign Investment, and External Debt Survey \\
\hline ROSC & Report on the Observance of Standards and Codes \\
\hline RUC & Unique Register of Taxpayers \\
\hline $\mathrm{SBIC}$ & Superintendency of Banks and Insurance Companies \\
\hline SDDS & Special Data Dissemination Standard \\
\hline SFIED & Services, Foreign Investment, and External Debt Survey \\
\hline SIAF & Integrated System of Financial Administration \\
\hline SICON & National System of Accounting Integration \\
\hline SITC & Standard International Trade Classification \\
\hline SMD & Systems Management Department, CRBP \\
\hline SUNAT & National Superintendency of Tax Administration \\
\hline TDSDIT & $\begin{array}{l}\text { Technical Directorate of Statistical Dissemination and Information } \\
\text { Technology, NISI }\end{array}$ \\
\hline TOD & Technical Office of Dissemination, NISI \\
\hline TOI & Technical Office of Informatics, NISI \\
\hline TOPB & Technical Office of Planning and Budgeting, NISI \\
\hline USGAAP & United States Accounting Principles \\
\hline VAT & Value Added Tax \\
\hline WPI & Wholesale Price Index \\
\hline
\end{tabular}




\section{Detailed Assessment Using the Data Quality Assessment Framework (DQAF)}

The following detailed information on indicators of statistical practices in the areas of the national accounts, prices, government finance, money and banking, and balance of payments statistics was gathered from publicly available documents and information provided by the Peruvian officials. This information, which is organized along the lines of the generic DQAF (see Appendix II), was used to prepare the summary assessment of data quality elements, based on a four-part scale of observance, shown in Peru's Report on the Observance of Standards and Codes (ROSC)—Data Module.

\section{National Accounts}

\section{Prerequisites of quality}

\section{$0.1 \quad$ Legal and institutional environment}

\subsubsection{The responsibility for collecting, processing, and disseminating statistics is clearly specified}

The responsibility for collecting, processing, and disseminating official statistics in Peru is laid out in a series of laws and legislative decrees. In 1969, the National Directorate of Statistics and Census (NDSC) was transformed into the National Office of Statistics and Census (NOSC), within the National Institute of Planning (NIP), through the Legal Decree No. 17532 "Organizational Law of the Republic Presidency." However, the Central Reserve Bank of Peru (CRBP) collected, compiled, and published official national accounts statistics from 1946 to 1974. Later, the National Statistical System (NSS) was created and the NOSC was transformed into the National Institute of Statistics (NIS), with the obligation to report to the Prime Minister, through the Legal Decree No. 21372 of December 30, 1975. The legal framework for the collection and dissemination of official national accounts statistics was specified under the Decree, which made the Chief of the NIS the head authority of the NSS.

In 1978, the NIS was transferred to the NIP as the National Office of Statistics (Legal Decree No. 22411/12-26-78). In 1980, the NIS was reinstituted as part of the Presidency of the Council of Ministers (Law No. 23233/12-29-80). In 1983, the Regional Offices of Statistics of the NIS were established (NIS Chief Resolutions No. 005 and 008/01- 25 and 26-83), and the NIS was transferred to the Ministry of Economy and Finance (MEF), maintaining its autonomy as a decentralized public entity (Legislative Decree No. 261/06-24-83). In 1984, the NIS was reinstituted again to its original level with the President of the Council of Ministers (Legislative Decree No. 316/12-21-84). However, the MEF and the NIP continued compiling national accounts statistics for their own use up to the 1980s. The CRBP also continued compiling and publishing national accounts statistics, even though the first issue of the NIS series from 1970 to 1976 was published in 1978. In 1988, the CRBP started publishing the national accounts statistics compiled by the NIS in its Annual Report.

On April 5, 1990, Article No. 56 of the Executive Power Law (Legal Decree No. 560) was amended (Legal Decree No. 563) in order to broaden the responsibilities of the NIS as the National Institute of Statistics and Informatics (NISI), with the additional responsibility of 
formulating and evaluating the national policy of information technology, regulating the computing and information activities of the public sector, and administrating the National System of Statistics and Informatics (NSSI). Furthermore, the Law of Organization and Functions of the NISI (Legislative Decree No 604/04-30-90) established the NISI as a decentralized public organism with technical autonomy, and an obligation to report to the President of the Council of Ministers.

The coordination and production of statistics referred to as the system of national and regional accounts, among other data sets, is clearly defined as one of the functions of the NISI in its Regulations (Supreme Decrees No. 018-91-PCM and No. 043-2001-PCM/04-212001) and in Article 9 of the Legislative Decree No. 604. These laws are also available on the Institute's website (http://www.inei.gob.pe).

To fulfill its mission, the NISI is organized into two Sub Heads, one for Statistics and one for Informatics, and in six Directorates: National Directorate of Censuses and Surveys, National Directorate of National Accounts, Technical Directorate of Economic Indicators, Technical Directorate of Demography and Social Indicators, Technical Directorate of Standardization and Promotion, and Technical Directorate of Computer Development. In addition, the NISI has units of support and control and Regional Offices of Statistics and Informatics in each one of the 24 states of Peru.

The operational responsibility for collecting, compiling, and disseminating annual national accounts lies with the National Directorate of National Accounts (NDNA) of the NISI. The work is performed through four Divisions or Directorates: Executive Directorate of Nonfinancial Goods and Services, Executive Directorate of Government and Financial Sector Accounts, Executive Directorate of Household Accounts, and an Unit of Methodology.

In addition, Articles 2 and 74 of the CRBP Organizational Law (Decree-Law No. 26123/0101-1993), Articles 95 and 97 of its By-Law (02-27-94), and Article 84 of the Constitution of Peru give the responsibility of regularly releasing accurate information on the national finances to the CRBP. Therefore, the Bank reports periodically on the nation's finances and publishes the main macroeconomic statistics. The mandate to collect, compile, and disseminate national accounts statistics is clearly specified in the Legislative Decree No. 604 and gives responsibility in this regard to the NISI, which compiles monthly and annual data. The CRBP estimates quarterly national accounts and makes annual GDP forecasts that reconcile with the NISI source data and estimates when they are available for dissemination in its Weekly Bulletin and its Annual Report.

The operational responsibility for collecting, compiling, and disseminating quarterly national accounts lies with the CRBP's Department of Production Indicators (DPI), unit of the Real Sector Sub-Management within the Economic Studies Management.

The legal and institutional environment of Peruvian statistics features a highly decentralized statistical system, which includes Sectoral Statistical Offices, Statistical Offices in the Ministries, in the Centralized and Decentralized Public Entities, in the Public Enterprises, and in the Regions. Owing to the decentralization of the statistical system and the history of Peruvian statistics, especially the changing of the compilation of national accounts from one 
public entity to another, a serious problem of duplication of efforts exists. Even though the statistical legislation broadly follows international standards, the budgetary allocation for statistical functions is insufficient.

\subsubsection{Data sharing and coordination among data producing agencies are adequate}

Articles 4 and 5 of the NISI Regulations give this statistical agency the necessary legislative support to obtain data from administrative sources and other data producing agencies. However, the National Superintendency of Tax Administration (SUNAT) has useful information for preparing an updated business register that is not accessible to the NISI due to legal restrictions regarding confidentiality. In this regard, an agreement has been recently signed with the SUNAT to exchange statistical information, but restrictions with respect to confidentiality still remain. NISI has also agreed with the CRBP to improve the Annual Economic Surveys (AES) for the services activities and to develop value added estimates at producer prices from 1994 to 2001.

Coordination among the statistical agencies is evident in the revision of the Annual Economic Survey's questionnaires and manuals, sample design, follow-up of the collection procedures, and transmission of databases. Coordination is the responsibility of the InterInstitutional Coordination Committee of Statistics and Informatics (ICCSI), with established coordination mechanisms in Article 16 of the Legal Decree No. 604. Article 16 states that the ICCSI of the NSSI, "...coordinate and agree on the policy as well as the formulation and development of the plans of the entities that integrated it. It is presided by the chief of the NISI and integrated by the responsible entities of conducting the systems at the central and local levels." Nevertheless, communication within the statistical system is infrequent. The ICCSI held monthly regular meetings until May 2002. Since then, the ICCSI has not met.

In addition, there is duplication of effort in the collection of source data on manufacturing and agriculture between the Ministry of Agriculture and the Ministry of Production (MP), and on manufacturing and mining between the Ministry of Mining and the MP. In addition, duplication in the collection of source data exists among the entities of the NSS and the NISI, and between the CRBP and the NISI in the compilation of monthly and annual national accounts statistics. This duplication of effort has led to a high respondent burden.

\subsubsection{Respondents' data are to be kept confidential and used for statistical purposes only}

Article 97 of the NISI Regulations guarantees the confidentiality of individual respondents' data and provides a legal mandate for reporting. Article 97 states that "the information provided by the sources is confidential, and it cannot be revealed in individualized form, even if an administrative or judicial order mediates. It can only be disclosed or published without identification. The information given cannot be used for tax purposes or police investigations. The exchange of information among the entities of the System for achieving its purposes does not transgress the statistical secret or the confidentiality of the information, neither the information used in the elaboration of directories."

All questionnaires used for censuses, surveys, and special investigations by the NISI make reference to the confidentiality requirements of the information in a section placed on the 
first page of the form. It reads: "Confidential questionnaire protected by the Supreme Decree No. 018-91-PCM: Statistical Secret." However, in order to better inform respondents, they also could benefit from including in this statement the articles of the Supreme Decree No. 604 that deal with confidentiality and the legal mandate of reporting.

Article 98 of the NISI Regulations states that "Workers that have direct relation with the handling of the statistical information and acted against the statistical secret, would be responsible for the disciplinary sanctions considered in the Law of Basis of the Administrative Carrier and Remuneration of Public Employees (Legislative Decree No. 276/1984), without damaging their civil or penal responsibility." Article 99 declares: " The rules to safeguard the statistical secret and the confidentiality of the information in the different levels of the organic structure of the National Systems of Statistics and Informatics will be made through a NISI Chief Resolution."

The personnel that compile national accounts at the NISI have access to the individual information of the sources and are aware of the confidentiality of the data and the penalties that the law contemplates. The original databases are administrated by the NISI's Technical Office of Informatics (TOI).

There are several levels of security that go from the NISI intranet to the administrative system of the database. It is necessary to have an authorized user name and a password to have access to it. As for the security of the whole system, two levels exist, internal and external. The internal is given by the levels of security of the operating system Windows 2000 Nets and the external one by barriers type Firewall.

As for preserving the integrity of individual information, online and off-line databases exist. A daily backup is made to the online databases, maintaining copies for seven days. A general backup is kept on a monthly basis in order to maintain the historical information.

Questionnaires, once processed, are sent to the Central File Room of the General Secretary of the State. They are subsequently sent to the General File Room of the Nation after several years, where they are stored and finally destroyed, in consultation with the NISI.

In addition, the CRBP Organizational Law clearly states that individual responses are to be treated as confidential and shall not be disclosed or used for other than statistical purposes. The Central Bank Charter states in Article 41 that no person at the Bank's service shall disclose to others any confidential information pertaining to or managed by the Bank. The CRBP Statute of February 10, 1994 states that this obligation persists for two years after the employee leaves. Offenders shall be liable to removal from office, in the case of Managers, or dismissal, in the case of the Bank employees. The Regulation about Institutional Representation, Confidentiality, and Interest Conflict of December 26, 2002 specifies the definition of confidential information. The CRBP is also part of the National Statistical System regulated by the Legislative Decree No. 604.

The CRBP surveys and letters directed to the private sector inform respondents of their rights and obligations with regard to the provision of information. Respondents are aware that the information they provide will be used for statistical purposes only. In general, access to individual data is restricted to staff who require it in the performance of their duties. Steps 
are taken to secure the premises of the CRBP and its computer systems to prevent unauthorized access to individual data. Confidentiality of data is appropriately guarded during storage and during the process of destroying records.

\subsubsection{Statistical reporting is ensured through legal mandate and/or measures to encourage response}

The legislation that allows the NISI to gather statistical information is clear with regard to the rights and the obligations of users and information suppliers. Article 81 of the Legislative Decree No. 604 reads: "Natural persons or legal entities that are in the country, are sources of statistical information of the National System of Statistics, and are obligated to give the information for statistical purposes to the entities of the System, in the form and terms authorized by the NISI's Chief Resolution and published in the official newspaper $E l$ Peruano. Also, the administrative records of the public sector are source of information. The sources whose information is considered classified and affects to the national security are excepted from this obligation."

Chapter III of the Legislative Decree No. 604 establishes the sanctions for noncompliance in providing statistical information. Therefore, those who do not respond to surveys, falsify the truth maliciously, or delay the established terms unjustifiably are liable to be fined without damaging their civil or penal responsibility.

The fines applied by the NISI are:

For natural persons: from 1 to 50 percent of the effective Imposed Tax Unit (UIT) to the cancellation date. The current UIT is 3,100 Nuevos Soles.

For legal entities: $\quad$ from 10 percent of the UIT up to 10 UIT to the cancellation date.

Despite the existence of legal provisions for obtaining information, and penalties for noncompliance, they have rarely been enforced. The intent is to encourage voluntary reporting, by explaining in detail to respondents the use that will be made of their information, its confidential nature, and its importance for the country in terms of quantifying and characterizing the economic activity.

The information burden imposed on respondents by the statistical system is a concern of the NISI, which has modernized the process for collecting information. The respondents can obtain the computerized formats of the surveys at the NISI website and present their information in magnetic medium. The NISI is studying the possibility of minimizing the compilation of data by requesting the most significant information only. However, coordination among the entities within the NSS needs to be improved in order to avoid duplicity of information requests and lower the high respondents' burden. In case of noncompliance, the NISI does not have the right to inspect books or enough resources to visit establishments.

The CRBP, in accordance with the regulations enacted by the MEF, also collects information from individual persons and public or private corporations. The Ministerial Resolution No. 239-93-EF-10 provides these regulations. Articles 73 and 74 empower the Bank to fine 
respondents in case of noncompliance or for submitting incomplete or inaccurate information. The Circular 004-2002-EF/90 issued by the CRBP indicates the penalties. Owing to the duplication of efforts in the collection of source data among the different statistical agencies, the respondent burden is unduly heavy.

\section{$0.2 \quad$ Resources}

\subsubsection{Staff, financial, and computing resources are commensurate with statistical programs}

The NDNA, besides the compilation of national accounts, is responsible for conducting the Annual Economic Survey (AES) of Trade and Services, conducting the surveys of the Nonfinancial Public Enterprises, and coordinating the AES of the rest of the industries. These include Agriculture, Manufacturing, Fishing, Mining, Hydrocarbons, Electric Services, Construction, Lodging, Transport and Communication, Travel Agencies, Operators of Postal Services, Educational Centers of non State Administration and non State Universities. This unit had 30 employees until December 2002, of which 23 were permanent and 7 were contractual. These 7 professionals were let go in January 2003 due to budgetary constraints.

A summary table of the staff involved in the compilation of national accounts is as follows:

\begin{tabular}{|l|c|c|}
\hline \multicolumn{1}{|c|}{ Directorate } & Professionals & Assistants \\
\hline National Director & 1 & 0 \\
Deputy Director & 1 & 0 \\
Nonfinancial Goods and Services & 10 & 1 \\
Government and Financial Sector Accounts & 4 & 1 \\
Households' Account & 4 & 0 \\
Methodology Unit & 2 & 0 \\
\hline Total & $\mathbf{2 1}$ & $\mathbf{2}$ \\
\hline
\end{tabular}

The NISI is experiencing serious deficiencies in resources with regard to personnel. Even though the staff are working at full capacity, there are insufficient resources for making needed updates on the national accounts program, particularly with regard to preparing a supply and use table and updating the base year. In order to develop a program for changing the base year and fully implementing the $1993 S N A$, it will be necessary to increase the number of employees, given the magnitude and complexity of the task.

Regarding national accounts methodology, there is no permanent training program. There are few universities that include this subject in the curriculum. The training is usually carried out through courses, seminars, workshops and international conferences, which are offered every year by several international organizations, such as the OECD, ECLAC, the CESD-Madrid, and the Andean Community. However, personnel from other areas that are not directly related with national accounts compilation have been designated to participate in the latest specialized courses on national accounts. There are organized work groups on national accounts among the staff that have carried out sessions to discuss methodological improvements and recommendations, as well as to restructure and simplify the procedures. 
The NDNA team has an accumulated experience of many years, during which the personnel have specialized in specific areas, applying the concepts and practices suggested in the 1968 and 1993 SNA and adapting them to the local needs and available information.

The stability of the national accounts personnel at the Institute can be appreciated from the following table:

\begin{tabular}{|l|c|c|}
\hline \multicolumn{1}{|c|}{ Years in service } & Staff & Percentage of staff \\
\hline $1-7$ & 6 & 26.1 \\
$7-14$ & 6 & 26.1 \\
$14-21$ & 3 & 13.0 \\
$21-28$ & 8 & 34.8 \\
\hline Total & $\mathbf{2 3}$ & $\mathbf{1 0 0 . 0}$ \\
\hline
\end{tabular}

Regarding computing resources, the NDNA has 38 computers and seven printers. Even though they are adequate in light of number of staff, only 23 computers have Pentium II or superior processors. In addition, three of the six printers are dot matrix printers.

The Institute tries to take advantage of the potential offered by the information technology. Besides the Intranet of the NDNA, each professional has access to the Internet, to electronic mail, and to computer programs, such as Excel, Word, Power Point, and Acrobat Reader. The NDNA has developed and introduced computer programs for faster and simplified work procedures for application in the compilation of Government Accounts, Goods and Services Accounts, and Household Accounts. However, this developmental work has suffered owing to the transfer of the programmer to another area.

Distribution of the 38 microcomputers within the national accounts area takes into account staff numbers assigned to the different coordination offices, as well as their work programs. Nevertheless, the distribution of the six printers and the computers assigned to the National Directorate does not seem adequate:

\begin{tabular}{|l|c|c|}
\hline \multicolumn{1}{|c|}{ Directorates } & Computers & Printers \\
\hline Nonfinancial Goods and Services Accounts & 17 & 2 \\
Government and Financial Sector Accounts & 7 & 1 \\
Household Account & 4 & 1 \\
Methodology Unit & 4 & - \\
National Directorate & 6 & 2 \\
\hline Total & $\mathbf{3 8}$ & $\mathbf{6}$ \\
\hline
\end{tabular}

Financial resources assigned to the NDNA are limited, considering the tasks of collecting and processing source data. Owing to the program of public sector austerity, there was a reduction in the NISI budget. This budget reduction has especially affected the collection and assessment of source data and has created inefficiencies in national accounts compilation. 
Overall, the number of staff, their qualifications, computers, and financial resources assigned to the Department of Production Indicators (DPI) of the CRBP for compiling quarterly national accounts statistics are adequate to perform the required tasks. This unit has seven economists and a supervisor. Each of them has a Pentium III computer with eight GW. The DPI also has two printers.

\subsubsection{Measures to ensure efficient use of resources are implemented}

The program of activities and projects of the NDNA are presented to the Technical Office of Planning and Budget (TOPB) that coordinates the program for the management of the NISI. The objectives, purposes, calendar program, and final products are established. The TOPB carries out a quarterly evaluation of the tasks and work actions, compares the programmed activities with those implemented, and analyzes which activities should be reprogrammed. The directors of the NDNA meet every two weeks in order to measure progress, define the work to be undertaken, and propose methodological improvements.

The NDNA has bimonthly work meetings to discuss concepts and international recommendations related to national accounts. In addition, the NDNA coordinates with the National Directorate of Census and Surveys (NDCS) the improvement of data sources and their consistency with the 1993 SNA requirements. Considering the austerity program of the government, the NDNA maintains an efficient administration of financial resources, assigning them to the high-priority activities and trying to maintain the permanent tasks.

Innovations have been introduced in the computer processes to reduce time and costs during the statistical collection, coding, editing, and tabulation of source data. The NDNA has implemented a very advanced electronic process for the collection of the AES starting in 2000. This modern technology collects the basic economic and financial data by industry through electronic formats obtained by the respondents on the NISI website. These formats eliminate the process of data transcription and have a number of basic consistency checks across chapters. In the event of errors, they are presented to the respondents, who correct any inconsistencies themselves. The information obtained is stored in databases that pass through another process of validation requiring additional consistency checks. These processes are carried out by the NDCS in coordination with the NDNA.

On the other hand, a program to elaborate the accounts of the units and institutional subsectors of the General Government is under development. This program will use the accounting and budgetary information integrated in the Integrated System of Financial Administration (SIAF) of the Government. It would improve efficiency in the treatment of source data to compile the Government's account. However, this task has been suspended owing to budgetary restrictions that caused the termination of the seven employees hired under contract.

The NDNA had technical assistance from the French government to review the methodologies and to systematize the compilation process of the complete set of institutional accounts through a pilot program. Furthermore, a project with technical assistance from 
Statistics Canada is expected to be implemented to improve existing data, expand the statistical program, and increase capacity of the NISI and other institutions of the NSS to provide statistical services, through training and the introduction of methodological improvements.

Managers in the CRBP also promote a vision and a sense of direction that are shared with the staff. Each year the Economic Studies Division (ESD) develops a project with the objectives and plans of each Department. It includes statistical projects as well as studies related to the topics of the Department. The staff are aware of these objectives.

Efficiencies are sought by encouraging consistent concepts and methodologies across the different units within the ESD. There are clear responsibilities assigned among the different areas. There is also a manual that compiles the duties of every analyst of the ESD.

Data procedures are managed to minimize processing errors such as coding, editing, and tabulation errors. Particularly in the case of big databases, there is a process of internal consistency before the data are finally processed. Usually, final reports for internal use consider aggregation and sorting of the data at different levels, which allow inconsistencies to be identified before the data are released to the public. Enterprises are in general identified by the code of Unique Register of Taxpayers (RUC).

There are no specific internal processes to measure resources used to compile the quarterly national accounts and to compare the resource usage to that of other statistical programs. The Bank has an annual budget which is reviewed to ensure that scarce resources are best employed in addressing major data problems or meeting new data priorities as well as other priorities of Management. Each year, working processes are reviewed considering the results of the previous year.

The CRBP strives to make the best use of newly emerging opportunities, such as computing technology for data processing and dissemination. When necessary, the CRBP seeks outside expert assistance to evaluate statistical methodologies and compilation systems.

Nevertheless, the existence of dual sets of accounts compiled by CRBP and NISI represent inefficient system-wide use of scarce resources. In addition, there is scope for more data access from the SUNAT in order to improve private sector source data and avoid duplication of efforts in this respect. 


\subsection{Quality awareness}

\subsubsection{Processes are in place to focus on quality}

Although NISI has not established an official program of quality awareness (e.g., total quality management), many elements of such a program are already in place, especially in terms of monitoring data collection, processing, and disseminating national accounts.

According to its mission statement, NISI "is a specialized public entity, that rules the National System of Statistics and Informatics, responsible of regulating, coordinating, promoting, producing, and disseminating official statistics, to support the design and formulation of policies of national interest, and promote the introduction of information technologies for the modernization of the public administration; as well as to supply training, statistical and information research and development services." This mission statement does not explicitly emphasize quality, but the use of information technology is emphasized. In addition, Article 3 of the Legislative Decree No. 604 on the scope of competence of the National System of Informatics (NSI) emphasizes the use of data banks: "Juridical instrumentation and implementation of technical mechanisms for putting in order computing resources and information activity of the State, as well as all the related documentation; operation and exploitation of the data banks and magnetic files of information at the service of the public administration..." are functions under the scope of competence of the NSI. Furthermore, reports on the demand of national accounts statistics by user type are prepared by the Technical Office of Dissemination (TOD).

On the other hand, the CRBP is externally audited each year and the report of this auditing is presented in its Annual Report.

\subsubsection{Processes are in place to monitor the quality of the collection, processing, and dissemination of statistics}

Tests are carried out to identify problems relating to the different stages of the processes of aggregation, compilation, and dissemination of data. During 2002, NDNA staff revised methodologies and analyzed, in some cases, the source data to cross-check them with other sources in order to validate them and improve work procedures. External trade statistics are compared to the data provided by enterprises in the case of mining and petroleum activities. However, there are no formal mechanisms for assessing the quality of national accounts statistics.

A National Council of Statistics and Informatics (NCSI) is envisaged in Articles 14 and 15 of the Legislative Decree No. 604/1990. Article 14 states that the NCSI "...is the organism for the participation of the nonpublic sector, in the National Systems of Statistics and Informatics, in charge of assisting the Chief of the NISI and the entities of the System." Among the functions of this Advisory Council are "to propose actions for improving the development of statistical and information activities in the country; to give their opinion and recommendations on the technical affairs in the statistical and information technology areas; 
to advise on the formulation of National Policies of Statistics and Informatics; and to support the dissemination of the national and international publications on these areas."

Article 15 declares that the NCSI “ ...is presided by the Chief of NISI and is constituted by representative of business, labor and professional organizations and the universities; designed by Ministerial Resolution, as proposed by the mentioned organizations." Nevertheless, this Council is not operational. Regular surveys to obtain the views of the users are not undertaken.

\subsubsection{Processes are in place to deal with quality considerations, including tradeoffs within quality, and to guide planning for existing and emerging needs}

The managers of NISI recognize the trade-offs among the dimensions of data quality; for example, between timeliness and accuracy and reliability.

The quality of national accounts data is a function of the timeliness of source data. This situation is taken into account to carry out short-term estimates of national accounts. In this respect, the NDNA and the CBRP inform users about the character of the data: very preliminary, preliminary, and definitive estimates.

Regarding users' needs, the NISI had monthly meetings with those entities that participate in the Inter-Institutional Committee of Statistical Coordination (ICSC) until May 2002, in order to examine the statistical development and establish new data requirements. However, this Committee has not met since then.

Even though quality awareness is high, as evidenced by the strong emphasis on quality issues of the National Statistical Policy for the Medium Term 2002-2006, regular procedures to obtain feedback from users, formal mechanisms for assessing statistics' quality, and work plans to improve national accounts statistics need to be implemented.

\section{Integrity}

\subsection{Professionalism}

\subsubsection{Statistics are compiled on an impartial basis}

The NISI and the CRBP recognize the importance of the professional independence of the staff. Professionalism in both institutions is evidenced by the early adoption of international standards and the permanence of the staff in the areas of national accounts statistics. The staff of the NISI have played a relevant role in regional and international statistical discussions.

Professionalism in both institutions is promoted by the publication of methodological papers and by organizing meetings of professional groups. The staff attends internal and international courses and conferences. The staff are internally evaluated each semester. The 
CRBP also encourages the participation of professional staff in an Annual Economists Meeting, where papers are presented for discussion.

The Legislative Decree No. 276/1984, on public employees, includes several aspects relative to the independence, specialization, and stability of the personnel, and describes the competencies required for recruitment and promotion of personnel. Regarding the stability of the staff, Article 4 states that "The Administrative Career is permanent and governed by the principles of: Equality of opportunities, stability, as well as fair and equal compensation, regulated by a unique system of remuneration." In addition, there are specific standards set within the NISI with regard to professional behavior, courtesy toward respondents, integrity, impartiality in hiring, execution of official duties, and the avoidance of influence by third parties. Staff with outstanding performance in the NISI are promoted within the institution by taking temporary charge of a higher position (encargaturas) that are established every three months.

The Chief of NISI is selected by the President of the Council of Ministers. However, the head of the statistical authority remains in its position for longer than the governance period of the Prime Minister.

In order to protect the reputation of the NISI and the CRBP, national accounts publications are reviewed and validated by all levels of the hierarchical chain within the institutions. In the case of the NISI, methodological documents are published with the statistical tables presenting macroeconomic variables.

\subsubsection{Choices of sources and statistical techniques are informed solely by statistical considerations}

Choices of sources and statistical techniques are made on the basis of statistical considerations and international standards. Data sources for the compilation of national accounts statistics are derived from information gathered from public and private sectors, including households. This information is used for statistical purposes only.

Methodologies are presented, discussed, and analyzed by the personnel of each area, following in most cases the manuals elaborated by international organizations.

\subsubsection{The appropriate statistical entity is entitled to comment on erroneous interpretation and misuse of statistics}

To avoid erroneous interpretations or misuse of published data, the NISI foments trust in its work by disclosing the statistical information and explanatory reports to the public through press notes, interviews, or on its website. Therefore, data sources and methodologies are presented in all statistical publications produced by the NISI. The institute is entitled to comment on misuse of statistics and has done so in the past.

The NISI's Technical Office of Dissemination closely monitors the specialized press and other media to keep records of news and articles that mention the NISI statistical data. These 
records are useful to produce an official statement to clarify or explain the scope of the data. Press information related to statistics is updated daily on the NISI Intranet.

The CRBP seeks to prevent misinterpretation or misuse of statistics by providing explanatory materials on its website and through publications. It does not comment on erroneous interpretations or misuse of statistics in the media.

\subsection{Transparency}

\subsubsection{The terms and conditions under which statistics are collected, processed, and disseminated are available to the public}

The NISI reproduces in its publications and website the first three articles of its Organizational Law, which clearly states the objectives and purposes of the National Statistical System and its functions. The NISI mission statement is also published on its website. The Technical Directorate of Statistical Dissemination and Information Technology (TDSDIT) is indicated as the place where supplementary information on the NISI and its products can be found.

The CRBP publications and website contain information about its roll and the articles of the Constitution of Peru and the CRBP Organizational Law and By-Law that deal with the terms and conditions under which statistics are collected, compiled, and disseminated. Statistical publications identify sources of additional information about the CRBP and its products. The CRBP also reproduces its Statute and the Regulation about Institutional Representation, Confidentiality, and Conflict of Interest on its website. Both mention the definition of confidential information, as well as the staff obligation regarding confidential information.

\subsubsection{Internal governmental access to statistics prior to their release is publicly identified}

The NISI and the CRBP indicate that the approval process for published national accounts series is entirely internal. However, the public is not aware of this approval process. In addition, the coverage and development of source data used for compiling national accounts are discussed and reconciled between the two institutions before publishing annual, quarterly, and monthly national accounts estimates.

Furthermore, a number of high level government officials have embargoed access to the annual series and the monthly production index the day before they are released. The list of individuals receiving advanced access is not published.

\subsubsection{Products of statistical agencies/units are clearly identified as such}

Because the NISI is a decentralized entity of the government, all NISI publications are identified with its logo. In the case of the Statistical Summary (Compendio Estadístico), it is published as a document of the National Statistical System, since the entities of the Statistical System participate in its elaboration. Nonetheless, the CRBP does not identify the NISI as the 
source of annual national accounts, price statistics, and the monthly production index in the SDDS, its website, or in some other tables of its Weekly Bulletin. ${ }^{l}$ Furthermore, the monthly production index is incorrectly labeled by the CRBP as "Monthly Gross Domestic Product (GDP).”

The bulletins and press notes produced by NISI and CRBP have their respective logos and are available on NISI and CRBP websites. Both NISI and CRBP have a policy of releasing their publications on national accounts in a standard format, in which the presentation, titles, colors, typography, etc., are consistent over time.

\subsubsection{Advance notice is given of major changes in methodology, source data, and statistical techniques}

Major changes in the methodology and source data are not announced in advance, except in the case of implementing a program for changing the base year. Users of statistics are informed in seminars and publications when new data are released. In particular, when the base year was changed from 1979 to 1994 and the 1993 SNA was adopted, press conferences, meetings with public and private institutions, and conferences at universities were carried out to explain the methodological improvements and differences between the two series.

\subsection{Ethical standards}

\subsubsection{Guidelines for staff behavior are in place and are well known to the staff}

Staff and officials of NISI are provided with clear guidelines on ethical standards through documents such as the Supreme Decree No. 018-1990-PCM (Regulations, Organization and Functions of NISI) and the Legislative Decree No. 276, as well as through internal publications. These documents are made available to staff when they sign their contracts and are available on the internal NISI website.

Law No. 27815 (Law of Code of Ethics of the Public Function) affects all public servants, including NISI staff, and specifies that public employees should act according to the following principles: respect, honesty, efficiency, suitability, truthfulness, loyalty and obedience, justice and justness. It also states that public servants have the following duties: neutrality, transparency, discretion, appropriate exercise of the position, appropriate use of resources, and responsibility in the performance of their job.

The CRBP Code of Ethics of August 4, 1999 has clear guidelines outlining correct behavior when the staff are confronted with potential conflict of interest situations. The reputation of the head of the CRBP and its management assure autonomy from political interference.

\footnotetext{
${ }^{1}$ After the visit of the mission, the CRBP updated its website, the Weekly Bulletin, and the DSBB to identify the NISI as the source of annual national accounts.
} 


\section{Methodological soundness}

\subsection{Concepts and definitions}

\subsubsection{The overall structure in terms of concepts and definitions follows internationally accepted standards, guidelines, or good practices}

The national accounts of Peru partially follow the concepts and definitions of the 1993 SNA as a general framework. Deviations from this framework are kept under review.

\subsection{Scope}

2.2.1 The scope is broadly consistent with internationally accepted standards, guidelines, or good practices

The Peruvian system of national accounts includes annual and quarterly estimates. The NISI produces the annual estimates and a monthly production index, while the CRBP produces the quarterly accounts. In June 2000, the NISI presented a revised GDP series using 1994 as base year. Annual GDP at current and constant prices by the production, expenditure, and income approaches are compiled and disseminated. Regional GDP was also compiled for the base year. Annual estimates are available from 1991 to 2001. However, estimates for 2001 have not been published. In addition, a monthly production index by industry is prepared and published by the NISI. Disaggregated data are calculated on a seasonally-adjusted basis, but only the aggregate index is published on a seasonally-adjusted basis.

The complete sequence of accounts for the total economy, one of the minimum requirements established by the Inter-secretariat Working Group on National Accounts (ISWGNA), is not compiled. Accounts for the institutional sectors were prepared and published until 1991 following the 1968 SNA. In addition, Peru does not publish input-output tables or detailed supply and use tables on a regular basis; the last of such tables date back to 1994. The 1993 $S N A$ scope cannot be fully implemented due to source data and resource constraints.

Government offices abroad and the free zone of Tacna are included as part of the economy. The delimitation of the constituent units of the economy and the production and assets boundaries are not fully in accordance with the 1993 SNA recommendations due to limitations in the source data-for instance, production of manufactured goods for own final consumption, production of computer software for own use, intellectual production (literary and artistic work), and illegal output sold are not covered; valuables and historical monuments, patented entities, systems and data bases are not included in the assets boundary. The coverage of informal activities is indirect and limited. Mineral exploration is included in output estimates valued at cost of production.

The CRBP compiles quarterly GDP estimates as recommended by the ISWGNA. Quarterly GDP is compiled by the production approach at constant prices (1994) and by the 
expenditure approach at constant and current prices. It also elaborates quarterly estimates on national disposable income and a monthly domestic demand index.

\subsection{Classification/sectorization}

\subsubsection{Classification/sectorization systems used are broadly consistent with internationally accepted standards, guidelines, or good practices}

The classification and sectorization systems used are broadly consistent with internationally accepted standards, with the exception of government final consumption expenditures, which are not classified by function. Production accounts are prepared for 237 activity branches using the four-digit classification of the International Standard Industrial Classification (ISIC Rev. 3). These accounts are published at aggregate level for 45 activity classes. However, there is a mixture of ISIC Rev. 2 and Rev. 3 with respect to the classification for clearing of cotton, agriculture services, recycling, and auxiliary financial services.

The 1994 supply and use table was prepared at a disaggregated level of 287 goods and services categories, generally classified according to the Central Product Classification (CPC, Rev. 1) and adapted to the local supply. The Classification of Individual Consumption by Purpose (COICOP) was broadly used to classify 1994 household final consumption expenditures. Currently, these expenses are compiled at aggregate level. A complete correlation with the Common Tariff Nomenclature of Member Countries of the Cartagena Agreement (NANDINA-Andean Community) is used to classify external trade.

\subsection{Basis for recording}

\subsubsection{Market prices are used to value flows and stocks}

Industries' transactions are recorded at market prices. Gross output and value added are valued at basic prices, while intermediate consumption is valued at purchaser's prices, including nondeductible value added tax and excise taxes. Expenditures on final consumption and fixed capital formation are also valued at purchaser's prices. Therefore, expenditures include taxes on products, nondeductible value added tax, and the respective distribution margins. Imports of goods and services are valued on c.i.f. basis and later adjusted to f.o.b. basis. Exports are valued on f.o.b. basis.

The agricultural production for own consumption is valued at equivalent market prices (chacra prices or factory gate prices). In industries where the production activity is integrated and inputs are transferred from one establishment to another, output is valued at market prices (average sale price). Customs data on imports and exports in foreign currency are converted to local currency (nuevo sol) using the monthly average exchange rate. 


\subsubsection{Recording is done on accrual basis}

In general, recording is done on an accrual basis with some exceptions. The exceptions are government's revenues and external transactions other than goods, which are recorded on a cash basis due to limitations in the source data. Work in progress is only recorded for permanent crops, and agricultural output is not adjusted from crop year to calendar year.

\subsubsection{Grossing/netting procedures are broadly consistent with internationally accepted standards, guidelines, or good practices}

Transactions among establishments of the same company are recorded at gross values, according to the recommendations of the $1993 \mathrm{SNA}$. Grossing and netting procedures are applied as long as the source data permit.

\section{Accuracy and reliability}

\subsection{Source data}

\subsubsection{Source data are collected from comprehensive data collection programs that take into account country-specific conditions}

Among the sources of available information are the last Population and Housing Census undertaken in July 1993, which provided universal information on population, active economic population, employment by economic activity and occupation categories, data on income, and other aspects of households.

Another source of information is the III Economic National Census carried out between 1993 and 1994. Its main objective was to identify the census framework of enterprises and establishments for Peru. Emphasis was given to large establishments by applying a census method of universal coverage. Nevertheless, sampling was applied for a segment of small establishments, but annual revenues and expenditures were not well collected owing to the lack of accounting records. This census was also conducted in two stages and only registered visible establishments. Another feature was the method of identification applied in the different regions, which caused the exclusion of some economic activities.

An Agricultural Census was also conducted in 1994 and provided abundant information on agriculture. The Ministry of Agriculture compiles output volume and prices for a range of agricultural and cattle products through a monthly survey. Sampling techniques, imputation, and grossing up methods are applied in the estimation of national estimates.

The MP collects information on marine and continental fishing by port, specie, and destination. However, the coverage of this information is low. The MP also conducts a monthly survey on manufacturing output in order to compile monthly production indexes by industry. In the case of mining, the Ministry of Energy and Mines collects monthly information by product. SUNAT provides external trade and customs duties. Nonfinancial 
enterprises have a Revised General Countable Plan approved by the National Commission of Enterprises and Securities (CONASEV), which will facilitate the compilation of the complete set of accounts for this institutional sector. Annual Economic Surveys (AES) are also conducted to collect economic and financial information, as well as complementary information on the different economic activities, according to the new accounting plan. After the data are processed, they are coded and transformed from business accounting to national accounting following the concepts and definitions of the 1993 SNA.

The NISI implemented a method called "for convocation" to collect data from nonfinancial enterprises. It publishes a press note in the official newspaper asking enterprises to pick up their questionnaires at the NISI Office of Dissemination during a given period of time, in order for the enterprise to fill out the information required. Convocation could be massive or directed to enterprises with certain levels of sales. Nevertheless, the response rate is not very high and coverage of the samples cannot be assessed due to the lack of an up-to-date establishment directory. It is important to note that these surveys do not have enough thematic coverage for the development of the complete sequence of national accounts of the nonfinancial enterprises.

Electronic formats posted at the NISI website were incorporated in 2000. This reduced transcription errors and improved information timeliness. However, small enterprises that do not have computer resources or Internet access might not respond to these surveys. Sampling procedures have been introduced in some economic activities, and scientific techniques of random sampling are still in process of being implemented. Imputation methods are not used to handled non response.

On the other hand, the NISI has tried since 1998 to reach an agreement with SUNAT on data exchange to elaborate a Directory of Enterprises and Establishments by economic activity. Nevertheless, these data have not been accessible to NISI due to legal restrictions regarding confidentiality. In 2001, the SUNAT gave to the NISI a directory of active enterprises and informants with their Social Reason, ISIC code, type of organization, unique register of taxpayers (RUC) and sales ranges, but this information was not enough to prepare a business register. It would be necessary to provide the specific amount of sales and number of employees of each enterprise to develop a business register.

The quality of some source data are a cause for concern, especially the data on private sector. The largest problem associated with the economic surveys is the lack of a sample framework that could be used to assess the coverage of the samples and to determine reliable expansion factors for estimating aggregates for total activity. The current expansion technique is based on the total labor force by industry, which does not take into account changes and differences in labor productivity among establishments. In addition, coverage is not adequate for private sector construction activities, which mainly use the production of cement as an indicator. The estimated change in inventories is obtained on a residual basis due to source data constraints. Furthermore, there are available data and details that are not used to compile national accounts statistics, e.g., annual costs structures from the AES. They could be used along with price indexes to apply the double deflation method for estimating GDP at constant prices. 
The NISI has conducted household surveys regularly in a range of different forms since 1970. The last Household Income and Expenditure Survey was conducted between 19931994, covering 25 capital cities.

Between 1995-2001, the NISI conducted the National Household Survey (ENAHO) on a quarterly basis, developing the employment and income modules in the first two quarters of the year. In the third quarter, a specialized survey of Employment Levels was undertaken; while in the fourth quarter, a National Survey to Measure the Standard of Living was conducted. The coverage of the ENAHO has regularly been national, urban, and rural. However, due to budget constraints, its coverage has only been national, urban, and in some cases at the level of Metropolitan Lima in some quarters. The survey also covers all socioeconomic groups. The size of the sample is variable. It has exceeded 16,000 households in 2001 and 2002. Random sampling, imputation, and expansion methods are applied.

The ENAHO is relatively detailed with a remarkable level of disaggregation at the level of product groups. The survey conducted in the fourth quarter includes information on purchases of consumption goods and incomes of the independent workers, as well as questions on the holding and acquisition of durable goods. The determination of the annual amount of the latter is unclear.

A module on the incomes of independent workers in the urban area was included in the ENAHO 2001-IV. The objective of this survey is to measure informal activities. Concepts have been included that allow an estimate of gross output, intermediate consumption, and value added for this economic segment. However, this information is not used in the compilation of national accounts estimates. In addition, this survey should be implemented during all four quarters of a selected year in order to have enough coverage and capture the complete seasonal movements of collected variables.

The National Survey of Multiple Purposes (ENAPROM) was conducted during 1993-1994. This survey was an income and expenditure survey with an annual design undertaken in the most important 25 cities of the country. It was conducted during the four quarters between October 1993 and September 1994. Its main purpose was to obtain the weights for the consumer prices index, as well as important information for the determination of households' incomes and expenditures. Households were visited daily during the seven days of the week to ask about the expenditures breakdown for the different goods and services of the family basket. The sample was around 10,000 households in each quarter. ENAPROM does not cover information on expenditure on leisure activities, the expenditures of the high income population, and expenditures in durable and luxury goods.

Household final consumption expenditures for the base year (1994) were estimated by using the results of the ENAPROM. These estimates were supplemented with the data coming from the National Survey to Measure the Standard of Living (ENNIV 1994) that covered the rural area. In addition, a School Census was carried out by the Ministry of Education in 1993 and a Census of Sanitary Infrastructure and Resources was conducted in 1996 by the Ministry of Health. 
The Ministry of Economy and Finance (MEF) collects annual and monthly budgetary and financial information from the central government, the decentralized public institutions, the Transitory Council of Regional Administration, and the public universities through the Integrated System of Financial Administration (SIAF) at different breakdown levels. It also has detailed information on Education and Public Health from the Offices of Statistics of the Ministry of Education and the Ministry of Health. This system is based on the Governmental Accounting Plan and has enough information to elaborate the complete system of government's integrated accounts. The local governments provide individual information in hard copies. In addition, the General Accounting of the Republic collects budgetary and financial information from the local governments, public societies of charity, autonomous institutions, and public enterprises that are not integrated to the SIAF, through an accounting software known as National System of Accounting Integration (SICON). Furthermore, information on the Excise Tax for Consumption, taxes on production, on products, and value added tax are obtained from the SUNAT.

The Peruvian Social Security Institute (SSI) provides information on the insured population, the different types of social contributions, the benefits by type of regimen, and on transfers in cash and in kind. The SSI moved from the Public Accounting System to a system based on private accounting standards in 1994.

Banking institutions have a Financial Accounting Plan and insurance companies have an Accounting Plan of Insurance. Data for these two groups of institutions are available at the Superintendency of Banks and Insurance Companies (SBIC).

For international trade, a complete set of statistics on exports and imports of goods at the level of NANDINA is available from the National Superintendence of Customs.

The information on imports and exports of services is provided by the CBRP in the balance of payments. Nevertheless, the level of aggregation of some items is too high for national accounts compilation.

For certain economic activities and variables where the information available is limited or is unavailable, studies or special ad hoc surveys need to be implemented: informal activities (sales and costs by group of products), distribution margins by product, services, the preparation of an up-to-date business register for the most important activities and geographic areas, and a national household income and expenditure survey.

The table below summarizes for each ISIC section the main basic sources for the annual accounts estimates and their coverage. In its construction, the results of all current exhaustive and sample surveys that directly measure the activity have been considered as positive contributions to coverage. Estimates using indirect methods to improve coverage have been considered as "soft" information, even though these estimates are often based on goodquality sources on employment such as the labor force survey. Taken over the total of all activities, the coverage of the main sources should be considered as not satisfactory. 
Main Sources for the Annual Accounts

\begin{tabular}{|c|c|c|}
\hline \multicolumn{3}{|c|}{ Production approach } \\
\hline ISIC Rev. 3 & Main source & $\begin{array}{l}\text { Assessment of } \\
\text { coverage }\end{array}$ \\
\hline Agriculture, hunting, forestry & $\begin{array}{l}\text { - Ministry of Agriculture and Regional } \\
\text { Offices of Statistics } \\
\text { - Prices of agricultural products }\end{array}$ & Satisfactory \\
\hline Fishing & - Ministry of Production & Poor \\
\hline Mining and quarrying & $\begin{array}{l}\text { - Enterprise surveys and the Ministry of } \\
\text { Energy and Mines }\end{array}$ & Good \\
\hline Manufacturing & $\begin{array}{l}\text { - Annual economic survey (Regional Offices } \\
\text { of Statistics and Ministry of Production) }\end{array}$ & $\begin{array}{l}\text { Poor (in some } \\
\text { manufacturing groups) }\end{array}$ \\
\hline $\begin{array}{l}\text { Electricity, gas, and water } \\
\text { supply }\end{array}$ & $\begin{array}{l}\text { - Detailed data from the Electric, gas, and } \\
\text { water companies collected by the Ministry of } \\
\text { Energy and Mines }\end{array}$ & Good \\
\hline Construction & $\begin{array}{l}\text { - Business surveys } \\
\text { - Cement } \\
\text { - Population } \\
\text { - Investment of Public Sector } \\
\text { - Price index on construction materials }\end{array}$ & Poor \\
\hline $\begin{array}{l}\text { Wholesale and retail trade, } \\
\text { repair of motor vehicles, and } \\
\text { personal and household goods }\end{array}$ & $\begin{array}{l}\text { - Business survey } \\
\text { - Fixed trade margins }\end{array}$ & Poor \\
\hline Hotels and restaurants & - Business survey & Poor \\
\hline $\begin{array}{l}\text { Transport, storage, and } \\
\text { communications }\end{array}$ & $\begin{array}{l}\text { - Business survey for road transport and } \\
\text { telecommunication } \\
\text { - Postal service }\end{array}$ & Poor \\
\hline Financial intermediation & - Data from supervisory bodies & Good \\
\hline $\begin{array}{l}\text { Real estate, renting, and } \\
\text { business activities }\end{array}$ & $\begin{array}{l}\text { - Population census } \\
\text { - Fixed input coefficients } \\
\text { - Employment statistics } \\
\text { - Business survey }\end{array}$ & Poor \\
\hline $\begin{array}{l}\text { Public administration and } \\
\text { defense; compulsory social } \\
\text { security }\end{array}$ & $\begin{array}{l}\text { - Budget data from central, state, and some } \\
\text { local authorities, as well as from other } \\
\text { government bodies }\end{array}$ & Good \\
\hline $\begin{array}{l}\text { Education/ } \\
\text { Health and social work }\end{array}$ & $\begin{array}{l}\text { - Health and education census } \\
\text { - Budget data (government) } \\
\text { - Social Security Institute and budget } \\
\text { - Ministries of Health and Education } \\
\text { - Business surveys to private schools and } \\
\text { universities }\end{array}$ & Good \\
\hline $\begin{array}{l}\text { Other community, social, and } \\
\text { personal service activities }\end{array}$ & $\begin{array}{l}\text { - Business survey } \\
\text { - Population }\end{array}$ & Poor \\
\hline $\begin{array}{l}\text { Net taxes less subsidies on } \\
\text { products }\end{array}$ & $\begin{array}{l}\text { - MEF } \\
\text { - SUNAT }\end{array}$ & Good \\
\hline
\end{tabular}




\begin{tabular}{|c|c|c|}
\hline \multicolumn{3}{|c|}{ Expenditure Approach } \\
\hline Expenditure category & Main source & Assessment of coverage \\
\hline $\begin{array}{l}\text { Household final consumption } \\
\text { expenditure }\end{array}$ & $\begin{array}{l}\text { - ENAHO quarter IV } \\
\text { - Commodity flow/fixed ratios } \\
\text { - Administrative sources }\end{array}$ & Poor \\
\hline $\begin{array}{l}\text { Final consumption expenditure } \\
\text { of nonprofit institutions serving } \\
\text { households }\end{array}$ & $\begin{array}{l}\text { - Fixed ratios } \\
\text { - CPI }\end{array}$ & Poor \\
\hline $\begin{array}{l}\text { Government final consumption } \\
\text { expenditure }\end{array}$ & - Budget records & Good \\
\hline $\begin{array}{l}\text { Acquisitions less disposals of } \\
\text { tangible fixed assets }\end{array}$ & $\begin{array}{l}\text { - Commodity flow } \\
\text { - Business surveys } \\
\text { - Government financial statements }\end{array}$ & Satisfactory \\
\hline $\begin{array}{l}\text { Acquisitions less disposals of } \\
\text { intangible fixed assets }\end{array}$ & - Business surveys & Poor \\
\hline $\begin{array}{l}\text { Additions to the value of } \\
\text { nonproduced nonfinancial } \\
\text { assets }\end{array}$ & - Budget records & Poor \\
\hline Changes in inventories & - Business surveys & Poor \\
\hline $\begin{array}{l}\text { Acquisitions less disposals of } \\
\text { valuables }\end{array}$ & $\begin{array}{l}\text { - Business surveys } \\
\text { - Balance sheets }\end{array}$ & Poor \\
\hline Exports and imports of goods & $\begin{array}{l}\text { - Foreign trade statistics } \\
\text { - Foreign unit value indices }\end{array}$ & Good \\
\hline Exports and imports of services & $\begin{array}{l}\text { - Balance of payments } \\
\text { - CPI, international price indices }\end{array}$ & Good \\
\hline
\end{tabular}

The above sources are supplemented with agricultural price indices, wholesale price indices (WPI), the consumer price index (CPI), and unit value indices for foreign merchandise trade. Producer price indices are not compiled.

The CRBP compiles quarterly national accounts since they are needed in the process of decision making in monetary and financial programs, and the NISI does not compile them. The CRBP uses the sum of NISI monthly GDP estimates by the production approach at constant 1994 prices to calculate quarterly GDP estimates. Monthly GDP estimates have been compiled by the NISI since 1976 for the use of government authorities, and were published for the first time in 1984. It is important to mention that monthly GDP estimates are based on a monthly production index, which does not include direct estimation of services, with the exception of government services. The usage of "Monthly Gross Domestic Product" to label the monthly production index is misleading and confuses users. It would be necessary to collect enough monthly information on production and costs by industry to compile monthly gross value added estimates for each economic activity. In addition, the CRBP calculates a monthly domestic demand index using the method of apparent consumption (GDP minus exports plus imports), without using information on actual sales. 
The table below summarizes for each ISIC section the main basic sources for quarterly estimates and their adequacy. The adequacy of sources is used since several sources are not adequate to compile quarterly national accounts estimates.

Main Sources for the Quarterly Accounts

\begin{tabular}{|c|c|c|}
\hline \multicolumn{3}{|c|}{ Production approach } \\
\hline ISIC Rev 3. & Main sources & $\begin{array}{c}\text { Adequacy for quarterly } \\
\text { estimates }\end{array}$ \\
\hline $\begin{array}{l}\text { Agriculture, hunting, and } \\
\text { forestry }\end{array}$ & $\begin{array}{l}\text { - Pre-fixed cycle of production and harvest } \\
\text { for permanent crops } \\
\text {-Monthly output volume }\end{array}$ & Reasonable \\
\hline Fishing & $\begin{array}{l}\text { - Surveys/administrative data on quantities } \\
\text { landed }\end{array}$ & $\begin{array}{l}\text { Adequate, but coverage } \\
\text { is poor }\end{array}$ \\
\hline Mining and quarrying & - Monthly production index & Adequate \\
\hline Manufacturing & $\begin{array}{l}\text { - Industrial production index for } 19 \\
\text { activities }\end{array}$ & $\begin{array}{l}\text { Adequate, but coverage } \\
\text { is poor (in some } \\
\text { manufacturing groups) }\end{array}$ \\
\hline $\begin{array}{l}\text { Electricity, gas, and water } \\
\text { supply }\end{array}$ & - Quantity data on electricity and gas & Adequate \\
\hline Construction & - Cement & Not adequate \\
\hline $\begin{array}{l}\text { Wholesale and retail trade, } \\
\text { repair of motor vehicles, and } \\
\text { personal and household goods }\end{array}$ & $\begin{array}{l}\text { - Fixed trade margins } \\
\text {-Commodity flow: monthly production and } \\
\text { imports of goods }\end{array}$ & $\begin{array}{l}\text { Reasonable, but ratios } \\
\text { are old }\end{array}$ \\
\hline Hotels and restaurants & - Fixed ratios & Not adequate \\
\hline $\begin{array}{l}\text { Transport, storage and } \\
\text { communication }\end{array}$ & - Fixed ratios & Not adequate \\
\hline Financial intermediation & - Information from BS & Adequate \\
\hline $\begin{array}{l}\text { Real estate, renting, and } \\
\text { business services }\end{array}$ & - Fixed input coefficients and population & Not adequate \\
\hline $\begin{array}{l}\text { Public administration, } \\
\text { Education/Health and social } \\
\text { work }\end{array}$ & $\begin{array}{l}\text { - MEF data on accrual basis for central } \\
\text { government and cash basis for local } \\
\text { government } \\
\text { - CPI }\end{array}$ & $\begin{array}{l}\text { Adequate } \\
\text { Not Adequate }\end{array}$ \\
\hline $\begin{array}{l}\text { Other community, social, and } \\
\text { personal service activities }\end{array}$ & - Fixed ratios & Not adequate \\
\hline $\begin{array}{l}\text { Net taxes less subsidies on } \\
\text { products }\end{array}$ & $\begin{array}{l}\text { - MEF data on cash basis } \\
\text { - WPI and CPI }\end{array}$ & $\begin{array}{l}\text { Reasonable } \\
\text { Not adequate }\end{array}$ \\
\hline
\end{tabular}




\begin{tabular}{|c|c|c|}
\hline \multicolumn{3}{|c|}{ Expenditure approach } \\
\hline Expenditure category & Main sources & $\begin{array}{c}\text { Adequacy for quarterly } \\
\text { estimates }\end{array}$ \\
\hline $\begin{array}{l}\text { Household final consumption } \\
\text { expenditure }\end{array}$ & $\begin{array}{l}\text { - Fixed ratios } \\
\text { - Commodities Flow of imported } \\
\text { consumption goods } \\
\text { - Industrial production index of goods (used } \\
50 \% \text { or more in final consumption } \\
\text { expenditures) } \\
\text {-CPI }\end{array}$ & $\begin{array}{l}\text { Not adequate } \\
\text { Reasonable }\end{array}$ \\
\hline $\begin{array}{l}\text { Final consumption expenditure } \\
\text { by government }\end{array}$ & $\begin{array}{l}\text { - Budgetary data (accrual basis) } \\
\text {-CPI }\end{array}$ & $\begin{array}{l}\text { Adequate } \\
\text { Not adequate }\end{array}$ \\
\hline $\begin{array}{l}\text { Nonprofit institutions serving } \\
\text { households }\end{array}$ & - None & Not adequate \\
\hline Gross fixed capital formation & $\begin{array}{l}\text { Commodity flow approach on the basis of: } \\
\text { - Production index of fixed assets } \\
\text { - Imports of capital goods } \\
\text { - Cement } \\
\text { - CPI } \\
\text { - Price index of foreign trade partner } \\
\text { countries and exchange rate changes } \\
\text { Institutional sectors: } \\
\text { - Public investment } \\
\text { - Private investment }\end{array}$ & $\begin{array}{l}\text { Adequate } \\
\text { Adequate } \\
\text { Not adequate } \\
\text { Not adequate } \\
\text { Adequate } \\
\text { Adequate } \\
\text { Reasonable }\end{array}$ \\
\hline Changes in inventories & $\begin{array}{l}\text { - Inventories of } 45 \text { enterprises } \\
\text { - Residual }\end{array}$ & $\begin{array}{l}\text { Adequate, but coverage } \\
\text { is poor } \\
\text { Not adequate }\end{array}$ \\
\hline Exports and imports & $\begin{array}{l}\text { - Foreign trade statistics } \\
\text { - Balance of payments } \\
\text { - Unit value indices }\end{array}$ & Adequate \\
\hline
\end{tabular}

On the whole, the adequacy and the coverage of source data for compiling quarterly accounts need to be improved. Source data on private construction and services activities, final consumption expenditures, changes in inventories, and producer price indices need to be developed. For example, monthly employment data from the Permanent Survey on Employment, conducted since March 2001, could be used to calculate employment indices by industry. These indices are useful to estimate the behavior of nonfinancial services and evaluate results.

INEI seasonally adjusts monthly GDP by applying ARIMA X-12 at disaggregated levels, in accordance with the recommendations of the IMF's Handbook on Quarterly National Accounts. 


\subsubsection{Source data reasonably approximate the definitions, scope, classifications, valuation, and time of recording required}

Source data reasonably approximate the definitions, scope, classifications, valuation, and time of recording required for compiling national accounts statistics. National accounts compilers are aware of the differences in concepts and definitions used in the source data from those required by the national accounts.

Annual data requested to establishments and nonfinancial enterprises are recorded on an accrual basis and disaggregated according to the general revised accounting plan of the private sector. However, increased detail on other revenues and expenditures is needed to correctly classify these transactions. Likewise, the information on financial enterprises is recorded on an accrual basis according to the accounting framework of financial institutions (banks) and insurance companies, respectively. In addition, the government has its own governmental accounting plan. Government's expenditures are recorded on an accrual basis and incomes on a cash basis. The available information can be easily reclassified according to the 1993 SNA.

Work in progress is only estimated for permanent crops since information on growing crops' calendar is not available. Nevertheless, the Ministry of Agriculture is conducting the National Survey of Production and Sales (ENAPOVE) in order to improve coverage and the methods applied on this activity. This survey will collect information on production, sales, and costs, among other variables.

\subsubsection{Source data are timely}

The data collected from the annual economic surveys (AES) are usually not timely because of the lack of human resources at the sectoral and regional statistical offices. National accounts compilers cannot implement follow-up procedures to ensure the timely reception of source data due to the scarcity of resources to visit establishments and to the cancellation of most local phone lines at the NISI.

The NDNA receives price indices on a timely basis. Data sources on financial institutions, insurance companies, general government, taxes, and international trade are also timely.

\subsection{Statistical techniques}

\subsubsection{Data compilation employs sound statistical techniques}

\section{Production approach procedures}

Technical assistance was provided by the Fund from 1996 to 1999 to assess the changing of the base year from 1979 to 1994. Input-output tables and matrices were elaborated at three valuations: basic, producer, and purchaser prices. Likewise, matrices of production, taxes, and distribution margins were prepared and published. 
Production and intermediate consumption estimates are compiled for 287 industries at the four-digit level of the ISIC Rev. 3. This information is aggregated at 45 activity branches for publication. The fixed coefficient of the 1994 input-output table are used for estimating intermediate consumption at constant prices at the four-digit level of ISIC. Intermediate consumption at current prices is estimated by applying the ratios from the business surveys.

The single indicator method is applied to estimate GDP by industry; that is, no double deflation is used. Prices of intermediate consumption are implicit price indices. In general, output and value added of goods-producing industries at constant prices are calculated by extrapolating the base year estimates with a Laspeyres volume index. Output estimates of services at constant prices are calculated by deflating the nominal values with the CPI of other services. Services to enterprises are calculated by using fixed input-output ratios from the base year. Indirect estimates for informal activities are made by expanding sample data for the base year with employment figures, but estimates for own-account workers are not evaluated separately.

Government output is estimated by cost component at constant prices, which are calculated separately for health, education, and public administration services. Health services at constant prices are calculated by extrapolating the base year estimates using the number of medical appointments and medical personnel. Education services are estimated by extrapolating base year estimates using the number of pupils and professors. The rest of governmental services at constant prices are calculated by deflating the respective estimates at current prices by the price index of public compensation of employees, by the price index of fixed assets for the consumption of fixed capital, and by the price index of the main goods and services purchased by the government. However, data on these price indices were discontinued in recent years.

Housing services of owner-occupied dwellings is estimated by using the market average rent paid by households who live in rented dwellings. Estimates for the base year were obtained by using the number of owner-occupied dwellings from the 1993 population census and the average rent for that year. The number of dwellings for current years is extrapolated with the information on the number of dwellings of the ENAHO.

Output of private construction is based on the behavior of cement domestic consumption (output minus exports) and the expenditures of the Program for the Improvement of Highways and Rural Roads implemented by the Ministry of Transport and Communications. Population developments are used to estimate informal construction because cement is not the main input used in the construction of dwellings located in rural areas. Informal construction is significant.

Allocation of harvests in time is inaccurate since data on the calendar of growing crops are not available. Work in progress is only estimated for permanent crops. Adjustments to remove holding gains are made to the information on inventories of raw materials from the 
business surveys. Changes in inventories of raw materials at four-digit ISIC are grossed up with ratios with respect to output from the business surveys.

Consumption of fixed capital is estimated with fixed ratios from the base year or by using information on depreciation from the business surveys. Taxes, subsidies, and government revenues on a cash basis are not converted to accrual by allocating them to the period they relate.

Regarding the deflators used for constant price estimates, the wholesale price index (WPI) is a mixture of a PPI and a WPI owing to the inclusion of prices of imports, producers' prices, and wholesale prices. Price indices on government's purchases and salaries are not compiled.

Volume measures of value added tax (general sales tax) and taxes on products are estimated by extrapolating the base-year tax using the volume indices of the industries subject to these taxes. Volume measures of the Selective Tax on Consumption are calculated by extrapolating the base-year tax with the percentage change of the supply of products subject to this tax. There are no subsidies in Peru. Import duties at constant prices are calculated by extrapolating the amount of import duties of the base year with the volume index of imports. Output volume of trade margins are estimated by extrapolating the base-year-trade margin with the volume indices of the supply of goods by products. Total estimates of trade margins at current prices are obtained by extrapolating current total margins of the previous year by the percentage change of margins from the business surveys. Proportions of current margins by product with respect to total margins are calculated by inflating margins by product at constant prices by a price index (CPI or WPI). Final price indices are obtained as implicit price indices.

GDP volume change is not measured by using annual chain indices, and the base year has not been changed on a five to 10 year basis.

Owing to the lack of coverage, deficiencies in methodology and inaccuracies in the data of annual and monthly GDP, the NISI has announced its intention to implement a program for changing the base year of national accounts statistics from 1994 to 2001 .

\section{Expenditure approach procedures}

Household final consumption expenditure for the base year was calculated by category of products according to the nomenclature of goods and services, which is based on the CPC. It was also calculated and published by COICOP category. Data on Household consumption expenditures for 1994 were obtained from ENAPROM 1993/94. The results for the fourth quarter of 1993 were updated to the fourth quarter of 1994, using CPIs and quantities to obtain the final values of household consumption expenditures in the 25 cities of the urban area for the calendar year 1994. The results were stratified by cities of 2,000 to 20,000 inhabitants, 20,000 to 100,000 inhabitants, and more than 100,000 inhabitants. 
Household final consumption expenditures for the remaining urban areas were estimated by using the results on the final consumption expenditures of the cities with 20,000 to 100,000 inhabitants and the difference between the urban population from the population census and that from the ENAPROM.

The estimates of household final consumption expenditures of rural areas were calculated from the coefficients rural/urban of expenditures percapita by product, calculated from the 1994 ENNIV. These coefficients were applied to the urban expenditures per capita from the ENAPROM 1994 in order to obtain rural expenditures per capita by product. These expenditures were multiplied by the rural population to obtain the consumption expenditures of rural areas.

For current years, household final consumption expenditures are calculated at aggregate levels by using the development of the consumption expenditures from the ENAHO sample, conducted every fourth quarter. Consumption expenditures at current prices are deflated by the CPI at the level of aggregate consumption groups to obtain constant price estimates. Household final consumption expenditures are published at an aggregate level, including household expenditures abroad and excluding expenditures in the country by nonresidents.

Final consumption expenditures of nonprofit institutions are estimated by extrapolating the estimate for the base year with the growth rate of household final consumption expenditure. Government consumption expenditures for the base year were classified and published according to the COFOG. Government consumption expenditures at current prices are broadly classified by COFOG. However, this information is not published owing to the level of aggregation of some basic data. Government final consumption expenditures at current prices are obtained from data on an accrual basis for government purchases of goods and services and compensation of employees for the central government, decentralized institutions, and some local governments. Government final expenditure excludes incidental sales. Constant price estimates are obtained by deflating current figures by the CPI, an inadequate method. Price indices on government purchases of goods and services and data on salaries and employment in the public sector are needed to improve constant price estimates.

Gross fixed capital formation estimates are obtained through the commodity flow based on the developments of imports and output of capital goods. Estimates at current prices are obtained by applying import value indices and output of capital goods value indices to current price estimates. Book values of inventories are obtained from the economic surveys and are adjusted to eliminate holding gains. Nevertheless, only the sign and trend of this information is used in the balancing of supply and expenditures, since changes in inventories estimated for the base year were considerably lower than those obtained from the surveys. Discrepancies between supply and expenditures are assumed to be part of the expenditure side, since supply estimates are considered more reliable. The estimated change in inventories is obtained on a residual basis.

Customs data on imports are adjusted by the estimates of smuggled goods based on information on expropriation. Balance of payments statistics on exports of services are 
adjusted by exports of financial services indirectly measured, insurance, and reinsurance. Imports of services at constant prices are obtained by deflating current figures with an index composed of international inflation and devaluation of the domestic currency. Exports of services at constant prices are calculated by deflating current figures with an index composed of changes in the CPI and the devaluation of the domestic currency.

\section{Quarterly estimates}

Quarterly estimates of GDP by the production approach are compiled at constant prices only. They are calculated as the sum of monthly GDP estimates at constant prices. Monthly GDP estimates are based on the developments of the monthly production index. This index is obtained by integrating the indices of each industry. Indices for agriculture, livestock, fishing, mining, manufacturing, electricity and water, construction, governmental services, financial and insurance services, import duties, and VAT are calculated by using monthly data. These activities represent 54.3 percent of GDP for the base year. Trade margins and other services are estimated by indirect methods based on fixed ratios from the 1994 inputoutput table. These indices present deficiencies in coverage, especially regarding the production of services. The CRBP disseminates this production index as a monthly GDP estimate. More realistically, this index should be called "monthly production index."

Quarterly GDP by the expenditure approach is estimated at constant and current prices. Private consumption is calculated by the commodity flow method. Private consumption estimates at constant prices are based on the behavior of imported consumption goods and volume indices of products that represent 50 percent or more of output consumed by households. Estimates at current prices are obtained by applying the CPI to constant price estimates.

Government final consumption expenditures at current prices are obtained the same way as the annual data, i.e., from data on government purchases and compensation of employees for the central government, decentralized institutions, and some local governments on an accrual basis. Constant price estimates are obtained by deflating current figures by the CPI, an inadequate method.

Gross fixed capital formation is estimated separately for private and public sectors. Investment of the private sector at constant prices is calculated through the commodity flow method, taking into account the growth rate of construction output, imports, and output of capital goods at constant prices. Investment in construction is estimated by using the growth rate of population and cement consumption. Estimates at current prices are obtained by applying the construction materials price index to construction constant price estimates. Constant price estimates of capital goods are calculated by using the price indices of foreign trade partner countries and exchange rate changes. National capital goods at current prices are estimated by applying the price index of national machinery to the constant price estimates. However, during the past three years, the percentage change in the CPI has been used to extrapolate the construction materials price index and the price index of national machinery, owing to the limitations of these indices. 
Monthly investment expenses of government and public enterprises are available on an accrual basis. Estimates at constant prices are obtained by deflating current figures of construction and imported capital goods with the price indices mentioned above.

Total changes in inventories are calculated as a residual. The sign and trend of the inventories of 45 private enterprises adjusted by the WPI are taking into account to analyze the results of total changes in inventories. In addition, supply and use analysis is made for some exported products (agriculture, fishing, mining, petroleum and its derivatives).

Weaknesses include the technique used for the benchmarking of the quarterly data, the lack of coverage of construction estimates and changes in inventories, and the deflators and methods used to calculate government final expenditures and taxes at constant prices. The proportional adjustment of monthly and quarterly estimates to fit the annual data, causes a step problem in the percentage change of the estimates for the first quarter with respect to those of the fourth quarter of the previous year. Taxes at constant prices are obtained by deflating monthly value added taxes by the CPI and import duties by the WPI of imported goods, methods that are not consistent with annual estimates.

Balance of payments data on exports and imports of goods and services are used for the estimates of these variables at current prices. Exports and imports of goods at constant prices are calculated by deflating current values with unit value indices prepared by the CRBP. Exports and imports of services at constant prices are calculated by deflating current values with the price indices of foreign trade partner countries. In the case of export of services, this method is neither correct nor consistent with annual estimates.

The consistency and revision policy between annual and quarterly GDP estimates need to be improved. A method of benchmarking, such as the Denton method (D-4), needs to be implemented.

Monthly seasonally adjusted GDP is only published by the NISI at the aggregate level. Quarterly estimates are not seasonally adjusted. However, the CRBP has implemented Tramo-Seats (program recommended in the European Hand-book of Quarterly Accounts) with the assistance of the Bank of Spain in some exercises. The CRBP expects to publish these results in the near future.

The CRBP also compiles quarterly estimates of national disposable income and absorption by using the quarterly GDP estimates by the production and expenditure approaches and the data on external transactions from the balance of payments.

On the other hand, the NISI is contemplating the possibility of elaborating quarterly national accounts and using the Denton method for benchmarking. However, this would cause more duplication of effort between the NISI and the CRBP, even though the NISI has the legal mandate for compiling national accounts estimates. 


\subsubsection{Other statistical procedures (e.g., data adjustments and transformations, and statistical analysis) employ sound statistical techniques}

Production estimates at constant prices of small establishments and own account workers are made by using employment statistics and the production per capita from the base year. Production estimates are separated by strata into nonfinancial corporations (autorepresented), the rest of corporations, and the unincorporated units, including small establishments and the own account workers.

Data on output and costs of own account workers were obtained from a module on the informal sector included in the ENAPROM and through special studies on urban transport. However, costs structures and production per capita are fixed since 1994. Illegal activities are not included in the national accounts estimates.

\subsection{Assessment and validation of source data}

3.3.1 Source data-including censuses, sample surveys and administrative records-are routinely assessed, e.g., for coverage, sample error, response error, and nonsampling error; the results of the assessments are monitored and made available to guide planning

Data from annual and monthly AES are routinely assessed for internal consistency. Establishments are not selected from probabilistic samples due to the lack of an up-to-date business register. Therefore, coverage cannot be accurately assessed. Sampling errors, non sampling errors, and response errors are not available. Enterprises are asked to respond to surveys by convocation through a press note. In practice, response to surveys is voluntary. Information about sampling errors is only available for the Household Survey, but information about imputation methods and internal processes is not available.

Some processes to assess accuracy of the data on external trade, financial institutions, insurance companies and government are implemented.

\subsection{Assessment and validation of intermediate data and statistical outputs}

\subsubsection{Main intermediate data are validated against other information where applicable}

Basic data are checked with information from other sources when they are available. For example, business information from annual surveys is compared with data from the National Supervisory Commission of Enterprises and Securities (CONASEV). Information on external trade is validated with data from mining corporations, oil, and insurance companies. Ad hoc assessment of potential discrepancies is done, but checks only occur after discrepancies are identified. 


\subsubsection{Statistical discrepancies in intermediate data are assessed and investigated}

When discrepancies in intermediate data are identified, they are evaluated and investigated in order to remove them. If some information from the business surveys is not clear or appears irregular, specialists call enterprises' accountants to ask for an explanation in order to reconcile the information.

When there are two data sources regarding the information on an enterprise (business surveys vs. financial statements), the information is validated and reconciled.

\subsubsection{Statistical discrepancies and other potential indicators of problems in statistical outputs are investigated}

Annual GDP estimates are calculated by the three approaches: production, expenditure, and income. Net operating surplus is obtained as a residual. Discrepancies usually exist between the production and expenditure approaches, which are estimated independently. The expenditure approach is made at the aggregate level and its coverage is less than that of the production approach. Discrepancies are evaluated and supply and use figures are reconciled by adjusting the inconsistent variables. In general, discrepancies are assumed to be part of expenditures on GDP. Nevertheless, supply and use tables are not used to address discrepancies in data. Explanatory notes about the discrepancies are not included in the publication.

No discrepancies exist between the quarterly GDP estimates by the production and expenditure approaches because changes in inventories are obtained as a residual.

NISI does not use unofficial estimates to validate national accounts estimates. Moreover, it does not carry out studies to ensure that bias in the GDP estimate is negligible and stable over time.

\subsection{Revision studies}

\subsubsection{Studies and analyses of revisions are carried out routinely and used to inform statistical processes}

The direction and magnitude of revisions between preliminary data and final data are analyzed and investigated. When final figures of GDP change with respect to the preliminary estimates owing to coverage improvements, changes in trends are internally explained, but are not published. 


\section{Serviceability}

\subsection{Relevance}

\subsubsection{The relevance and practical utility of existing statistics in meeting users' needs are monitored}

The Inter-institutional Coordination Committee on Statistics (ICCS) was established to meet regularly to deal with the statistical issues, including those related to the relevance and practical utility of statistics, although no meetings have been held since 2002.

The relevance and practical utility of statistics are also assessed through users requests and visits to the NISI, which has a unit (the Technical Directorate on Statistical Dissemination and Information Technology, or TDSDIT) to deal with dissemination policies and practices. The TDSDIT manages a documentation center and maintains the NISI website.

NISI staff participate in international statistical meetings and seminars organized by international and regional organizations, such as ECLAC and the Andean Community, among others.

\subsection{Timeliness and periodicity}

\subsubsection{Timeliness follows dissemination standards}

The quarterly national accounts are published with a time-lag of eight weeks, thus well within the Special Data Dissemination Standard (SDDS) requirements of three months. However, annual national accounts estimates for 2001 have not yet been published, even though these were ready in October, 2002.

\subsubsection{Periodicity follows dissemination standards}

National accounts are compiled on a quarterly basis, thus meeting the SDDS requirements.

\subsection{Consistency}

\subsubsection{Statistics are consistent within the dataset}

In general, the annual GDP estimates are internally consistent. However, a set of consistent GDP estimates by activity and expenditure components are not derived by using a proper reconciliation framework (supply and use tables). Discrepancies between the supply and expenditure approaches are adjusted as part of the final household consumption expenditure estimates, since supply sources are considered more reliable than those of the expenditure side. 
In addition, monthly taxes at constant prices for monthly GDP estimates are derived by deflating current figures by the CPI or the WPI, which is not the method used for annual GDP estimates. Moreover, a step problem exists in monthly and quarterly estimates of GDP owing to the proportional benchmarking of monthly with annual figures.

\subsubsection{Statistics are consistent or reconcilable over a reasonable period of time}

The national accounts have been compiled at the NISI since 1970. The latest major revision of GDP estimates, with the adoption of the base year 1994, allows for coherent time series for the period 1991-2001. As for previous years, interpolation work is still pending owing to the problems posed by Peru's inflation during 1988-1990. National accounts publications include notes and explanations on historical discontinuities of the series and unusual changes in economic trends.

\subsubsection{Statistics are consistent or reconcilable with those obtained through other data sources and/or statistical frameworks}

National accounts statistics are generally consistent with the balance of payments statistics, except in the case of smuggling estimates and exports of financial services indirectly measured, insurance, reinsurance, and fishery products generated by nonresidents in Peruvian waters who pay for the right to fish. Balance of payments statistics do not include estimates on smuggling (illicit imports) and exports of financial services indirectly measured, insurance, and reinsurance as national accounts do. In addition, fishery products generated by nonresidents are recorded as exports in balance of payments statistics. These fishery products, however, are treated as output of nonresidents for national accounts purposes, following 1993 SNA recommendations. Monetary and government finance statistics are consistent with the national accounts estimates since the data sources used in their compilation are identical.

\subsection{Revision policy and practice}

\subsubsection{Revisions follow a regular, well-established and transparent schedule}

An estimate of the current year is elaborated regularly, as well as a revision of the previous year's estimate that is still preliminary. A final estimate is published two years after the first estimate is elaborated. Nevertheless, the revision of provisional estimates is not stable from year to year. Base years are not changed following a predetermined schedule. Therefore, the general public is not informed of any predetermined revision policy. However, adequate documentation on major revisions is included in the publication of statistical series and in the database (website) accessible to users. 


\subsubsection{Preliminary data are clearly identified}

Users are informed in the text of the releases that the initially published data are preliminary and subject to revision, and preliminary data are labeled. The revised data are disseminated with the same level of detail as previously published for the data being revised.

\subsubsection{Studies and analyses of revisions are made public}

Only analysis and causes of major revisions (e.g. change in the base year) are made public. Analysis on the extent and causes of current revisions are elaborated, but are not made public.

\section{Accessibility}

\subsection{Data accessibility}

5.1.1 Statistics are presented in a way that facilitates proper interpretation and meaningful comparisons (layout and clarity of text, tables, and charts)

National accounts statistics are readily accessible on the NISI and the CRBP websites. The annual national accounts estimates are presented in a clear manner, and charts, tables, and analysis of recent developments are disseminated with the data. However, household and government final consumption are disseminated at a high level of aggregation. Quarterly accounts in the Weekly Bulletin are not published in a seasonally adjusted form. Analysis of the developments of the quarterly GDP by the expenditure approach are not published. Nevertheless, a brief analysis of the developments of the monthly GDP index is included in some issues of the Weekly Bulletin. Furthermore, the Report on Inflation published by the CRBP includes GDP forecasts and an analysis of recent developments of quarterly estimates in the chapter on economic activity. Datasets are published with various level of detail that broadly facilitates meaningful comparisons.

\subsubsection{Dissemination media and formats are adequate}

The primary dissemination media is a press release, and subsequently the information is posted on the NISI website. Data are also published in hard copy for the period 1991-2000. Publications are sold at nominal prices that do not cover printing costs. Electronic versions are also available in diskette and CD-Rom.

\subsubsection{Statistics are released on a pre-announced schedule}

The CRBP publishes an advanced release calendar for quarterly estimates. Nonetheless, the release schedule for the annual national accounts estimates is not formally preannounced. Moreover, expected release dates of annual estimates are often not adhered to. 


\subsubsection{Statistics are made available to all users at the same time}

A press note is sent to the media the day of the publication of the data. A press conference is also held for the presentation of the publication.

\subsubsection{Nonpublished (but nonconfidential) sub-aggregates are made available upon request}

Nonpublished, but nonconfidential, subaggregates of the statistics are available to users upon request.

\subsection{Metadata accessibility}

5.2.1 Documentation on concepts, scope, classifications, basis of recording, data sources, and statistical techniques is available, and differences from internationally accepted standards, guidelines, or good practices are annotated

The annual publication provides detailed metadata, which is also available on the NISI website. Limited metadata for quarterly national accounts are available on the DSBB and on the CRBP website. However, detailed metadata are not published. Extensive documentation on concepts and methods is published whenever the base year is changed.

\subsubsection{Levels of detail are adapted to the needs of the intended audience}

Documentation is available to inform general users about the statistical series. However, specialized users might find some explanations very general.

\subsection{Assistance to users}

\subsubsection{Contact person for each subject field is publicized}

A contact person for each subject field and the phone number of the NISI's Office of Sales is publicized in the annual publication. There is a NISI e-mail address (infoine@inei.gob.pe) at which users can send their queries and requests. In addition, the NISI has a dissemination unit (Technical Directorate on Statistical Dissemination and Information Technology, or TDSDIT) that centralizes data requests and queries from users to direct them to the respective contact person or technical directorate.

The Library of the CRBP gives information to users about a contact person, including phone number and email address, to answer additional information requests. The CBRP and the NISI also give presentations to college students in order to explain the contents of their publications. 
5.3.2 Catalogues of publications, documents, and other services, including information on any charges, are widely available

The NISI and the CRBP disseminate a catalogue of publications, documents, and services. Catalogues are available on the NISI and CRBP websites and in hard copy. 
Table 1. Peru: Data Quality Assessment Framework-Summary of Results for National Accounts

(Compiling Agency: National Institute of Statistics and Informatics)

\begin{tabular}{|c|c|c|c|c|c|c|}
\hline \multirow{2}{*}{ Element } & \multirow{2}{*}{ NA } & \multicolumn{4}{|c|}{ Assessment } & \multirow{2}{*}{ Comments } \\
\hline & & $\mathrm{O}$ & $\mathrm{LO}$ & $\mathrm{LNO}$ & $\mathrm{NO}$ & \\
\hline \multicolumn{7}{|l|}{ 0. $\quad$ Prerequisites of quality } \\
\hline 0.1 Legal and institutional environment & & & $\mathrm{X}$ & & & $\begin{array}{l}\text { Weak inter-agency coordination, leading to duplication of } \\
\text { efforts. NISI has no access to some public records due to } \\
\text { confidentiality. Respondent burden is not carefully considered. }\end{array}$ \\
\hline 0.2 Resources & & & & $\mathrm{X}$ & & $\begin{array}{l}\text { Resources not adequate for maintenance and developmental } \\
\text { work. Some computing resources are obsolete. Staff has limited } \\
\text { access to training. Dual sets of accounts represent inefficient } \\
\text { system-wide use of scarce resources. }\end{array}$ \\
\hline 0.3 Quality awareness & & & $\mathrm{X}$ & & & $\begin{array}{l}\text { No formal mechanisms for assessing quality of data or for } \\
\text { receiving feedback from users. }\end{array}$ \\
\hline \multicolumn{7}{|l|}{ 1. Integrity } \\
\hline 1.1 Professionalism & & $\mathrm{X}$ & & & & \\
\hline 1.2 Transparency & & & & $\mathrm{X}$ & & $\begin{array}{l}\text { Access of government officials to data before publication not } \\
\text { made public. CRBP does not clearly identify NISI as the } \\
\text { source of annual and monthly national accounts statistics. } \\
\text { Except in the case of implementing a program for changing the } \\
\text { base year, changes in methodology and source data are not } \\
\text { usually announced in advance. }\end{array}$ \\
\hline 1.3 Ethical standards & & $\mathrm{X}$ & & & & \\
\hline \multicolumn{7}{|l|}{ 2. Methodological soundness } \\
\hline 2.1 Concepts and definitions & & & $\mathrm{X}$ & & & $1993 S N A$ concepts and definitions only partially followed. \\
\hline 2.2 Scope & & & $\mathrm{X}$ & & & $\begin{array}{l}\text { Financial transactions not covered and accounts for the } \\
\text { institutional sectors not compiled. } 1993 \text { SNA scope cannot be } \\
\text { fully implemented because of source data constraints. }\end{array}$ \\
\hline 2.3 Classification/sectorization & & & $\mathrm{X}$ & & & $\begin{array}{l}\text { Government final consumption expenditures not classified by } \\
\text { function. Mixture of ISIC Rev. } 2 \text { and Rev. } 3 \text {. }\end{array}$ \\
\hline 2.4 Basis for recording & & & $\mathrm{X}$ & & & $\begin{array}{l}\text { Government revenues and external transactions other than } \\
\text { goods recorded on a cash basis. Work in progress only } \\
\text { recorded for permanent crops, and agricultural output not } \\
\text { adjusted from crop year to calendar year. }\end{array}$ \\
\hline
\end{tabular}

\footnotetext{
${ }^{2}$ After the visit of the mission, the CRBP updated its website, the Weekly Bulletin, and the DSBB to identify the NISI as the source of annual national accounts.
} 
Table 1. Peru: Data Quality Assessment Framework-Summary of Results for National Accounts

(Compiling Agency: National Institute of Statistics and Informatics)

\begin{tabular}{|c|c|c|c|c|c|c|}
\hline \multirow{2}{*}{ Element } & \multirow{2}{*}{ NA } & \multicolumn{4}{|c|}{ Assessment } & \multirow{2}{*}{ Comments } \\
\hline & & $\mathrm{O}$ & LO & LNO & NO & \\
\hline \multicolumn{7}{|l|}{ 3. Accuracy and reliability } \\
\hline 3.1 Source data & & & & $\mathrm{X}$ & & $\begin{array}{l}\text { Inadequate source data due to the lack of a business register. } \\
\text { Response to surveys is low and not enforced. A household survey } \\
\text { is only collected during the fourth quarter. No short-term data on } \\
\text { services and changes in inventories. Inadequate ISIC classification } \\
\text { of data from SUNAT. PPI not compiled. }\end{array}$ \\
\hline 3.2 Statistical techniques & & & & $\mathrm{X}$ & & $\begin{array}{l}\text { Wide use of single indicator method to estimate GDP. Excessive } \\
\text { reliance on old fixed ratios. Households consumption expenditures } \\
\text { compiled only at aggregate level. Inaccurate allocation of harvests } \\
\text { over time. Indirect estimates for informal activities not evaluated } \\
\text { separately. Quarterly estimates are based on a production index } \\
\text { that only covers } 54 \% \text { of GDP. Inadequate benchmarking between } \\
\text { monthly and quarterly estimates and annual data. No seasonal } \\
\text { adjustment of quarterly data. Quarterly government final } \\
\text { expenditures deflated by CPI. }\end{array}$ \\
\hline 3.3 Assessment and validation of source data & & & & $\mathrm{X}$ & & $\begin{array}{l}\text { Information on sampling errors only available for the Household } \\
\text { Survey. Information on imputation methods and internal processes } \\
\text { not available. Limited assessment of administrative records. }\end{array}$ \\
\hline $\begin{array}{l}\text { 3.4 Assessment and validation of intermediate data and } \\
\text { statistical outputs }\end{array}$ & & & $\mathrm{X}$ & & & $\begin{array}{l}\text { No systematic validation processes. Supply and use tables not use } \\
\text { to address discrepancies in data. No study to detect bias in GDP } \\
\text { estimates. }\end{array}$ \\
\hline 3.5 Revision studies & & & $\mathrm{X}$ & & & Analysis of revisions is done but is not published \\
\hline \multicolumn{7}{|l|}{ 4. $\quad$ Serviceability } \\
\hline 4.1 Relevance & & & $\mathrm{X}$ & & & User's feedback not solicited in a structured manner. \\
\hline 4.2 Timeliness and periodicity & & & $\mathrm{X}$ & & & Annual estimates are not timely. \\
\hline 4.3 Consistency & & & $\mathrm{X}$ & & & $\begin{array}{l}\text { Lack of a proper reconciliation framework. Monthly taxes at } \\
\text { constant prices derived by deflating current figures by CPI or } \\
\text { WPI. Step problem in monthly and quarterly estimates of GDP. }\end{array}$ \\
\hline 4.4 Revision policy and practice & & & $\mathrm{X}$ & & & Only analysis and causes of major revisions are made public. \\
\hline \multicolumn{7}{|l|}{ 5. Accessibility } \\
\hline 5.1 Data accessibility & & & $\mathrm{X}$ & & & $\begin{array}{l}\text { Household final consumption and government final consumption } \\
\text { published only at aggregate level. No formal publication schedule. } \\
\text { Expected release dates are often not adhered to. }\end{array}$ \\
\hline 5.2 Metadata accessibility & & & $\mathrm{X}$ & & & Disseminated metadata needs to be expanded and updated. \\
\hline 5.3 Assistance to users & & $\mathrm{X}$ & & & & \\
\hline
\end{tabular}




\section{CONSUMer Price IndeX}

\section{Prerequisites of quality}

\subsection{Legal and institutional environment}

\subsubsection{The responsibility for collecting, processing, and disseminating statistics is clearly specified}

The responsibility for collecting, processing, and disseminating official data relating to prices is laid out in a series of laws and legislative decrees that define the legal and institutional environment for the consumer price index (CPI). Legal Decree No. 17532 (Decreto Ley 17532 "Ley Orgánica de la Presidencia de la República" de 1969) established the National Office of Statistics and Census under the Ministry of Economy and Finance ("Hacienda") as the office responsible to compiling and disseminating price indices. In December of 1975 the Legal Decree No. 560 transformed the National Office of Statistics and Census into the National Institute of Statistics (NSI) placing it directly under the Prime Minister. The responsibilities of NSI were expanded in April of 1990 to include informatics by Legal Decree No. 563, which modified Article 56 of the Law of Executive Power (Legal Decree No 560). In April of 1990, Legal Decree No 604 "Law for the Organization and Functions of the National Institute of Statistics and Informatics (NISI)" was passed specifying in Chapter IV Article 9-e that the new NISI has the function of producing and disseminating consumer price indices. Also, Clause f of Article 5 of Supreme Decree No. 018-1990-PCM states that NISI has the responsibility for producing and disseminating consumer price indices as well as other series relating to economic and social conditions. Article 10 of Legislative Decree No. 502 states that NISI is required to publish the CPI for Lima in "El Peruano", the official newspaper of the government of Peru, on the first working day of the month following the reference month. In fact, the index is published in "El Peruano" on the first day of the month regardless of whether or not it falls on a working day.

Working arrangements for producing the CPI are consistent with the legal and institutional structure specified for its production. Since all major source data for the CPI are produced within NISI, there is no need for a special legal structure regarding data sharing.

\subsubsection{Data sharing and coordination among data producing agencies are adequate}

Although the major source data for the CPI are produced within NISI, ancillary data are obtained from other government and private sources for the purposes of updating the item structure of the CPI market basket and the outlet sample for price collection.

The prices section has established regular working groups composed of experts from other sections within NISI, as well as experts from the private sector and other government entities, to implement improvements to the index and to coordinate efforts in producing regular 
updates to the index. Efforts are made to ensure proper understanding of data requirements, minimize respondent burden and avoid duplication.

\subsubsection{Respondents' data are to be kept confidential and used for statistical purposes only}

Article 97 of Legal Decree No. 604 the "Law for the Organization and Functions of NISI" specifies that data provided by respondents must be held confidential and not be revealed in any form that could identify any individual respondent even by administrative or judicial order. Additionally, it specifies that confidential data may not be used for criminal or tax related investigations. Article 98 provides for sanctions against employees who misuse confidential data. These sanctions are specified in Legislative Decree 276.

All NISI survey instruments relating to the CPI contain explanations that the data being collected are confidential and will be used solely for statistical purposes. NISI has the policy of never publishing any data in a way that would allow an individual respondent to be identified.

NISI has established procedures that protect its computer databases from unauthorized access. Different levels of access have also been established according to the sensitivity of the data. In addition to these measures, each computer has its own security system.

\subsubsection{Statistical reporting is ensured through legal mandate and/or measures to encourage response}

Historically, NISI has conducted its price surveys with respondents participating on a voluntary basis. Field agents are trained to look for the most efficient manner for collecting the required data. They always explain that the information is confidential and that it will be used only for statistical purposes. In extreme cases where there is a resistance on the part of the respondent to cooperate, the supervisor visits the outlet with a letter of introduction that explains the obligatory nature of providing the data requested ( Legislative Decree No. 604, Articles 81-84.) and again reiterates the guarantee of confidentiality.

\section{$0.2 \quad$ Resources}

\subsubsection{Staff, financial, and computing resources are commensurate with statistical programs}

NISI is experiencing serious deficiencies in resources with regard to personnel and computer processing equipment. This lack of sufficient staff and aging computers has created inefficiencies for data collection, transmission, and processing.

NISI produces separate consumer price indices for Metropolitan Lima and the 24 departmental capital cities on a monthly basis. These 25 city indices are aggregated to form the new national CPI that was introduced in January 2003. Data entry, editing, and index calculation for these indices is carried out independently in each city. Of the 88 NISI employees responsible for this work, 49 are price collectors (41 of which are shared with the 
WPI), 24 are field supervisor-analysts for the cities, 4 are field supervisors for Lima, 1 is the chief of supervisors, 7 are analysts ( 3 for Lima and 4 for the departmental capitals - shared with the WPI), 2 are data processors, and 1 is a computer programmer. Data entry in the departmental capitals is handled by the price collectors and supervisors. Even though the CPI staff is working at full capacity, there are insufficient resources for properly verifying the indices, conducting analysis, carrying out needed updates in the item structure, and making corrections to the market basket weights for the departmental capitals. Although this work has been completed for Metropolitan Lima, each city will require a similar effort. This work does not include the planning and implementation for a new ENAPROM to update the 199394 expenditure weights.

The NISI prices staff, many of which have years of experience, are well qualified and possess the needed skills for producing high quality price indices that meet international standards. Even though salaries are modest, there is no significant problem of retention of personnel since the job market is very tight.

Given the legal requirement that the Metropolitan Lima CPI must be published on the first day of the month following the reference month and that data processing and index calculation for the national CPI is carried out in a decentralized fashion in each of the departmental capitals, NISI has developed a sophisticated data processing and index calculation system. To the extent possible, this system is automated. However, there are serious problems with the capacity and number of computers available for this work. Some of the computers, in both Lima and the departmental offices, do not have sufficient capacity for efficient transfer of data from the departmental offices to the central office.

\subsubsection{Measures to ensure efficient use of resources are implemented}

On a regular basis, the directors of the office of prices carry out meetings with those responsible for price collection and data processing for the CPI in Lima and the departmental capitals. These meeting serve to coordinate these activities and to assist personnel with the application of new procedures and concepts.

Resources are directed toward achieving efficiencies in data collection and processing. Coding, editing, and data processing errors are analyzed on a regular basis and measures are implemented to make necessary improvements.

Cost accounting procedures have been implemented to determine the relative cost of each program in terms of personnel and economic resources. As a result of this analysis and recent budget cuts, NISI has developed plans to reduce the number of price quotations collected in Metropolitan Lima and correspondingly increase the number of price quotations collected in the departmental capitals. Nonetheless, the resources currently available for a CPI program of the magnitude that exists in Peru, with separate indices for 25 different cities, are not adequate for properly ensuring the quality of the index and providing for a new ENAPROM to update the market basket weights. 


\subsection{Quality awareness}

\subsubsection{Processes are in place to focus on quality}

Although NISI has not established an official program of total quality management, many elements of such a program are already in place, especially in terms of monitoring data collection, processing, and dissemination for the CPI.

\subsubsection{Processes are in place to monitor the quality of the collection, processing, and dissemination of statistics}

NISI has developed a system for the detection of errors such as keying errors, incomplete data entries, duplication of entries, and atypical values. Analysis of this information is conducted and procedures are implemented to reduce these types of errors. A manual for price collection and data processing has been developed.

For Metropolitan Lima a group of analysts has been designated to conduct periodic reviews of the different types of errors encountered in price collection and data processing. This group then makes recommendations for improvements in the process.

The Directorate of Economic Indicators (DEI), the organizational unit within NISI responsible for the preparation of the $\mathrm{CPI}$, has established a program for supervising the work of preparing the consumer price indices in the departmental capitals. A scheduled has been established for visits to each of the capital cities by a team of supervisors. During these visits, the team verifies that the objectives of the CPI program are understood and are being carried out, that instructions for price collection and tabulation are being followed, that the work is organized properly, that the prices being collected for the index are valid, and that any other problems with regard to the field work are identified. The team then prepares a report the presents any corrective and/or preventive measure that should be taken. Although NISI does not normally conduct user surveys, studies by other organizations are available.

As part of the recent project to improve the CPI for Metropolitan Lima, three international missions and one local mission provided technical assistance to NISI. In addition, meetings have been held on a regular basis with specialists from both the private and government sector. This project resulted in the publication of a revised index for Metropolitan Lima with corrected market basket weights, an updated list of items, and improved index calculation procedures.

\subsubsection{Processes are in place to deal with quality considerations, including tradeoffs within quality, and to guide planning for existing and emerging needs}

Periodically, NISI convenes meeting of the statistical advisory council that consists of important users and experts from other government entities, the private sector, and academia. This group evaluates the current index series and proposes improvements to these series. 
NISI also takes advantage of this opportunity to seek comments and evaluations concerning these index series from council members.

DEI has established a plan to upgrade the 24 departmental capital indices using the same methodology employed for Metropolitan Lima. It is understood by the officials of NISI that this is a major project that will require significant resources. Unfortunately, there is no budget and no fixed plan for a new ENAPROM that is needed to update the aging market basket weight structure for the index.

\section{Integrity}

\subsection{Professionalism}

\subsubsection{Statistics are compiled on an impartial basis}

NISI has a tradition of professionalism with regard to the individual behavior of the employees and officials, confidentiality of data, selection of methods of analysis, dissemination of data, and participation in conferences and meeting with other professional groups. In Articles No. 97 and 98 of Supreme Decree No. 018-1990-PCM, "Regulations and Organization and Functions of NISI", specific standards of conduct for employees with regard to confidentiality, management of statistical data and avoiding the influence of third parties are specified. In the Legislative Decree 276 sanctions are specified for abuse of official data and violation of confidentiality. In addition, there are specific standards set within NISI with regard to professional behavior, courtesy toward respondents, integrity, impartiality in hiring, execution of official duties, and the avoidance of influence by third parties.

The officers and professional staff of DEI are encouraged to conduct research and participate in conferences and meetings with other groups of professionals from the academic community and from private research groups.

\subsubsection{Choices of sources and statistical techniques are informed solely by statistical considerations}

The choice of statistical methods and sources of data is made solely on the basis of statistical and budgetary considerations. DEI has recently published a thorough description of the research that lead to changes in index calculation methodology, the selection of a new list of items and the recalculation of market basket weights for the CPI for Metropolitan Lima. In this document, the reasoning behind the changes is well documented.

\subsubsection{The appropriate statistical entity is entitled to comment on erroneous interpretation and misuse of statistics}

Even though NISI has the capacity to comment on inaccurate interpretation and misuse of published price statistics, it is usually not done. However, NISI makes every effort to provide 
to its users in depth explanations of its statistical series and their proper use in analysis. NISI also has established an office of information and institutional image.

\subsection{Transparency}

\subsubsection{The terms and conditions under which statistics are collected, processed, and disseminated are available to the public}

NISI disseminates its statistical series in press releases, on its web page, and in written bulletins in a detailed format that includes methodological documents describing the processes employed for data collection, processing, and index tabulation. Also included are the laws and decrees governing the functioning of NISI. These publications indicate where further information on the statistical series may be obtained. Advance notice of important changes in source data, methodology, and statistical techniques is given to users.

\subsubsection{Internal governmental access to statistics prior to their release is publicly identified}

Although NISI indicates that the approval process for published index series is entirely internal, a number of high level government officials have embargoed access to these series the day before they are released publicly. The list of individuals receiving privileged access is not published.

\subsubsection{Products of statistical agencies/units are clearly identified as such}

All NISI publications include the Institute's logo. In the case of joint publications, each entity, whether public or private, is clearly identified in the footnotes of all published tables and/or on the title page of the document.

\subsubsection{Advance notice is given of major changes in methodology, source data, and statistical techniques}

Advance notice is given to users regarding all changes to concept, scope, methodology, weighting structure, and major data sources. The recent update to the CPI for Metropolitan Lima was announced six months before publication to major users and the public.

\subsection{Ethical standards}

\subsubsection{Guidelines for staff behavior are in place and are well known to the staff}

NISI employees and officials are provided with clear guidelines on ethical standards in legal documents, including Supreme Decree No. 018-1990-PCM, "Regulations and Organization and Functions of NISI," and Legislative Decree 276, as well as in internal NISI publications made available directly to all personnel. 
In the case of the CPI, the data collection manual is given to all personnel involved in the calculation of the indices. In addition to technical instructions for price collection and data processing, this manual contains norms of conduct and courtesy that must be followed by field agents.

\section{Methodological soundness}

\subsection{Concepts and definitions}

\subsubsection{The overall structure in terms of concepts and definitions follows internationally accepted standards, guidelines, or good practices}

In general, the CPI is based on internationally accepted concepts, definitions, practices and standards. Separate indices are calculated for metropolitan Lima and 24 departmental capitals cities. These indices are combined to produce a national level index that represents the entire urban population of Peru. Concepts and definitions for calculating market basket weights are generally those recommended by the 1993 SNA for household consumption expenditures. In January 2002, NISI began publication of an updated CPI for Metropolitan Lima that has increased coverage of consumer households, an updated list of market basket items, recalculated market basket weights from the 1993-94 ENAPROM, updated item specifications, and the use of geometric means for the calculation of elementary aggregate price relatives. In addition, imputed rent for owner-occupied housing was removed from the weighting structure for the new index. A project is currently underway to make similar updates to individual consumer price indices for the 24 departmental capital.

\subsection{Scope}

\subsubsection{The scope is broadly consistent with internationally accepted standards, guidelines,} or good practices

Market basket weights for the CPI are based on tabulations of urban household expenditure data from the 1993-94 ENAPROM. For the Metropolitan Lima index, expenditure data reported by all types of urban households are reflected in the weights. However, the weighting structures for the 24 departmental CPI market baskets exclude data from single family households and households falling in the tails of distribution by total household expenditure, i.e., households with high and low total expenditures. In general, these weights reflect all type of expenditures relating to personal consumption, including own production of goods for personal use. The major exception is the treatment of owner-occupied housing. The weight for imputed rent was removed from the new index for Metropolitan Lima. However, imputed rent is still included in the weighting structures of the 24 departmental capital indices. The removal of imputed rent from the Metropolitan Lima index is a clear deviation from international recommendations for the treatment of this component. It should be noted that the removal of imputed rent for owner-occupied housing from the Metropolitan Lima index has created a mixture of concepts for the national CPI since the departmental capital indices include imputed rent. 


\subsection{Classification/sectorization}

\subsubsection{Classification/sectorization systems used are broadly consistent with internationally accepted standards, guidelines, or good practices}

Tabulations for expenditure data from the 1993-94 ENAPROM, as well as the market basket item and weight structure for the CPI, are based on the classification system recommended by the $1968 S N A$ rev.3. This classification structure provides for 8 major groups, rather than the 12 major groups resulting from the latest version of the Classification of Individual Consumption by Purpose (COICOP) recommended by the 1993 SNA. Although NISI has not officially adopted COICOP, a comprehensive concordance has been constructed for conversion from the current system to COICOP. A significant part of the motivation for the planned conversion to COICOP is for the preparation of statistical data that are harmonized with data from other countries in the Andean Community.

It should be pointed out that the concordance between the current classification structure and COICOP is done at a very detailed level. This should provide for a rather smooth transition to COICOP. Some thought was given to making a conversion to COICOP for the December 2001 CPI revision of the Metropolitan Lima index. However, it was decided that the conversion would take place after the weights and item structures for the 24 departmental capital indices have been updated.

\subsection{Basis for recording}

\subsubsection{Market prices are used to value flows and stocks}

For the 1993-94 ENAPROM, the source of the market basket weight for the indexinformation on consumer expenditures-is valued at market prices including taxes. Market prices are also collected for the monthly price survey. Price determining characteristics are considered in determining the specifications for the monthly survey. These specifications are evaluated and updated every two years.

\subsubsection{Recording is done on an accrual basis}

The basis for recording stocks and flows in both the calculation of weights and the monthly price collection process meet international standards in that all transactions are valued on an accrual basis. This applies to the valuation for own production, own consumption, and products and services received by the households as part of compensation for work performed. 


\subsubsection{Grossing/netting procedures are broadly consistent with internationally accepted standards, guidelines, or good practices}

For the 1993-94 ENAPROM, purchases of durable goods are reported as expenditures and valued at the market value of the asset at the time of acquisition. Sales of consumer durables are registered as income. The market basket weight for purchase of vehicles does not net out sales of vehicles. This deviation from internationally recommended procedures is not mentioned in the metadata for the index posted on the IMF's Data Standards Bulletin Board (DSBB).

\section{Accuracy and reliability}

\subsection{Source data}

\subsubsection{Source data are collected from comprehensive data collection programs that take into account country-specific conditions}

The weight structure for the CPI is derived from the 1993-94 ENAPROM. A three-stage stratified sampling procedure was used to select samples of approximately 10,000 households for each of the four quarters beginning in October 1993 and ending in September 1994. This survey is the last household survey conducted in Peru that covers an entire year.

For all of the household surveys in Peru, scientific sampling is used for the selection of households, all type of expenditures relating to consumption are covered, imputations are made for own production and consumption, and values for all expenditures and imputations are based on market prices, including taxes at the time of acquisition.

In Metropolitan Lima, approximately 35,000 monthly price quotations are obtained from approximately 5,000 commercial establishments, 41 markets, 5 supermarkets, 500 rented homes, 505 educational centers, and 210 urban and interstate transport lines, among others. A total of approximately 40,000 monthly price quotations are collected in the 24 other departmental capital cities. Plans are in effect to collect fewer prices in Metropolitan Lima and more in the departmental capitals.

Special studies are conducted on a regular basis to determine the need for changes in products and pricing specifications. These studies are based on both internal data and data obtained from other government and private sources.

\subsubsection{Source data reasonably approximate the definitions, scope, classifications, valuation, and time of recording required}

The expenditure data obtained from the 1993 ENAPROM are sufficiently detailed to support the needs of the CPI program, and the scope, coverage, and definitions employed are also consistent with those of the CPI. 


\subsubsection{Source data are timely}

The 1993-94 ENAPROM is the last comprehensive household survey of income and expenditures conducted over the period of an entire year in Peru. Although annual household surveys have been carried out since 1998, these surveys are not designed for use in determining CPI weights. Among other drawbacks, they do not provide sufficient detail on expenditures. Unfortunately, they are conducted over a period of just the 45 days from the first of September through the fifteenth of October. Even though the households are asked to report expenditures for recall periods up to one year, depending on the type of expenditure, expenditure data from these surveys have a potential for serious bias due to seasonality. Given that the annual housing survey is not adequate for use in the CPI, there is a critical need for a new comprehensive income and expenditure survey. The weights for the current CPI are based on nine year old data and need to be updated.

Data on price behavior from sources outside NISI that are used on a regular basis for verification purposes are available on a timely basis.

\subsection{Statistical techniques}

\subsubsection{Data compilation employs sound statistical techniques}

Although, in general, NISI employs sound statistical techniques for data collection, processing and monthly index calculation, the new market basket weights are based on nine year old expenditure data and were not updated for price change between 1993-94 and December 2001, when they were introduced into the index. In addition, based on bad advise from outside technical experts, the coverage of owner-occupied housing was eliminated from the Metropolitan Lima index by removing the imputed rent component. Current plans are to eliminate imputed rent from the market basket weights for the departmental capital indices also.

NISI uses a the long-term relative matched price algorithm for index computation. For Metropolitan Lima the geometric mean was introduced for the calculation of primary aggregates. This methodology will also be introduced for the other city indices.

Substitutions are well handled, and new base period prices, when they are needed, are calculated at price quotation level. Temporarily unavailable and seasonally unavailable prices are held constant. The product sample and specifications are reviewed bi-annually and, when new varieties of products are identified, they are linked into the index.

The most recent tabulations from the 1993-94 ENAPROM were carried out on a very detailed level, allowing for the calculation of detailed market basket weights and virtually complete flexibility in index aggregations with regard to the current classification system and the latest version of COICOP. 


\subsubsection{Other statistical procedures (e.g., data adjustments and transformations, and statistical analysis) employ sound statistical techniques}

The market basket weights for the CPI cover approximately 75 percent of final household consumption in the national accounts. Indicator of price change for those components not included are available, to some extent, from the WPI and implicit deflators for the national accounts.

\subsection{Assessment and validation of source data}

3.3.1 Source data-including censuses, sample surveys and administrative records-are routinely assessed, e.g., for coverage, sample error, response error, and nonsampling error; the results of the assessments are monitored and made available to guide planning

A serious problem was detected by NISI with regard to the market basket weights for the CPI. Test tabulations using the original 1993-94 ENAPROM expenditure data and tabulation procedures similar to those used in 1994 were unable to reproduce anything close to the original results. On the basis of these results, it was decided to calculate new market basket weights for the Metropolitan Lima index that were introduced in January 2002.

Price data collected in the monthly price survey are under constant scrutiny, first by field supervisors, then by analysts, and finally in the annual updates for outlets and bi-annual updates for products and specifications. Monthly visits are conducted by supervisors to ensure that correct procedures are followed in registering and processing price data.

\subsection{Assessment and validation of intermediate data and statistical outputs}

\subsubsection{Main intermediate data are validated against other information where applicable}

CPI indices are compared with similar indices in the WPI and with price data from other sources, such as price data on agricultural and fish products.

\subsubsection{Statistical discrepancies in intermediate data are assessed and investigated}

Significant increases and decreases in monthly price index series are investigated and corrected, when appropriate, as part of the monthly review process for the index. This process starts with the field supervisors and is followed up by analysts in Lima.

\subsubsection{Statistical discrepancies and other potential indicators of problems in statistical outputs are investigated}

Since aggregations are consistent across type of market basket consumption and across geography, and since missing prices are held constant, there are no potential inconsistencies 
in the CPI due to imputation and aggregation methods. Should an "apparent" inconsistency develop, the error would be found and corrected.

\subsection{Revision studies}

\subsubsection{Studies and analyses of revisions are carried out routinely and used to inform statistical processes}

The CPI is published without official revisions. However, when errors are detected in the price data, the corrections are made to the current data and the index self-corrects in the next period due to the current-period-to-base-period index calculation algorithm.

\section{Serviceability}

\subsection{Relevance}

\subsubsection{The relevance and practical utility of existing statistics in meeting users' needs are monitored}

Over the last several years the consumer price index has been the focus of extensive interaction with advisory groups and outside experts in connection with several important projects, the first of which was the recalculation of market basket weights, and the improvement of index calculation methodology for the Metropolitan Lima index. The updated index with recalculated weights, based on the 1993-94 ENAPROM, and an updated list of market basket items was published beginning in January 2002 with a December 2001 reference base. Another project was undertaken to produce a national level index by combining the Metropolitan Lima index with indices representing the 24 departmental capitals. Publication for the new national index began in January 2003, with seven years of historical data.

\subsection{Timeliness and periodicity}

\subsubsection{Timeliness follows dissemination standards}

The Metropolitan Lima CPI is published on the $1^{\text {st }}$ of each month and the national CPI is published on the $15^{\text {th }}$ of each month. Both official indices meet the SDDS requirements for timeliness.

\subsubsection{Periodicity follows dissemination standards}

Both the Metropolitan Lima CPI and the national CPI are published monthly in keeping with SDDS requirements. 


\subsection{Consistency}

\subsubsection{Statistics are consistent within the dataset}

Both the Metropolitan Lima CPI and the national CPI are consistent with regard to order of aggregation.

\subsubsection{Statistics are consistent or reconcilable over a reasonable period of time}

For the publication of the updated Metropolitan Lima Index in January 2002 and the new national CPI in January 2003 detailed documentation was published. For the national CPI, a historical index series was published for the six-year period, 1996-2002. Linked historical series were published to reflect the new reference base of December 2001 for the Metropolitan Lima index.

\subsubsection{Statistics are consistent or reconcilable with those obtained through other data sources and/or statistical frameworks}

Where compatible, the CPI indices are consistent with WPI indices, implicit deflators from the national accounts, and price information on agricultural products and fish.

\subsection{Revision policy and practice}

\subsubsection{Revisions follow a regular, well-established, and transparent schedule}

There is no set revision policy for updating base period weights for the CPI. The current CPI weights are based on 9 year old expenditure data from the latest ENAPROM in 1993-94.

\subsubsection{Preliminary data are clearly identified}

Preliminary indices are not published for the CPI.

\subsubsection{Studies and analyses of revisions are made public}

Extensive documentation is published for major changes in market basket weights, coverage, scope, and methodology. This documentation includes a detailed analysis of the motivation for, and circumstances leading to, the updates. 


\section{Accessibility}

\subsection{Data accessibility}

\subsubsection{Statistics are presented in a way that facilitates proper interpretation and meaningful comparisons (layout and clarity of text, tables, and charts)}

The monthly CPI for Metropolitan Lima and the monthly national CPI are disseminated in a number of different formats, including the press releases, the NISI website, and a monthly bulletin. The press releases are well designed and include tables of index results at various levels of aggregation and with adequate historical detail. The press releases also include helpful charts and graphs and analysis of the factors leading the large variations in price by component.

\subsubsection{Dissemination media and formats are adequate}

Although the press releases for the metropolitan Lima CPI and the national CPI have an appropriately limited format, the NISI website and the monthly and annual bulletins include detail and historical index series. These other media also include methodological documents describing the processes employed for data collection, data processing and index tabulation, as well as the laws and decrees governing the functioning of NISI.

On a weekly basis, the Central Reserve Bank of Peru (CRBP) is provided with weekly data on food and beverages. A monthly report is also prepared for the CRBP that summarizes these data at item level detail.

\subsubsection{Statistics are released on a preannounced schedule}

The Metropolitan Lima CPI is released on the $1^{\text {st }}$ of the month following the reference month for the index and the national CPI is released on the $15^{\text {th }}$ of the same month.

\subsubsection{Statistics are made available to all users at the same time}

Although the press have embargoed access to the CPI prior to its publication each month, the index is released to the all users and the general public simultaneously on the NISI website and in various written formats.

\subsubsection{Nonpublished (but nonconfidential) subaggregates are made available upon request}

Unpublished detail for the CPI is available upon request as long as the principles of confidentiality under which the data were collected are not violated. 


\subsection{Metadata accessibility}

5.2.1 Documentation on concepts, scope, classifications, basis of recording, data sources, and statistical techniques is available, and differences from internationally accepted standards, guidelines, or good practices are annotated

Although metadata for the CPI are available on the NISI website and in published bulletins, there are several deficiencies. First, no mention is made that the current market basket weights for the Metropolitan Lima index were not updated for price change between the base period of 1993-94 and the reference period of December 2001. Another omission is the lack of a statement describing the nature of privileged access to the CPI by government officials prior to its release to the public.

\subsubsection{Levels of detail are adapted to the needs of the intended audience}

The NISI publishes metadata on its website, on the DSBB, and in a catalogue listing its publications.

\subsection{Assistance to users}

\subsubsection{Contact person for each subject field is publicized}

The NISI publications list the contact persons, and their telephone numbers and e-mail addresses, to whom users can turn with their queries and data requests. These publications indicate where further information on the statistical series may be obtained.

\subsubsection{Catalogues of publications, documents, and other services, including information on} any charges, are widely available

NISI has an Office of Dissemination, an Information Center, and a Library where information on publications about the CPI may be obtained. Periodically, NISI publishes a catalog of publications, documents, and other services available to the public, as well as the cost and process required for obtaining these items. 
Table 2. Peru: Data Quality Assessment Framework-Summary of Results for Consumer Price Index

(Compiling Agency: National Institute of Statistics and Informatics)

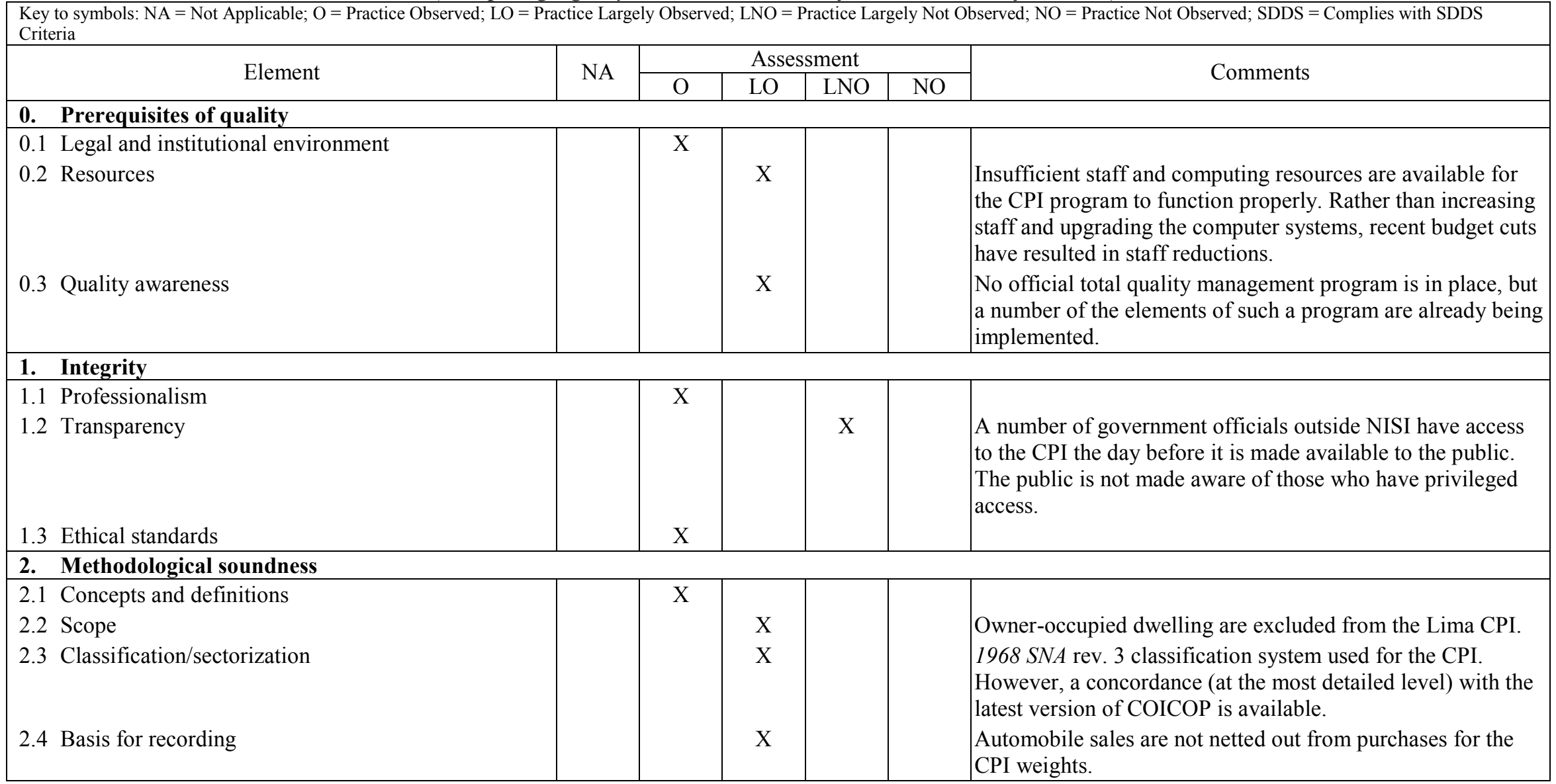


Table 2. Peru: Data Quality Assessment Framework-Summary of Results for Consumer Price Index

(Compiling Agency: National Institute of Statistics and Informatics)

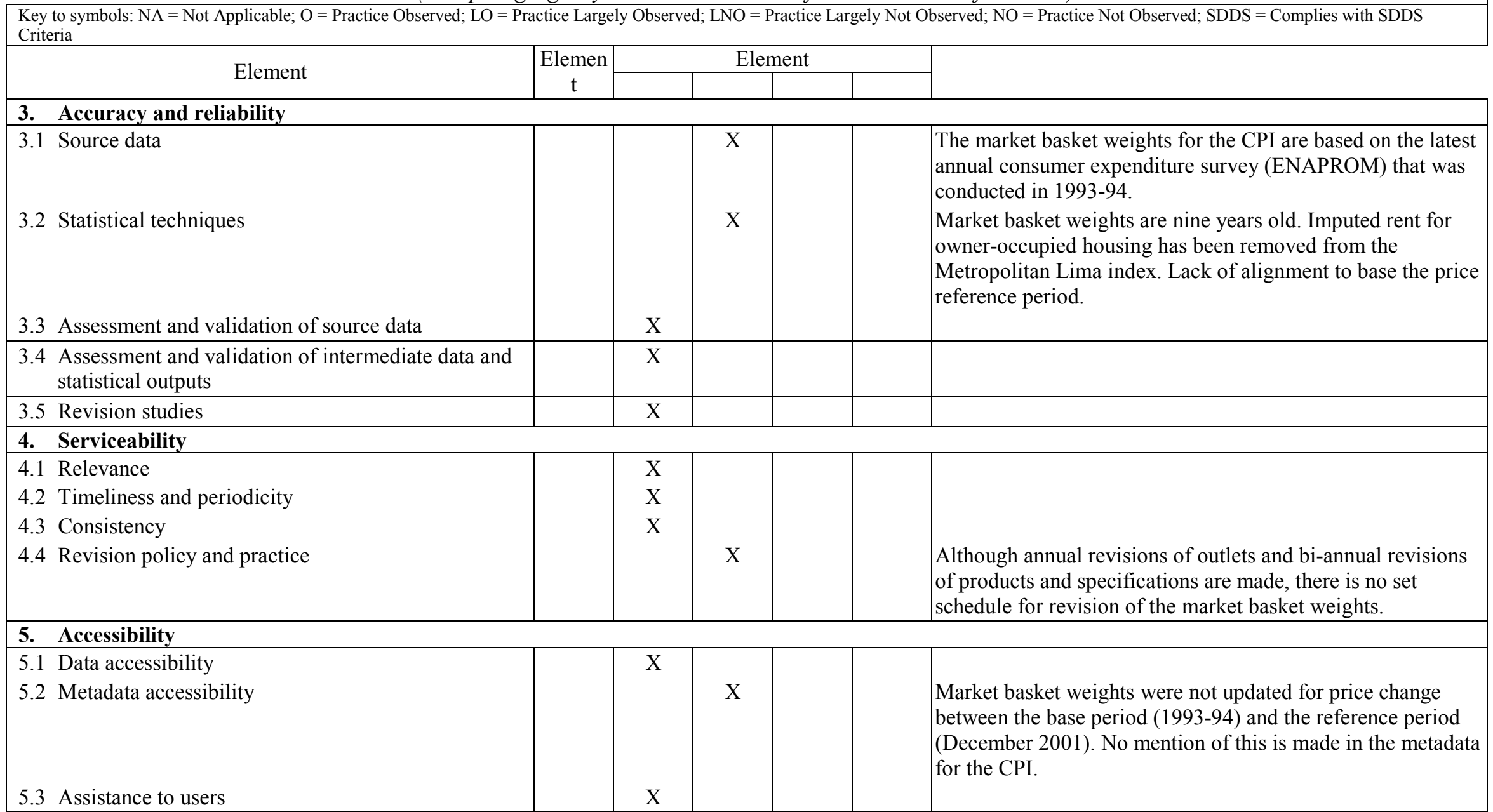




\section{Wholesale Price IndeX}

\section{Prerequisites of quality}

\subsection{Legal and institutional environment}

\subsubsection{The responsibility for collecting, processing, and disseminating statistics is clearly specified}

The responsibility for collecting, processing, and disseminating official data relating to prices is laid out in a series of laws and legislative decrees that define the legal and institutional environment for the wholesale price index (WPI). Legal Decree No. 17532 (Decreto Ley 17532 "Ley Orgánica de la Presidencia de la República" de 1969) established the National Office of Statistics and Census under the Ministry of Economy and Finance ("Hacienda") as the office responsible to compiling and disseminating price indices. In December of 1975 the Legal Decree No. 560 transformed the National Office of Statistics and Census into the National Institute of Statistics (NIS) placing it directly under the Prime Minister. The responsibilities of NIS were expanded in April of 1990 to include informatics by Legal Decree No. 563, which modified Article 56 of the Law of Executive Power (Legal Decree No 560). In April of 1990, Legal Decree No 604 "Law for the Organization and Functions of the National Institute of Statistics and Informatics (NISI)" was passed specifying in Chapter IV Article 9-e that the new NISI has the function of producing and disseminating price indices. Also, Clause f of Article 5 of Supreme Decree No. 018-1990-PCM states that NISI has the responsibility for producing and disseminating price indices as well as other series relating to economic and social conditions.

In general, the legal and institutional environment for NISI is adequate for producing price statistics, with the exception of providing source data for a new establishment sampling frame and weights for the WPI. Data are available at the tax authority, but not readily accessible to NISI due to legal restrictions regarding confidentiality.

\subsubsection{Data sharing and coordination among data producing agencies are adequate}

There are no adequate data for an establishment sampling frame for the selection of a new establishment sample for the WPI. Data on measure-of-size for establishments are available at the National Superintendency of Tax Administration (SUNAT) but are not provided to NISI at a sufficient level of detail due to confidentiality restrictions.

\subsubsection{Respondents' data are to be kept confidential and used for statistical purposes only}

Article 97 of the NISI Law (Legal Decree No. 604) specifies that data provided by respondents must be held confidential and not be revealed in any form that could identify any individual respondent even by administrative or judicial order. Additionally, it specifies that confidential data may not be used for criminal or tax related investigations. Article 98 
provides for sanctions against employees who misuse confidential data. These sanctions are specified in Legislative Decree 276.

All NISI survey instruments relating to the WPI contain explanations that the data being collected are confidential and will be used solely for statistical purposes. NISI has the policy of never publishing any data in a way that would allow an individual respondent to be identified.

NISI has established procedures that protect its computer databases from unauthorized access. Different levels of access have also been established according to the sensitivity of the data. In addition to these measures, each computer has its own security system.

\subsubsection{Statistical reporting is ensured through legal mandate and/or measures to encourage response}

Historically, NISI has conducted its price surveys with respondents participating on a voluntary basis. Field agents are trained to look for the most efficient manner for collecting the required data. They always explain that the information is confidential and that it will be used only for statistical purposes. In extreme cases where there is a resistance on the part of the respondent to cooperate, the supervisor visits the outlet with a letter of introduction that explains the obligatory nature of providing the data requested (Legislative Decree No. 604, Articles 81-84) and again reiterates the guarantee of confidentiality.

\section{$0.2 \quad$ Resources}

\subsubsection{Staff, financial, and computing resources are commensurate with statistical programs}

NISI is experiencing serious deficiencies in resources with regard to personnel and computer processing equipment dedicated for producing the WPI. This lack of sufficient staff and aging computers has created inefficiencies for data collection, transmission, and processing.

The NISI prices staff, many of which have years of experience, are well qualified and possess the needed skills for producing high quality price indices that meet international standards. Even though salaries are modest, there is no significant problem of retention of personnel since the job market is very tight. However, there are only 7 office staff ( 4 shared with the CPI) and 41 data collectors (shared with the CPI) dedicated to work on the WPI. This is insufficient for the production of a high quality index.

There are serious problems with the capacity and number of computers available for the WPI. Some of the computers do not have sufficient capacity for efficient transfer of data and to receive the monthly flow of fax load needed for efficient price collection. 


\subsubsection{Measures to ensure efficient use of resources are implemented}

The WPI has been marginalized for many years. There is a crucial need for a producer price index (PPI), but very few resources are currently dedicated to its development.

\subsection{Quality awareness}

\subsubsection{Processes are in place to focus on quality}

Although NISI has not established an official program of quality awareness, e.g., total quality management, many elements of such a program are already in place, especially in terms of monitoring data collection, processing and dissemination for the WPI. Monthly quality assurance visits by central office staff to the field have been implemented for the CPI. Although a similar program is planned for the WPI, it has not yet been implemented.

\subsubsection{Processes are in place to monitor the quality of the collection, processing, and dissemination of statistics}

NISI has developed a system for the detection of errors such as keying errors, incomplete data entries, duplication of entries, and atypical values. Analyses of this information are conducted and procedures are implemented to reduce these types of errors.

Currently, most of the resources for improving price indices have been dedicated to the CPI program. Except for a proposal to begin the preparation of a PPI, very little is being done.

\subsubsection{Processes are in place to deal with quality considerations, including tradeoffs within quality, and to guide planning for existing and emerging needs}

With regard to quality assurance and efficient use of resources, efforts should be directed toward replacing the WPI, that has a flawed conceptual basis, with a PPI that is conceptually sound. However, NISI officials appear to be resigned to the idea that it would be very difficult to eliminate the WPI and replace it with a proper PPI. The current plan is to produce both indices for some period of time. This would be neither desirable nor efficient.

\section{Integrity}

\subsection{Professionalism}

\subsubsection{Statistics are compiled on an impartial basis}

NISI has a tradition of professionalism with regard to the individual behavior of the employees and officials, confidentiality of data, selection of methods of analysis, dissemination of data, and participation in conferences and meeting with other professional groups. In Articles No. 97 and 98 of Supreme Decree No. 018-1990-PCM, "Regulations and Organization and Functions of NISI", specific standards of conduct for employees with 
regard to confidentiality, management of statistical data, and avoiding the influence of third parties are specified. In the Legislative Decree 276 sanctions are specified for abuse of official data and violation of confidentiality. In addition, there are specific standards set within NISI with regard to professional behavior, courtesy toward respondents, integrity, impartiality in hiring, execution of official duties, and the avoidance of influence by third parties.

The officers and professional staff of the Directorate of Economic Indicators (DEI) are encouraged to conduct research and participate in conferences and meetings with other groups of professionals from the academic community and from private research groups.

\subsubsection{Choices of sources and statistical techniques are informed solely by statistical considerations}

The choice of statistical methods and sources of data is made solely on the basis of statistical and budgetary considerations. DEI has recently published a thorough description of the research that lead to changes in index calculation methodology, the selection of a new list of item, and the recalculation of market basket weights. In this document, the reasoning behind the changes is well documented.

\subsubsection{The appropriate statistical entity is entitled to comment on erroneous interpretation and misuse of statistics}

Even though NISI has the capacity to comment on inaccurate interpretation and misuse of published WPI data, it is usually not done. However, NISI makes every effort to provide to its users in depth explanations of its statistical series and their proper use in analysis. NISI also has established an office of information and institutional image.

\subsection{Transparency}

\subsubsection{The terms and conditions under which statistics are collected, processed, and disseminated are available to the public}

NISI disseminates its statistical series in press releases, on its web page, and in written bulletins in a detailed format that includes methodological documents describing the processes employed for data collection, processing, and index tabulation. Also included are the laws and decrees governing the functioning of NISI. These publications indicate where further information on the statistical series may be obtained. Advance notice of all important change in source data, methodology, and statistical techniques is given to users.

\subsubsection{Internal governmental access to statistics prior to their release is publicly identified}

Although NISI indicates that the approval process for published index series is entirely internal, a number of high level government officials have embargoed access to these series 
the day before they are released publicly. The list of individuals receiving privileged access is not published.

\subsubsection{Products of statistical agencies/units are clearly identified as such}

All NISI publications include the Institute's logo. In the case of joint publications, each entity, whether public or private, is clearly identified in the footnotes of all published tables and/or on the title page of the document.

\subsubsection{Advance notice is given of major changes in methodology, source data, and statistical techniques}

Advance notice is given to users regarding all changes to concept, scope, methodology, weighting structure, and major data sources.

\subsection{Ethical standards}

\subsubsection{Guidelines for staff behavior are in place and are well known to the staff}

NISI employees and officials are provided with clear guidelines on ethical standards in legal documents, including Supreme Decree No. 018-1990-PCM, "Regulations and Organization and Functions of NISI," and Legislative Decree 276, as well as in internal NISI publications made available directly to all personnel. Internally produced manuals also contain norms of conduct and courtesy that must be followed by field agents with regard to collecting and verifying price data.

\section{Methodological soundness}

\subsection{Concepts and definitions}

\subsubsection{The overall structure in terms of concepts and definitions follows internationally accepted standards, guidelines, or good practices}

The WPI that has been published in Peru since 1920, like wholesale price indices produced in other countries, does not have a clear conceptual framework in that approximately half of the monthly prices included in the index are producer prices, with taxes included, and the other half are wholesale prices and prices for imported goods. In other words, there is a mixture of concepts; the index neither reflects price change at the factory gate, nor price changes at some specified level of commercialization, e.g., the last stage of commercialization before the retail sale of the products to consumers. A true PPI, on the other hand, has a clear conceptual basis, since only producer prices, free of taxes, at the factory gate, are included.

Although the WPI does not have a clear conceptual basis, the weighting structure and the subset of prices that are producer prices could theoretically be used to produce a preliminary PPI for Peru. On this basis the current index is being evaluated for this ROSC mission. 


\section{$2.2 \quad$ Scope}

2.2.1 The scope is broadly consistent with internationally accepted standards, guidelines, or good practices

Although the WPI covers agricultural production, fishing, and manufacturing, there is no coverage of forestry, mining, oil and gas extraction and refining, electricity and water production, public transportation, and communication.

\subsection{Classification/sectorization}

\subsubsection{Classification/sectorization systems used are broadly consistent with internationally accepted standards, guidelines, or good practices}

The WPI employs a national classifications system that is an extended version of the fourdigit ISIC rev. 3. However, in so far as the WPI is concerned, this classification system is in fact a classification of products by economic activity, since secondary production for the establishments selected for price collection is not included. WPI indices are not calculated for economic activities.

\subsection{Basis for recording}

\subsubsection{Market prices are used to value flows and stocks}

The basis for recording stocks and flows for both the calculation of weights and for the prices used in the index is in accordance with international standards. Market prices are used for determining values for source data for weights from the national accounts and for price data in the monthly price survey.

\subsubsection{Recording is done on an accrual basis}

All values are calculated on an accrual basis, reflecting the market value at the time of the transaction.

\subsubsection{Grossing/netting procedures are broadly consistent with internationally accepted standards, guidelines, or good practices}

This is not applicable. No indices are produced that require net weights. 


\section{Accuracy and reliability}

\subsection{Source data}

\subsubsection{Source data are collected from comprehensive data collection programs that take into account country-specific conditions}

The weights for the WPI are obtained from the 1994 input-output table from the national accounts, reports of the National Superintendency of Tax Administration (SUNAT), and publications of relevant ministries. Monthly prices data are obtained from a national survey of 520 establishments. Approximately 3,900 price quotations covering approximately 350 products are collected each month.

Although monthly and annual economic surveys are conducted, there has not been an economic census since 1994. There are no plans or budgeting for a new economic census.

A serious problem exists with regard to constructing a sampling frame for a new establishment sample for the WPI. An updated business register does not exist, and detailed measure-of-size data for establishments, available at SUNAT, are not shared with NISI because of confidentiality restrictions.

\subsubsection{Source data reasonably approximate the definitions, scope, classifications, valuation, and time of recording required}

Except for its age, the source data for the weights of the WPI generally meets the needs of the index in terms of scope, definitions, and valuation. Although the 1994 input-output table did not provide sufficient detail, the weights from this table were disaggregated using supplementary data from other sources, including the monthly and annual business surveys, data from SUNAT, and data from appropriate ministries and trade organizations.

\subsubsection{Source data are timely}

In order to meet the $1^{\text {st }}$ day of the month deadline for publication of the WPI, the average prices are calculated using data from the last week of the month previous to the reference month and the first three weeks of the reference month. Given this schedule, prices are collected and processed on a timely basis to meet the monthly publication deadline. However, this is an example of what must be done to meet an unreasonable and unnecessary deadline.

\subsection{Statistical techniques}

\subsubsection{Data compilation employs sound statistical techniques}

Some problems exist with regard to statistical techniques employed for the WPI. The format in which indices are reported is somewhat limited. Indices are produced by origin (national 
goods and imported goods by major group) and by destination (goods for intermediate consumption, final demand, and capital goods). In addition, indices by product by ISIC code are available at various levels of detail.

The second problem is with regard to base period weights. It has been almost 10 year since the weights for the WPI were updated. There are no plans for a new comprehensive economic census. It should be pointed out, however, that a project is underway to improve the coverage of the monthly and annual economic surveys.

Index calculation techniques are adequate. Equally weighted arithmetic averages are used for the elementary aggregates, missing prices are held constant, and substitutions for products that are no longer available and new products are properly linked into the index. Only a very limited amount of direct quality adjustment is carried out.

\subsubsection{Other statistical procedures (e.g., data adjustments and transformations, and statistical analysis) employ sound statistical techniques}

The WPI covers only approximately 25 percent of the gross domestic product. Other price data covering the rest of the economy are available, to a limited extent, through other government ministries, the CPI, trade associations, and private research groups. However, these other sources of price data cannot possibly take the place of a complete set of price indices from a producer price index program with broad coverage of the economy.

\subsection{Assessment and validation of source data}

\subsubsection{Source data-including censuses, sample surveys and administrative records-are} routinely assessed, e.g., for coverage, sample error, response error, and nonsampling error; the results of the assessments are monitored and made available to guide planning

The assessment of source data for the WPI is generally well handled. The bulk of the data are received by fax or by direct delivery to the NISI central office. These data are reviewed thoroughly by WPI analysts and entered into the computer. A thorough review of the data is conducted to detect missing observations, atypical values, keying errors, transcription errors, and errors of other types. On annual basis, the enterprise sample is evaluated and updated and, on a bi-annual basis, the product sample and specifications are updated.

\subsection{Assessment and validation of intermediate data and statistical outputs}

\subsubsection{Main intermediate data are validated against other information where applicable}

WPI indices are compared with similar indices in the CPI and with price and index data from other government ministries, trade associations, and other private entities. 


\subsubsection{Statistical discrepancies in intermediate data are assessed and investigated}

Unusual behavior of the component indices of the WPI are investigated to determine the source of the atypical behavior and to verify that there are no errors in the price collection and index tabulation process. When necessary, appropriate steps are take to correct the problem.

\subsubsection{Statistical discrepancies and other potential indicators of problems in statistical outputs are investigated}

Tabulation processes produce consistent results for tabulations by origin and by destination. Discrepancies between product-based tabulations and economic activity-based tabulations do not exist since no activity-based indices are produced. Since missing prices are held constant, there are no discrepancies due to imputation.

\subsection{Revision studies}

\subsubsection{Studies and analyses of revisions are carried out routinely and used to inform statistical processes}

The results of the annual economic survey as well as other source data for the wholesale price index are reviewed regularly. The results of these studies are used to update the establishment sample and product specifications.

\section{Serviceability}

\subsection{Relevance}

4.1.1 The relevance and practical utility of existing statistics in meeting users' needs are monitored

For many years, the WPI has been marginalized and there is little consultation with users regarding its relevance.

\subsection{Timeliness and periodicity}

\subsubsection{Timeliness follows dissemination standards}

The WPI is published on the $1^{\text {st }}$ of each month and thereby exceeds SDDS standards. However, it needs to be noted that monthly price data for the last week of the reference month is included with the following month's index.

\subsubsection{Periodicity follows dissemination standards}

The WPI is published monthly, thus meeting SDDS standards. 


\subsection{Consistency}

\subsubsection{Statistics are consistent within the dataset}

WPI aggregates are consistent whether tabulations are made by source or by origin.

\subsubsection{Statistics are consistent or reconcilable over a reasonable period of time}

NISI has thorough documentation of major changes in official indices due to change in concept, scope, weight structure, and methodology. Historical series are maintained for a number of years with the old reference bases.

\subsubsection{Statistics are consistent or reconcilable with those obtained through other data sources and/or statistical frameworks}

There are no major problems with inconsistencies with other databases. The concepts for the indices by origin and destination are straightforward.

\subsection{Revision policy and practice}

\subsubsection{Revisions follow a regular, well-established, and transparent schedule}

There is no well established schedule for weight updates. Weight revisions were made in $1960,1973,1990$, and 1994. The international recommendation is that weights be updated at least every 10 years. Although this recommendation is technically met, there is no budgeted plan for a new economic census. Any adjustments done to the weights would have to be done on less than adequate data obtained from the annual and monthly economic surveys.

\subsubsection{Preliminary data are clearly identified}

Preliminary indices are not published for the WPI.

\subsubsection{Studies and analyses of revisions are made public}

Revisions to the base year weights are well explained in published documents and other metadata available to the public. 


\section{Accessibility}

\subsection{Data accessibility}

\subsubsection{Statistics are presented in a way that facilitates proper interpretation and meaningful comparisons (layout and clarity of text, tables, and charts)}

The monthly WPI is disseminated in a number of different formats including the press release, the NISI website, and a monthly bulletin. The press release is well designed and includes tables of index results at various levels of aggregation and with adequate historical detail. The press release also includes helpful charts, graphs and analysis of the factors leading the large variations in price by component.

\subsubsection{Dissemination media and formats are adequate}

The press release for the WPI has an appropriately limited format. The publications also include methodological notes describing the processes employed for data collection, data processing, and index tabulation, as well as the laws and decrees governing the functioning of NISI.

\subsubsection{Statistics are released on a preannounced schedule}

The WPI is released on the $1^{\text {st }}$ of the month following the reference month for the index.

\subsubsection{Statistics are made available to all users at the same time}

Although members of the press have embargoed access to the WPI prior to its publication each month, the index is released to all users and the general public simultaneously on the NISI website, and in various written formats.

\subsubsection{Nonpublished (but nonconfidential) subaggregates are made available upon request}

Nonpublished detail for the WPI is available upon request as long as the principles of confidentiality under which the data were collected is not violated.

\subsection{Metadata accessibility}

5.2.1 Documentation on concepts, scope, classifications, basis of recording, data sources, and statistical techniques is available, and differences from internationally accepted standards, guidelines, or good practices are annotated

The metadata published by NISI regarding the WPI is generally complete and well presented. 


\subsubsection{Levels of detail are adapted to the needs of the intended audience}

The NISI publishes metadata on its website, on the DSBB, and in a catalogue listing its publications. Metadata are no completely up to date on the website.

\subsection{Assistance to users}

\subsubsection{Contact person for each subject field is publicized}

The NISI publications list the contact persons, and their telephone numbers and e-mail addresses, to whom users can turn with their queries and data requests. These publications indicate where further information on the statistical series may be obtained.

5.3.2 Catalogues of publications, documents, and other services, including information on any charges, are widely available

NISI has an Office of Dissemination, an Information Center, and a Library where information on publications about the WPI may be obtained. Periodically, NISI publishes a catalog of publications, documents, and other services available to the public as well as the cost and process required for obtaining these items. 
Table 3. Peru: Data Quality Assessment Framework-Summary of Results for Wholesale Price Index

(Compiling Agency: National Institute of Statistics and Informatics)

\begin{tabular}{|c|c|c|c|c|c|c|}
\hline \multirow{3}{*}{\multicolumn{2}{|c|}{\begin{tabular}{c|c} 
Key to symbols: $\mathrm{NA}=$ Not Applicable; $\mathrm{O}=$ Practice Observed; $\mathrm{LO}=$ Practice Larg \\
Element & NA \\
\end{tabular}}} & \multirow{2}{*}{\multicolumn{4}{|c|}{ Assessment }} & \multirow{3}{*}{ Comments } \\
\hline & & & & & & \\
\hline & & $\mathrm{O}$ & LO & LNO & NO & \\
\hline \multicolumn{7}{|c|}{ 0. $\quad$ Prerequisites of quality } \\
\hline \multirow[t]{2}{*}{0.1 Legal and institutional environment } & & & $\mathrm{X}$ & & & $\begin{array}{l}\text { There are no adequate source data for an establishment } \\
\text { sampling frame. These data are available at the National Tax } \\
\text { Superintendency, but are not shared with NISI due to } \\
\text { confidentiality considerations. }\end{array}$ \\
\hline & & & & $\mathrm{X}$ & & $\begin{array}{l}\text { Inadequate number of staff. Computer resources inadequate. } \\
\text { Very few resources dedicated toward improving the index. }\end{array}$ \\
\hline \multicolumn{7}{|l|}{ 1. Integrity } \\
\hline \multirow{2}{*}{$\begin{array}{l}\text { 1.1 Professionalism } \\
\text { 1.2 Transparency }\end{array}$} & & $\mathrm{X}$ & & & & \multirow[b]{2}{*}{$\begin{array}{l}\text { A number of government officials outside NISI have access to } \\
\text { the WPI the day before it is made available to the public. The } \\
\text { public is not made aware of those who have privileged access. }\end{array}$} \\
\hline & & & & $\mathrm{X}$ & & \\
\hline 2.2 Scope & & & $\mathrm{X}$ & & & $\begin{array}{l}\text { The WPI excludes mining and oil extraction, electricity and } \\
\text { water production, and public transportation and } \\
\text { communication. Imports are included. }\end{array}$ \\
\hline 2.3 Classification/sectorization & & $\mathrm{X}$ & & & & \\
\hline \multirow{2}{*}{\multicolumn{7}{|c|}{$\begin{array}{l}2.4 \text { Basis for recording } \\
\text { 3. } \text { Accuracy and reliability }\end{array}$}} \\
\hline & & & & & & \\
\hline 3.1 Source data & & & $\mathrm{X}$ & & & $\begin{array}{l}\text { No business register. Limited data on measure of size for a new } \\
\text { establishment sampling frame. }\end{array}$ \\
\hline 3.2 Statistical techniques & & & $\mathrm{X}$ & & & Outdated weights. \\
\hline 3.3 Assessment and validation of source data & & $\mathrm{X}$ & & & & \\
\hline $\begin{array}{l}\text { 3.4 Assessment and validation of intermediate data and } \\
\text { statistical outputs }\end{array}$ & & $\mathrm{X}$ & & & & \\
\hline
\end{tabular}


Table 3. Peru: Data Quality Assessment Framework-Summary of Results for Wholesale Price Index

(Compiling Agency: National Institute of Statistics and Informatics)

\begin{tabular}{|c|c|c|c|c|c|c|}
\hline \multirow{2}{*}{ Element } & \multirow{2}{*}{ NA } & \multicolumn{4}{|c|}{ Assessment } & \multirow{2}{*}{ Comments } \\
\hline & & $\mathrm{O}$ & LO & LNO & $\mathrm{NO}$ & \\
\hline \multicolumn{7}{|l|}{ 4. $\quad$ Serviceability } \\
\hline 4.1 Relevance & & \multirow{3}{*}{$\begin{array}{l}X \\
X\end{array}$} & \multirow[b]{3}{*}{$\mathrm{X}$} & \multirow[t]{3}{*}{$\mathrm{X}$} & & \multirow[t]{2}{*}{ There is no consultation with users regarding the WPI. } \\
\hline 4.3 Consistency & & & & & & \\
\hline 4.4 Revision policy and practice & & & & & & $\begin{array}{l}\text { No regular schedule for weight revisions. Weights are } 9 \text { years } \\
\text { old. }\end{array}$ \\
\hline 5.2 Metadata accessibility & & & \multirow[t]{2}{*}{$\mathrm{X}$} & & & \multirow[t]{2}{*}{ Metadata are not completely up to date on the website. } \\
\hline 5.3 Assistance to users & & $\mathrm{X}$ & & & & \\
\hline
\end{tabular}




\section{Government FinanCE Statistics}

\section{0. $\quad$ Prerequisites of quality}

\subsection{Legal and institutional environment}

\subsubsection{The responsibility for collecting, processing, and disseminating statistics is clearly specified}

Government finance statistics (GFS) on the central government, general government, and the nonfinancial public sector are compiled and disseminated by the Central Reserve Bank of Peru (CRBP), in accordance with the terms and conditions established in the following laws and regulations: (a) the Constitution of the Republic of 1993; (b) the Charter of the CRBP (Law No. 26123 of January 1, 1993); (c) the Statute of the CRBP of March 1, 1994; and (d) Ministerial Resolution No. 239-93-EF-10 of November 29, 1993.

Article 84 of the Constitution mandates the CRBP to inform the country, in an accurate and regular manner, on the nation's finances. Article 2 of the CRBP Charter states that one of the functions of the Bank is to report on the nation's finances, and Article 74 mandates that the Bank report regularly on the state of the nation's finances and publish the main national macroeconomic statistics. It should be noted that Article 73 of the CRBP charter states that the Bank is the only entity that compiles the balance of payments and the monetary accounts; however, there is no similar statement concerning GFS. Article 97 of the Statute of the CRBP states that the Bank should discharge said obligations under the Constitution and its Charter through regular and occasional publications. The Ministerial Resolution establishes the procedures to collect information. In particular, it specifies that all individuals and enterprises, whether private or public, must comply with the CRBP's request for statistical information, and that such must be accurate and provided within the established deadlines. Failure to comply is punishable by fines.

Working arrangements are consistent with the assignment of responsibility. The tasks associated with compiling and disseminating GFS are assigned to three units of the CBRP's Economic Studies Division (ESD): (a) the Public Sector Unit (PSU), (b) the External Sector Unit (ESU), and (c) the Global Analysis Unit (GAU). More specifically, within the PSU, the Government Entities Department (GED) compiles the GFS on operations of the central government and general government, the Public Enterprises Department (PED) compiles the GFS on nonfinancial public enterprises, and the Public Sector Analysis Department (PSAD) consolidates the statistics generated by the other two departments to compile the GFS on operations of the nonfinancial public sector. The External Debt Department (EDD) of the ESU compiles the long term external debt of the public sector. Finally, the Economic Situation Research Department (ESRD) of the GAU disseminates all macroeconomic statistics compiled by the CRBP, including GFS. 
Over the past two years, the Ministry of Economy and Finance (MEF) has began compiling and disseminating an increasing number of fiscal statistics, as a result of legislation aimed at promoting fiscal transparency and access to public information (Law No. 27245 on Fiscal Prudence and Transparency, of December 26, 1999, and its regulations; and Law No. 27806 on Transparency and Access to Public Information, of July 13, 2002). These laws, however, while promoting the widespread availability of fiscal statistics, do not mandate the MEF to compile and disseminate GFS. Thus, in addition to the usual information related to budget monitoring and execution, the MEF has began compiling fiscal statistics increasingly similar to the statistics compiled and disseminated by the CRBP. However, there is limited coordination between the two institutions concerning their fiscal statistics. Furthermore, the MEF aims to eventually compile and disseminate GFS. The current situation represents a duplication of effort and leads to confusion among users. An agreement should be reached between the two institutions concerning the compilation and dissemination of GFS. This agreement should ensure the continuity and quality of GFS.

\subsubsection{Data sharing and coordination among data producing agencies are adequate}

The CRBP collects the data needed to compile GFS from different agencies, mainly units of the MEF, the National Superintendency of Tax Administration (SUNAT), public enterprises, and the Accountant General's Office. Formal and informal working arrangements are in place to ensure timely access to data, and more generally to ensure that the data required to fulfill the CRBP's responsibility for compiling and disseminating GFS are available. In addition, close liaison is maintained between compilers of GFS and monetary data to reconcile GFS and banking sector financing data. The CRBP website provides users with an e-mail address for consultations or requests for more detailed information.

Beginning in January 1999, the Integrated System for Financial Administration (ISFA) became operational. This system, which was designed to support the Treasury in its budget execution role, records income and expenditure transactions at all stages. All budget executing units are electronically linked to the Treasury on real time. The ISFA is a database that provides timely and reliable information on budget execution and for compiling GFS. It is a major source of primary information for several public agencies, that has significantly reduced the duplication of effort and the burden on reporting units associated with data collection. A formal agreement between the MEF and the CRBP provides the Bank with direct access to the ISFA.

\subsubsection{Respondents' data are to be kept confidential and used for statistical purposes only}

The confidentiality of data received from respondents is protected by existing legislation and regulations. Article 41 of the CRBP Charter states that all CRBP employees are obligated not to disclose any confidential information pertaining to or managed by the Bank, under penalty of dismissal. The same prohibition to disclose confidential information appears in Article 50 of the CRBP Statute. The Regulation on Institutional Representation, Confidentiality, and Conflict of Interest, approved by the Board of Directors on September 26, 2002, defines what constitutes confidential information. Furthermore, Article 2 of Ministerial Resolution 
No. 239-93-EF-10 states that statistical information provided to the CRBP can not be revealed by administrative or judicial order, nor can it be used for tax or police purposes. Public corporations are familiar with the legislation on confidentiality.

\subsubsection{Statistical reporting is ensured through legal mandate and/or measures to encourage response}

There are legal and administrative provisions that ensure that the CRBP has access to all data required for compiling GFS. Article 74 of the Bank's Charter states that the CRBP is entitled to directly request information from all individuals and enterprises, whether private or public, and to impose fines for failure to comply or the provision of inaccurate data. This entitlement is made operational by Ministerial Resolution No. 239-93-EF-10.

\section{$0.2 \quad$ Resources}

\subsubsection{Staff, financial, and computing resources are commensurate with statistical programs}

The human resources assigned for GFS compilation are adequate. On-the-job and external training are provided to staff on methodological aspects. Each analyst has a modern computer available and adequate technical support to facilitate the use of modern technology in the compilation and dissemination of GFS. Staff rotation is limited, as efforts to develop and retain specialized personnel are Bank policy.

\subsubsection{Measures to ensure efficient use of resources are implemented}

The costs associated with compiling GFS are not calculated, but measures are adopted to ensure efficient use of resources, including (a) a demanding selection process for the hiring of economists, (b) continuous training of staff, and (c) extensive use of computer hardware and software. The top students of a summer-long economics course with a national competitive admission process are hired, and provided with training opportunities, including scholarships to pursue graduate education. Automated processes for GFS compilation are used, leading to significant cost savings.

\subsection{Quality awareness}

\subsubsection{Processes are in place to focus on quality}

The CRBP makes efforts to maintain and enhance its professional reputation. In terms of the compilation and dissemination of macroeconomic statistics this means an emphasis on quality as the cornerstone for producing reliable statistics. Efforts have been made in recent years to increase the coverage and timeliness of the statistics made available to the public. 


\subsubsection{Processes are in place to monitor the quality of the collection, processing, and dissemination of statistics}

Mechanisms are in place for assessing the quality of GFS compilation and dissemination. These mechanisms are geared primarily to ensuring the consistency of the primary information with the results. In particular, steps have been taken to encourage automation of the various processes for producing and cross-checking data.

The introduction of the IFSA has resulted in significant improvements in the quality of source data. All budget executing units must enter data into the system according to uniform formats and classifiers, as well as a timetable. The data entered are validated by the unit responsible for the system. The National Fund for the Financing of the State Entrepreneurial Activity (FONAFE), which has responsibility for the nonbudgetary public sector, also collects information from all entities according to uniform formats and classifiers, and validates the data received.

The Law on the National Accounting System (Law No. 24680) and its regulations, establish the accounting guidelines to be followed by the public and private sector. In particular, Regulation No. 013-98-EF/93.01, dated July 17, 1998, states that all public and private enterprises must follow the International Accounting Standards (IAS), which have been officially adopted by Peru. It further states that for cases not covered by the IAS the United States Accounting Principles (USGAAP) must be followed. Thus, the accounting standards underlying the source data for compilation of GFS follow international standards.

The CRBP website provides users with an e-mail address for consultations or requests for further information. However, there are no systematic arrangements in place to obtain feedback from users.

\subsubsection{Processes are in place to deal with quality considerations, including tradeoffs within quality, and to guide planning for existing and emerging needs}

Formal processes have not been established for assessing the quality of the statistics and the information disseminated. However, continuous efforts are made to ensure the internal consistency of the data and to improve their quality. For example, (a) a database for the ESD is being developed that will help ensure consistency of data across sectors, and (b) the IFSA is being extended to include local governments, which will result in a major improvement in the timeliness of GFS compilation for these governments.

Trade-offs between quality and other considerations are acknowledged and communicated to users. GFS are published according to an advance release calendar known to users, which strikes a balance between timeliness and data coverage. New and emerging data requirements are taken into account. For example, the use of IFSA is going to be extended to include the newly established regional governments. 


\section{Integrity}

\subsection{Professionalism}

\subsubsection{Statistics are compiled on an impartial basis}

The autonomy of the CRBP is enshrined in Article 84 of the Constitution of the Republic and Article 3 of the CRBP Charter, and its obligation to report on the nation's finances is mandated by the legislation discussed in Section 0.1.1. Furthermore, there is a long-standing tradition within the Bank of professional independence on technical matters.

Professionalism is promoted by the publication of methodological and research papers and by organizing meetings of professional groups. The ESD has a publication where articles written by staff are published and encourages the participation of its economists in an annual economists meeting, where papers are presented for debate. Staff attend, on a regular basis, internal and external courses and conferences to keep abreast of the latest methodological and organizational developments. More importantly, professionalism is a key factor in the evaluation and promotion of staff.

\subsubsection{Choices of sources and statistical techniques are informed solely by statistical considerations}

Statisticians are free of political influence in the choice of the most appropriate data sources and methods for compiling the GFS, and changes in the statistical procedures are made solely on the basis of technical criteria. Data sources are selected according to how useful and adequate the information they provide is to compile and disseminate sound GFS. Moreover, the information is automatically processed. Finally, the accounting standards and compilation methodology follow international standards.

\subsubsection{The appropriate statistical entity is entitled to comment on erroneous interpretation and misuse of statistics}

GFS compilers can and do provide expert advice on technical aspects of GFS. Public response to misinterpretation of GFS is permitted, though it is the Bank's policy not to comment. Requests for information or clarification from Congress are handled directly by the President or General Manager. The CRBP seeks to prevent misinterpretation of data by providing an explanation of recent developments in its weekly statistical bulletin and in its annual report. In addition, periodic meetings with the press and other interested parties are held to explain how to read/interpret the statistical tables published by the Bank. 


\subsection{Transparency}

\subsubsection{The terms and conditions under which statistics are collected, processed, and disseminated are available to the public}

The legislation governing the compilation and dissemination of GFS is freely available to the public on the CRBP website, and the Bank's publications reproduce the terms and conditions under which the CRBP produces GFS. The legislation available in the CRBP website includes the CRBP Charter, Statute and the Regulation about Institutional Representation, Confidentiality, and Conflict of Interest. There are no restrictions on public access to GFS.

\subsubsection{Internal governmental access to statistics prior to their release is publicly identified}

No official or public agency outside the CRBP has access to GFS prior to dissemination and the statistics are released simultaneously through the CRBP website according to a published advance release calendar. The Board of Directors authorizes the release of GFS. The procedures followed for authorizing dissemination of GFS are deemed internal arrangements and are not made public.

\subsubsection{Products of statistical agencies/units are clearly identified as such}

All GFS disseminated, whether in publications or through the CRBP website, clearly identify the producing agency and the source of the data.

\subsubsection{Advance notice is given of major changes in methodology, source data, and statistical techniques}

No advance notice of major changes in methodology or other significant changes that materially affect the GFS is given to the public. Changes and explanatory notes are provided when the changes are introduced in publications. Changes which cause a break in the time series are clearly identified and explained when they occur.

\subsection{Ethical standards}

\subsubsection{Guidelines for staff behavior are in place and are well known to the staff}

There are clear ethical standards guiding staff behavior: (a) the Internal Work Regulations, of June 15, 1995; (b) a Code of Ethics, of August 4, 1999; and (c) Regulation about Institutional Representation, Confidentiality, and Conflict of Interest. All staff receive a copy of these documents and their observance is mandatory. Sanctions, including dismissal, are imposed on staff who breach ethical standards.

Article 2 of the Code of Ethics states that CRBP staff must act with honesty, truthfulness, and transparency. These values are deemed key criteria to determine responsibilities in any particular situation. 


\section{Methodological soundness}

\subsection{Concepts and definitions}

2.1.1 The overall structure in terms of concepts and definitions follows internationally accepted standards, guidelines, or good practices

The concepts and definitions used for GFS compilation and dissemination are based on the recommendations of the GFSM 1986.

\section{$2.2 \quad$ Scope}

2.2.1 The scope is broadly consistent with internationally accepted standards, guidelines, or good practices

The structure of Peru's public sector is set out below.

\section{Consolidated central government (CCG), A+B}

A. Central government (CG)

1. Ministries

2. Public institutions

3. Universities

4. Fonavi-Mivivienda

5. Regional governments (CTAR)

B. Rest of central government (RCG)

1. EsSalud

2. Pension standardization office (ONP)

3. Fonahpu-FCR

4. Regulatory agencies

5. Registry offices

6. Public charity entities

\section{Local governments (LG)}

III. General government (GG), I+II

IV. Nonfinancial public enterprises (NFPE)

V. Nonfinancial public sector (NFPS), III+IV

GFS are compiled and disseminated on an annual basis for the central government, rest of the central government, consolidated central government, local governments, general government, nonfinancial public enterprises, and nonfinancial public sector; on a quarterly basis for central government, general government, and nonfinancial public sector; and on a monthly basis only for central government. The institutional scope of the coverage for the various levels of government is in line with the recommendations of the GFSM 1986. For 
purposes of reporting GFS data for publication in the Government Finance Statistics Yearbook (GFSY) statistics for regional governments are presented separately, although these governments have only existed since 2002 according to the CRBP. The so-called regional governments prior to 2002 were not independent from the central government and therefore in the CRBP's view did not satisfy the criteria established in the GFSM 1986 to be considered a separate level of government.

The presentation format for GFS follows closely the Summary Table of Major Components in the GFSM 1986 for all levels of coverage. In addition, for central government there are revenue and expenditure tables that follow the format of tables A (Government Revenue and Grants) and C (Economic Classification of Government Expenditure and Lending minus Repayments). There are no tables for functional classification of government expenditure, financing by type of debt holder, and financing by type of debt instrument (tables B, D and E). The tables on debt are mostly related to total public external debt, which is presented gross and in a variety of breakdowns. The focus of GFS is on the key aggregates used to design and monitor fiscal policy; limited breakdown of aggregates is provided for the various levels of government. Preliminary GFS data are compiled with comprehensive information coverage.

The CRBP publishes GFS in its two major statistical publications: the Weekly Bulletin and the Annual Report. The Weekly Bulletin includes five tables with monthly data on central government operations, and 14 tables with quarterly data on the operations of the central government, general government, and the nonfinancial public sector, as well as five tables on total public debt (of which one provides data for internal debt). The Annual Report includes 11 tables on the operations of the various levels of government for which GFS are compiled and 10 tables on total public external debt. Both publications are available on the CRBP website.

The MEF publishes fiscal statistics in its monthly Fiscal Transparency Bulletin, which is disseminated on its website. The publication includes summary tables on the consolidated public sector, central government, nonfinancial public enterprises, regulatory agencies, and supervisory entities. Several tables on central government revenues and expenditures are presented with a variety of breakdowns (economic, functional, budgetary). Tables on total public external debt are also included. At present, the definition of central government in the statistics differs from the definition in the GFSM 1986; however, it is expected to conform with it in the near future.

The Accountant General Office is mandated by Article 81 of the Constitution to annually prepare the General Account of the Republic, which contains financial and budgetary information for the public sector (2,327 entities). The General Account of the Republic is presented to Congress together with the Audit Report prepared by the Comptroller General Office no later than November 15 of the following year. The General Account contains detailed information on the operations of public sector entities in a nonGFS format. 


\subsection{Classification/sectorization}

\subsubsection{Classification/sectorization systems used are broadly consistent with internationally accepted standards, guidelines, or good practices}

GFS are provided separately for the various levels of government. The classification of revenue and expenditure is mostly in accordance with the recommendations of the GFSM 1986. A minor exception refers to imports of five fertilizers for agriculture that are exempted from paying the customs and value added taxes. These taxes are paid by the importer with documents issued by the MEF, i.e., no cash flows are involved. However, for GFS purposes, the value of the taxes exempted is recorded under revenues as though they were collected, and a transfer is recorded under expenditures. Another minor exception refers to tax refunds, which are recorded as a separate item instead of being netted against the corresponding taxes. No functional classification of government expenditure is regularly compiled and published. However, such a classification has been recently provided for the past three years for publication in the GFSY.

Financing is classified as external or internal, and the inflows from privatization are included under financing but identified separately. There are no classifications of financing by type of debt holder, although there is one by type of instrument, which is published in the Weekly Bulletin and in the GFSY. Detailed external medium and long term debt data are published for the entire public sector with a variety of breakdowns. A table with data on short and long term internal debt is published, but there are no debt tables classified solely by type of debt holder or by type of instrument. Again, the information necessary to compile such classifications is available.

The classification of financing and debt as internal or external is determined by the residence criterion, applied on the basis of location rather than of nationality. Accordingly, financing or domestic debt is the debt contracted on the local market and payable within Peru, while financing or external debt is that contracted abroad and payable abroad in foreign currency.

\section{$2.4 \quad$ Basis for recording}

\subsubsection{Market prices are used to value flows and stocks}

Flows are valued on the basis of the amount of payments in cash. External outstanding public debt is recorded gross at face value and in the original currencies, and converted to U. S. dollars for statistical and publication purposes. The exchange rate used to convert flows is the monthly average of the sell rate and to convert stocks is the sell rate at the end of the corresponding period. External debt disbursements are recorded at the actual amount received. Internal public debt is recorded gross at face value and in the original currency, and converted to dollars in the manner indicated above. 
To reconcile the financing figures in the GFS with the monetary statistics, foreign currency flows are converted to domestic currency at the average sell exchange rate published by the Superintendency of Banks and Insurance Companies (SBIC).

\subsubsection{Recording is done on an accrual basis}

For central government revenue, financing and debt disbursements are presented on a cash basis. Expenditures and debt service are presented on an accrual basis, though information on a cash basis is available. An exception to revenues on a cash basis refers to tax refunds, which are presented on an accrual basis. For the other levels of government all data is on a cash basis.

\subsubsection{Grossing/netting procedures are broadly consistent with internationally accepted standards, guidelines, or good practices}

All transactions are expressed in gross values, except for financing transactions, which are shown in net values.

\section{Accuracy and reliability}

\subsection{Source data}

\subsubsection{Source data are collected from comprehensive data collection programs that take into account country-specific conditions}

The main sources of information for the compilation of GFS on the central government are the administrative systems used to monitor budget execution: the SUNAT for tax revenues, the IFSA for nontax revenues and expenditures, the Treasury for revenues in foreign currency, the Public Credit General Department (PCGD) for external financing and debt, and the National Bank (NB) for internal financing and debt. The main sources of information for the rest of the central government are the corresponding entities; for local governments, the source is the General Account of the Republic, prepared by the Accountant General's Office; and for nonfinancial public enterprises the sources are the enterprises and FONAFE. This information is supplemented and cross-checked with information from other sources.

The above sources of information provide information on the whole range of economic flows and stocks. In addition, information is available to consolidate data at the central government, general government, and nonfinancial public sector level. Moreover, the GFS are normally presented in consolidated form.

3.1.2 Source data reasonably approximate the definitions, scope, classifications, valuation, and time of recording required

The accounting guidelines followed by the public and private sector are in accordance with international accounting standards. The annual budget directives include the classifiers to be 
applied for reporting information on budget execution. The classifiers also include a description and a code for each budgetary item. A FONAFE annual directive includes the classifiers and formats to be used for reporting information by all nonbudgetary public entities. Derivation of GFS categories from the accounting standards and classifiers is possible.

There is no automated mechanism for generating GFS items directly from budgetary items, but compilers know the procedures to be followed for moving from the primary sources to the concepts in the GFSM 1986. The timing of recording and valuation are in conformity with GFS concepts.

The MEF and the Accountant General's Office are mandated to present reports on budget execution to Congress. The institutional coverage of government in the reports differs from the coverage in GFS, and the formats used to present information differ from GFS formats. However, the reports and the GFS all rely on essentially the same sources of information and are in that sense consistent with one another. Limited reconciliation of the data in the reports and the GFS is normally done.

\subsubsection{Source data are timely}

Accounting and administrative records provide comprehensive, up-to-date data on the budgetary and nonbudgetary public sector. The information is available three weeks after the end of the period for information reported indirectly and 30 days for information reported directly by public entities. Preliminary information is available for GFS compilation on local governments four months after the end of the year and definitive information is available 16 months after the end of the year. Thus, information is available for extra budgetary agencies and local governments with sufficient timeliness for GFS compilation.

\subsection{Statistical techniques}

\subsubsection{Data compilation employs sound statistical techniques}

GFS are based on comprehensive information, except for public charity entities and local governments, where information for some of the smaller entities is not available. The missing information for local governments is estimated by using alternative sources, such as transfers from the central government to local governments, which account for the bulk of their resources, and by relying on a study conducted five years ago on the universe of local governments.

\subsubsection{Other statistical procedures (e.g., data adjustments and transformations, and statistical analysis) employ sound statistical techniques}

Generally accepted statistical methods are used to adjust GFS. 


\subsection{Assessment and validation of source data}

3.3.1 Source data-including censuses, sample surveys and administrative records-are routinely assessed, e.g., for coverage, sample error, response error, and nonsampling error; the results of the assessments are monitored and made available to guide planning

There are no substantial problems in the coverage or integrity of statistical compilation. As indicated above, GFS are compiled on the basis of comprehensive information. The main sources of information on the various levels of government are cross-checked with other accounting or administrative records that allow for verification of their accuracy. Similarly, differences are checked between transaction flows and changes in stocks.

Preliminary GFS are compiled using the most up-to-date data that are appropriate for formulating and analyzing fiscal policy. All GFS are preliminary until the last revision is done with final budget execution data, and the pertinent tables are labeled as preliminary or definitive in all CRBP publications. If discrepancies are noted later, corrections are made as applicable.

\section{$3.4 \quad$ Assessment and validation of intermediate data and statistical outputs}

\subsubsection{Main intermediate data are validated against other information where applicable}

The major sub-annual GFS aggregates are not normally reconciled with similar data published elsewhere. The monthly GFS for central government are not reconciled with the monthly data published by the MEF in its Fiscal Transparency Bulletin. However, the 2001 annual GFS data were reconciled last year with the data on the MEF's annual budget report and with the data published by the Accountant General's Office in the General Account of the Republic.

\subsubsection{Statistical discrepancies in intermediate data are assessed and investigated}

Information on revenue, expenditure, financing, and debt is routinely reconciled with the records of various MEF departments and with the bank balances of the CRBP and the National Bank. Significant statistical discrepancies are investigated, and the pertinent series are adjusted or corrected, as needed.

\subsubsection{Statistical discrepancies and other potential indicators of problems in statistical outputs are investigated}

Above and below-the-line information are reconciled on a monthly basis, as well as information on financing and the monetary accounts. Any remaining statistical discrepancy is included under internal financing in the GFS. Discrepancies with the monetary accounts are usually associated with differences in timing of recording or the classifier used. 


\subsection{Revision studies}

\subsubsection{Studies and analyses of revisions are carried out routinely and used to inform statistical processes}

Revisions incorporate all changes resulting from available up-to-date data. The characteristics, reasons, direction, and magnitude of changes in the source data that give rise to revisions are known but not published. Source data reliability is continuously assessed and revisions are periodically assessed to improve the quality of GFS.

\section{Serviceability}

\subsection{Relevance}

\subsubsection{The relevance and practical utility of existing statistics in meeting users' needs are monitored}

The GFS timeframe is aligned with the budget cycle. Budget preparation begins in April, when preliminary GFS data for the previous year becomes available. Monthly and quarterly monitoring of the budget is facilitated by GFS, which are also used to monitor fiscal performance under Peru's program with the IMF. In addition, the data used for the projections and assessment associated with the Macroeconomic Multiannual Budget Framework also rely on GFS. Furthermore, the CRBP has to submit to Congress annually an assessment of the government's performance under the Macroeconomic Framework for the previous year; this assessment also relies on GFS data. The level of detail and timeliness of the GFS enables users to assess the government's fiscal policy. Thus, the statistics are of practical utility to users; however, feedback from nongovernmental users is not sought on a regular basis.

\subsection{Timeliness and periodicity}

\subsubsection{Timeliness follows dissemination standards}

Monthly data on central government operations are published five-six weeks after the end of the reference month, i.e., later than the one month period stipulated by the SDDS. For this reason, Peru has adopted a flexibility option for the timeliness of data on central government operations. ${ }^{3}$

Annual data on general government operations are published two quarters after the end of the reference year, i.e., in accordance with the period stipulated by the SDDS.

\footnotetext{
${ }^{3}$ After the visit of the mission, the CRBP began publishing data with a four-week lag, in accordance with the period stipulated by the SDDS.
} 
Quarterly data on central government debt are published not later than eight weeks after the end of the reference quarter, i.e. earlier than the one quarter period stipulated by the SDDS.

\subsubsection{Periodicity follows dissemination standards}

Data on central government operations are disseminated monthly, quarterly and annually; data on general government operations are disseminated quarterly and annually; and data on central government debt are disseminated quarterly. SDDS requirements on periodicity are met.

\subsection{Consistency}

\subsubsection{Statistics are consistent within the dataset}

The various accounting identities (deficit/surplus $=$ financing, major aggregates $=$ sum of the components, domestic financing is consistent with the change in domestic debt, external financing is consistent with the change in external debt, transfers paid = transfers received) are observed in the GFS. Since a table for functional classification of expenditure is not compiled, the identities between functional and economic classification of expenditure do not apply.

\subsubsection{Statistics are consistent or reconcilable over a reasonable period of time}

Statistics are consistent with expected revenue and expenditure trends and reflect discretionary changes, external shocks, and economic activity. Developments are explained in the CRBP publications. Time series are adjusted to account for methodological changes and coverage, which are also explained in the publications. Breaks in the time series and the reasons for them are clearly identified.

\subsubsection{Statistics are consistent or reconcilable with those obtained through other data sources and/or statistical frameworks}

Both the national accounts and the GFS use the ISFA as a major source of information; quarterly GDP figures compiled from the expenditure side use GFS. The monetary accounts are regularly reconciled with GFS data on financing; however, there are some discrepancies due to differences in recording criteria and timing. Balance of payments and GFS both use the PCGD data as their source for external debt and financing transactions.

\subsection{Revision policy and practice}

\subsubsection{Revisions follow a regular, well-established, and transparent schedule}

The release of revised data follows a well established schedule within the framework of the regular publication schedule, i.e., are released in accordance with the pre-announced 
publication calendar. Monthly data are revised every quarter and quarterly data are revised when the annual figures are published.

\subsubsection{Preliminary data are clearly identified}

Preliminary data are clearly identified in the publications and revised data are disseminated in the same manner as the original data. Preliminary data are coherent with final data and can be used with confidence for policy formulation and analysis.

\subsubsection{Studies and analyses of revisions are made public}

Preliminary data are reliable as they are based on comprehensive information. Differences between preliminary and final data are generally small. Time series and analyses of revisions are not published.

\section{Accessibility}

\subsection{Data accessibility}

5.1.1 Statistics are presented in a way that facilitates proper interpretation and meaningful comparisons (layout and clarity of text, tables, and charts)

The information is presented in a format that facilitates the identification and comparison of major aggregates and balancing items. The emphasis is on policy variables, suitable for use in budget development and monitoring, as well as the formulation of fiscal policies. Monthly data are presented in nominal and real terms; quarterly and annual data are presented in nominal terms and as a percentage of GDP. The coverage provided exceeds the recommendations of the GFSM 1986; however, the level of detail is significantly less than set out in the recommended tables. Monthly data are presented for the past 13 months, quarterly data for the past three years, and annual data for the past 10 years.

\subsubsection{Dissemination media and formats are adequate}

The two main statistical publications of the CRBP have segments dedicated to GFS. Both the Weekly Bulletin and the Annual Report are published in hardcopy and on the CRBP website. In addition, the Annual Report is also available in CD format. Monthly and quarterly GFS are published in the Weekly Bulletin.

\subsubsection{Statistics are released on a preannounced schedule}

Statistics are disseminated according to a pre-announced calendar, published in the Weekly Bulletin and on the CRBP website. The first issue of the Weekly Bulletin includes the release calendar for the whole year and, and the issue 45 days before the end of the year includes the schedule for the first two months of the following year. The actual date of publication meets the pre-announced date. 


\subsubsection{Statistics are made available to all users at the same time}

GFS are released simultaneously to all users.

\subsubsection{Nonpublished (but nonconfidential) subaggregates are made available upon request}

Nonpublished, nonconfidential, disaggregated data are supplied on request. To this end, users are provided with a name and an e-mail address on the CRBP website. However, the availability of nonpublished data is not publicized.

\subsection{Metadata accessibility}

5.2.1 Documentation on concepts, scope, classifications, basis of recording, data sources, and statistical techniques is available, and differences from internationally accepted standards, guidelines, or good practices are annotated

The concepts, sources, and methods are partially documented. Methodological changes from one period to the next are explained in the CRBP publications. The DSBB is the only source of metadata. There have been no requests for bridge tables showing the links between source data and GFS.

\subsubsection{Levels of detail are adapted to the needs of the intended audience}

As indicated above, the only metadata available to users are on the DSBB. A comprehensive methodological guide for all statistics published by the CRBP is under preparation and is expected to be available on the CRBP website by mid-2003.

\subsection{Assistance to users}

\subsubsection{Contact person for each subject field is publicized}

A contact person and an e-mail address is publicized on the CRBP website. The DSBB provides a name, telephone number, fax number, and e-mail address for each SDDS category. Expert service and support on technical matters are provided to users.

5.3.2 Catalogues of publications, documents, and other services, including information on any charges, are widely available

The CRBP has a catalog of its statistical and other publications on its website. A list of other services and applicable charges are also published on the CRBP website. 
Table 4. Peru: Data Quality Assessment Framework—Summary of Results for Government Finance Statistics

(Compiling Agency: Central Reserve Bank of Peru)

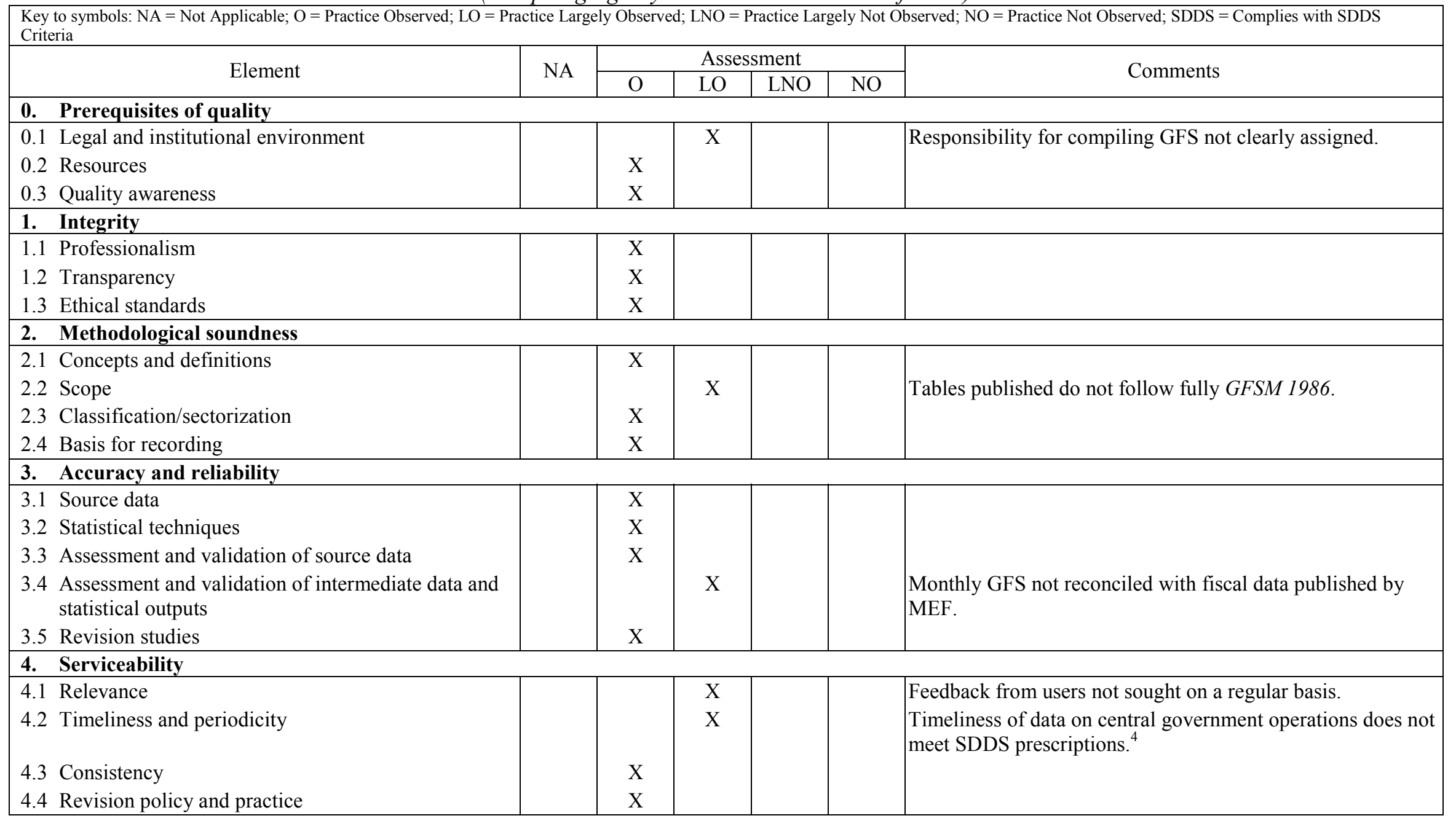

\footnotetext{
${ }^{4}$ After the visit of the mission, the CRBP began publishing data with a four-week lag, in accordance with the period stipulated by the SDDS.
} 
Table 4. Peru: Data Quality Assessment Framework-Summary of Results for Government Finance Statistics (Compiling Agency: Central Reserve Bank of Peru)

\begin{tabular}{|c|c|c|c|c|c|c|}
\hline \multicolumn{7}{|c|}{$\begin{array}{l}\text { Key to symbols: NA = Not Applicable; O = Practice Observed; LO = Practice Largely Observed; LNO = Practice Largely Not Observed; NO = Practice Not Observed; SDDS = Complies with SDDS } \\
\text { Criteria }\end{array}$} \\
\hline \multirow{2}{*}{ Element } & \multirow{2}{*}{ NA } & \multicolumn{4}{|c|}{ Assessment } & \multirow{2}{*}{ Comments } \\
\hline & & $\mathrm{O}$ & LO & LNO & $\mathrm{NO}$ & \\
\hline \multicolumn{7}{|l|}{ 5. Accessibility } \\
\hline 5.1 Data accessibility & & $\mathrm{X}$ & & & & \\
\hline 5.2 Metadata accessibility & & & $\mathrm{X}$ & & & $\begin{array}{l}\text { Concepts, sources and methods partially documented and } \\
\text { only published on the DSBB. }\end{array}$ \\
\hline 5.3 Assistance to users & & $\mathrm{X}$ & & & & \\
\hline
\end{tabular}




\section{Monetary Statistics}

\section{0. $\quad$ Prerequisites of quality}

\section{$0.1 \quad$ Legal and institutional environment}

\subsubsection{The responsibility for collecting, compiling and disseminating statistics is clearly assigned}

The collection, compilation, and dissemination of monetary statistics are governed by the Constitution of Peru of 1993, the Organic Law of the Central Reserve Bank of Peru (CRBP) (Decree Law No.26123, published in the Official Gazette on December 30, 1992), and the Bylaw ("Estatuto") of the CRBP of February 27, 1994.

Article 84 of the Constitution of Peru establishes that "the CRBP report, exact and periodically, on the nation's financial situation." The Organic Law of the CRBP considers this constitutional principle and provides the legal authority and responsibility for compiling and disseminating monetary statistics in Articles 2, 73, and 74. Article 73 establishes that the CRBP "exclusively formulate the balance of payments and the monetary accounts." Articles 2 and 74 state that the CRBP periodically report on the nation's finances and publish the main macroeconomic statistics.

Article 97 of the Bylaw indicates that the function of reporting on nation's finances is accomplished through the publications released on a periodic or eventual basis. One of these publications is the Weekly Bulletin of Peruvian macroeconomic statistics published by the CRBP.

The Economic Studies Department (ESD) of the CRBP is responsible for the collection, compilation, and dissemination of monetary and financial statistics. The sectoral balance sheets and additional information on financial institutions are collected and compiled by the Monetary Sector Division (MSD) of the ESD.

\subsubsection{Data sharing and coordination among data producing agencies are adequate}

Collection, compilation, and dissemination of monetary statistics fall under the responsibility of the CRBP. Arrangements are in place to ensure the efficient and timely flow of information among the following departments of the CRBP: the Accounting and Supervision Department (ASD), the ESD, the Credit and Financial Regulation Department (CFRD), and the International Operations Department (IOD). However, there is no centralized database. Data are shared among departments through magnetic media (mainly text files) or printed tables.

Occasional contacts are maintained with the Superintendency of Banks and Insurance Companies (SBIC) to ensure proper understanding of data requirements. Financial institutions provide information to both agencies (CRBP and SBIC) for statistical and 
supervisory purposes. Moreover, Article 97 of the Organic Law of the CRBP provides the legal authority to collect data directly from the SBIC, since the Supervisory Agency "shall provide the CRBP with all general and specific information that the latter may deem necessary for the accomplishment of its functions." However, the CRBP does not regularly require information from the SBIC. In 2000, the CRBP participated in the definition of data reporting forms following the new SBIC's "Accounting Manual for the Financial System Institutions."

The coordination between the CRBP and the SBIC could be enhanced to avoid duplication of effort in the validation of balance sheet data and to collaborate on future improvements to the plan of accounts for commercial banks.

\subsubsection{Respondents'data are to be kept confidential and used for statistical purposes only}

The confidentiality of data that financial corporations provide to the CRBP is primarily guaranteed by Article 41 of its Organic Law and Article 50 of the Bylaw of the CRBP. Article 41 of the Organic Law establishes that no person at the Bank's service shall disclose to others any confidential information pertaining to or managed by the Bank and that the offenders shall be liable to removal from office, in the case of managers, or dismissal, in the case of other Bank employees. In addition, Article 50 of the Bylaw states that this prohibition continues to be binding two years after the staff member leaves the CRBP.

The Regulation on Institutional Representation, Confidentiality, and Conflict of Interest, approved by the CRBP Board of Directors on December 26, 2002, defines confidential information. Furthermore, staff members are subject to provisions about the confidentiality of data as well as the abstention from using it for private purposes in accordance with the Code of Ethics of the CRBP, approved by the Board of Directors on August 4, 1999.

In addition, the legal framework for the National Statistical System includes provisions with regard to confidentiality of respondents' data. Article 7 of the Law of Organization and Functions of the National Institute of Statistics and Informatics (NISI) states that the CRBP is part of the National Statistical System governed by the NISI, due to its nature of autonomous entity governed by public law (Legislative Decree No.604, published in the Official Gazette on May 5, 1990). Furthermore, Article 97 of the Regulation on the Organization and Functions of the NISI (Supreme Decree No.043-2001-PCM, published in the Official Gazette on April 25, 2001) sets out the norms concerning the compilation of data, and stipulates that "the information provided to the Peruvian statistical system is confidential and cannot be disclosed individually, even by means of an administrative or judicial order."

Only authorized staff members of the MSD and the CFRD have access to data for individual financial institutions before they are aggregated and consolidated for publication. The CRBP has procedures to prevent the dissemination of confidential data. Moreover, access to individual financial corporations data is restricted to authorized CRBP personnel using access passwords. 


\subsubsection{Statistical reporting is supported by legal mandate and/or measures implemented to encourage voluntary response}

Article 74 of the CRBP Organic Law provides the legal basis for the collection of statistical information that supports the compilation of monetary statistics. According to this Article, the CRBP is empowered to fine financial corporations in case of noncompliance or for submitting incomplete or inaccurate information. The detailed legal provisions underpinning the obligation of financial corporations to report to the CRBP are contained in Circular No.04-2002-EF/90. In practice, these penalties have not been enforced, since the level of compliance by financial corporations is generally acceptable and it has not been necessary to impose sanctions for failure to provide information.

The CRBP provides appropriate support concerning the preparation and presentation of the forms used by financial corporations to submit information. There is an appointed CRBP officer to assist the financial corporations with all aspects relating to data reporting.

The CRBP fosters collaboration of respondents by trying to build an atmosphere of good faith. For this purpose, the CRBP has tried to convey to financial corporations the importance of the data they provide through constant communication and in meetings at the CRBP.

The CRBP also reaches voluntary agreements with financial corporations in order to gather information (through surveys) on short-term issues related to developments in the principal macro-financial variables. The CRBP informs respondents in advance on the nature of the data to be collected and the purpose of the survey. The statistical findings are shared with respondents.

\section{$0.2 \quad$ Resources}

\subsubsection{Staff, financial and computing resources are commensurate with institutional programs}

Monetary statistics are compiled by two sections of the MSD: the Banking Financial Intermediation Section and the NonBanking Financial Intermediation Section. The combined staff of these sections consist of 15 economists. Each economist has a personal computer and access to Internet. The human resources directly involved in collecting, validating, and preparing financial and monetary statistics are sufficient.

The staff engaged in the production of monetary statistics have a solid academic education (with at least a degree in accounting or economics, some with postgraduate studies) as well as general and specific training provided by the CRBP. Economists have an average of 10 years of experience. Most of them have attended relevant courses at the IMF, the Center for Latin American Monetary Studies (CEMLA), as well as training courses at various financial institutions, such as the Federal Reserve Bank of New York, the Deutsch Bundesbank, the Bank of England, and the Schweizerischen Nationalbank. Staff rotation is pursued actively. Final validation of data for the depository corporation survey is done by the section 
managers, who are also responsible for authorizing the incorporation of data in the database and for assessing the consistency of data over time.

The CRBP strives to update systems and programs for compiling and analyzing monetary statistics. Electronic media is used for the collection of source data and the compilation and dissemination of the monetary statistics. The compilation of the monetary survey has been performed in different software environments, which are currently been replaced by new programs designed in FAME (a time series database software).

The MSD enjoys the support of the Systems Management Department (SMD) in preparing monetary statistics. This department allocates resources in accordance with the priorities agreed upon as part of an annual program. These areas are adequately funded and requests for additional resources are generally accepted by the Board of Directors and other internal committees in the CRBP.

\subsubsection{Measures to ensure efficient use of resources are implemented}

The ESD holds meetings with the staff on issues that need to be addressed for enhancing the policy vision of the managers and the understanding of the professional staff. In general, all programs in the CRBP are subject to budget considerations and performance assessments. Article 84 of the Bylaw of the CRBP requires that its budget be prepared by the Especial Committee for approval by the Board of Directors. The performance of the budget is supervised by the Especial Committee on a quarterly basis (Article 89 of the Bylaw). The ASD measures on a monthly basis the cost-effectiveness in using resources to conduct the work undertaken by each unit. Reviews are also conducted regularly by the Administration Department to improve the work within each unit. New technology for data processing and dissemination is always tested by computer and system analysis experts.

Although no cost is imputed to the generation of monetary statistics, over the years the CRBP has been able to streamline the structure and resources engaged in these activities. This progress has been achieved largely due to the use of the latest technology for the compilation of statistics.

\subsection{Quality awareness}

\subsubsection{Procedures have been put in place for quality awareness}

Even though the CRBP does not have a formal mission statement for its statistical work, managers and staff recognize that official statistics must have the confidence of their users and exercises quality controls at every stage of data production and dissemination. The MSD verifies that data reporting practices followed by financial corporations are consistent with the regulations, and has systems and procedures in place to ensure quality in the compilation process. All levels of the staff compiling monetary statistics participate actively in the review of data prior to publication. The MSD consults with the reporting institutions to verify the data for possible misclassifications. 
Source data submitted by the reporting institutions to the MSD are crosschecked for accuracy and any discrepancy is investigated. Validation procedures for assessing the plausibility of reported data are undertaken both automatically and visually, on a bank-by-bank basis.

The CRBP's financial statements and management practices have been externally audited since 2000 .

\subsubsection{Procedures have been established for monitoring the quality of data collection, compilation, and dissemination}

Assessments on the quality of monetary statistics and their conformity with international standards are not conducted on a regular basis. There is no body or committee outside the MSD that provides guidance on the quality of monetary statistics or on strategies for improving data production. Nevertheless, the ESD makes efforts to ensure that international statistical standards are observed.

The quality of the collection, processing, and monitoring of statistics is monitored through crosschecks; reporting institutions receive feedback and guidance from the staff of the MSD.

\subsubsection{Procedures are in place to assess the quality of statistics, to acknowledge and deal with tradeoffs within quality, and to guide planning for existing and emerging needs}

There is a wide recognition of the tradeoffs among the dimensions of data quality. Timeliness is regarded as one of the most important elements of data quality. The production of monetary statistics is fully automated and includes a series of checks and validations at every stage of the production cycle. However, there is not a work program aimed at improving the methodological soundness of monetary statistics following MFSM guidelines.

Meetings are held periodically with policy makers and other data users to identify any emerging data requirements. The CRBP also invites user comments on the relevance and usefulness of the monetary statistics via its website.

\section{Integrity}

\subsection{Professionalism}

\subsubsection{Statistics are compiled on an impartial basis}

The statutory provisions under which the CRBP compiles monetary statistics are adequate to support its independence in conducting these functions. In this regard, the Constitution of the Republic and the Organic Law of the CRBP provide a legal framework that ensures the autonomy of the CRBP. Article 84 of the Constitution establishes that the CRBP has autonomy within the framework of its Organic Law. Several articles of the Organic Law of the CRBP stipulate that the CRBP shall enjoy autonomy in exercising the powers and in 
accomplishing the duties granted by the Law under its responsibility. Article 1 states that the CRBP "is a legal entity governed by public law, with autonomy within the framework of this Law." Article 3 indicates that "in exercising its autonomy and in observance of its purpose and functions, the Bank is exclusively governed by this Law and its Bylaws." Moreover, Article 11 establishes that the members of the Board of Directors - the highest institutional authority of the CRBP- "do not represent any entity or particular interest and their votes must only take into account the accomplishment of the Bank's purpose and functions."

Article 73 of its Organic Law states that the CRBP "exclusively formulate the balance of payments and the monetary accounts." In that sense, the choice of methodology for monetary statistics is the sole responsibility of the staff.

Professional competency plays a key role in recruitment and promotion policies. Professionalism of the staff in charge of the compilation of monetary statistics is promoted by the publication of methodological papers and by organizing meetings with professional groups. The CRBP encourages participation of professional staff in its Annual Economists Meetings, where papers are presented to debate. The CRBP promotes staff participation in internal and external courses, conferences, and meetings with other professional compilers. Staff performance is evaluated every six months.

\subsubsection{Choices of sources and statistical methods are informed solely by statistical considerations}

The compilation of monetary statistics is based on the sectoral balance sheets of the reporting financial corporations. The sources selected for the compilation of monetary statistics are those that meet the statistical requirements of the ESD.

\subsubsection{The appropriate statistical entity is entitled to comment on errors of interpretation and misuse of statistics}

The ESD does not comment publicly on erroneous interpretations or misuse of the monetary statistics in the media or other fora. Nevertheless, the ESD does monitor major media coverage of the CRBP and financial sector activities to detect any inappropriate interpretation of information. In those cases, staff prepare internal reports to the Board of Directors or the General Manager, explaining the technical reasons why data have been misinterpreted. Furthermore, whenever the Board of Directors or the General Manager are consulted on monetary statistics by the Congress or government officials, CRBP staff prepare reports to clarify doubts. The CRBP seeks to prevent misinterpretation or misuse of monetary statistics by providing explanatory notes in its publications. 


\subsection{Transparency}

1.2.1 The terms and conditions under which statistics are collected, compiled, and disseminated are available to the public

The CRBP Organic Law and Bylaw, which are available on its website, contain the terms and conditions under which statistics are collected, processed, and disseminated. The CRBP Organic Law is available in Spanish and English, while the Bylaw of the CRBP is available in Spanish only.

\subsubsection{Internal governmental access to statistics prior to their release is made known to the public}

No government agency outside the CRBP has access to monetary statistics prior to their release on the CRBP website. Weekly monetary statistics are compiled every Thursday, submitted to the Board of Directors for approval, and published on Fridays in the Weekly Bulletin.

\subsubsection{Products of statistical agencies/units are clearly identified as such}

All published monetary information bears the CRBP logo and captions specifying the source of the data and the corresponding section or division of the CRBP that elaborates the tables and charts published in the Weekly Bulletin.

The CRBP does not explicitly request acknowledgement of the source when its monetary statistics are reproduced or used by third parties, since it is common practice to identify data sources.

\subsubsection{Advance notice is given of major changes in methodology, source data and statistical techniques}

Methodological changes are announced when the new statistics are published. They are accompanied by a note explaining the changes in methodology and the appropriate link with the historical data.

\subsection{Ethical standards}

\subsubsection{Guidelines for staff behavior are made known to staff}

There are clear guidelines outlining correct behavior when the staff are confronted with potential conflict of interest situations. A code of conduct for staff members can be found in the Organic Law of the CRBP, the Code of Ethics, the Labor Regulations of the CRBP, and the Internal Regulation about Institutional Representation, Confidentiality, and Conflict of Interest that the CRBP provides to the staff. 
Management acknowledges its status as role model and is vigilant in following the guidelines. New staff are made aware of the guidelines when joining the organization. The staff are well aware of the norms and regulations of the institution, and are periodically reminded of the guidelines.

\section{Methodological soundness}

\subsection{Concepts and definitions}

\subsubsection{The overall structure in terms of concepts and definitions follows internationally accepted standards, guidelines, or good practices}

The concepts and definitions for monetary statistics generally follow the MFSM in terms of the concept of residency, valuation of financial assets at market prices (except for CRBP data), accrual-basis accounting, and presentation of assets and liabilities in gross terms.

The analytical framework of the depository corporations survey focuses on explaining the factors affecting the creation of money, by means of an institutional sectorization.

Furthermore, the accounting criteria for purposes of expressing in domestic currency values of assets and liabilities in foreign exchange and securities indexed to the exchange rate is consistent with the MFSM.

The depository corporations survey is compiled and presented as stock data in millions of nuevos soles, showing: (1) monetary aggregates (monetary liabilities of the banking system in domestic and foreign currencies); (2) gross and net credit to the public sector, broken down in central government and rest of the public sector; (3) credit to the private sector, which includes nonbank financial institutions; (4) external accounts, broken down by type of instrument and maturities for derivation of international reserves of the CRBP, other foreign assets, and short-and long-term foreign liabilities; and (5) other liabilities/assets, net.

The central bank survey, which is based on the CRBP balance sheet, includes: (1) monetary base and reserves in foreign currency; (2) net credit to the public sector, including net credit to non financial public sector, Banco de la Nación, Development Financial Corporation (COFIDE), and certificates of deposits of the CRBP held by public sector entities; (3) claims on other financial institutions; and (4) foreign assets and foreign liabilities.

\subsection{Scope}

\subsubsection{The scope is broadly consistent with internationally accepted standards, guidelines, or good practices}

The financial corporations sector in Peru identifies two main subsectors: banking and nonbanking. Due to this classification, some depository corporations that are not banks are included along with other financial intermediaries into the nonbaking sector. 
The banking sector comprises the CRBP, 15 commercial banks, a state-bank (Banco de la Nación), and a development bank ("Banco Agropecuario"). The nonbanking financial institutions and the commercial banks' offshore branches are not included in the banking sector.

The nonbanking sector includes the depository corporations not included in the banking sector (12 municipal credit and saving banks, the Caja Municipal de Crédito Popular, nine development institutions for the small and medium enterprises -EDPYMES, 170 credit and saving cooperatives, 13 rural credit and saving banks, four finance companies, 28 mutual funds, and other financial intermediaries (12 insurance corporations, four private pension funds, six financial leasing companies, and the state-owned COFIDE). Currently, the banking sector is predominant in the Peruvian financial sector, since about 85 percent of broad money is created by banks.

The depository corporations survey does not cover the range of institutions recommended in the MFSM. However, the coverage of the financial survey is comprehensive, and provides analytical aggregates that better reflect the volume of domestic financial activities. The CRBP is considering the possibility of widening the scope of the depository corporations survey by including depository corporations that are currently covered in the financial survey only.

\subsection{Classification/sectorization}

\subsubsection{Classification/sectorization systems used are broadly consistent with internationally accepted standards, guidelines, or good practices}

The CRBP uses the residency criterion to distinguish between residents and nonresidents accounts for the compilation of monetary statistics. The delineation between resident and nonresident institutional units is broadly consistent with the criterion in the IMF's Balance of Payments Manual, fifth edition (BPM5), the 1993 System of National Accounts (1993 SNA), and the MFSM.

The sectorization of the domestic economy is partially in line with the MFSM recommendations. In the monetary statistics compiled by the CRBP, the following sectoral groupings of resident institutional units are distinguished: (i) central government, (ii) local government, (iii) nonfinancial public institutions, (iv) central bank, (v) commercial banks, (vi) state banks, (vii) development banks, (viii) other nonbanking financial institutions, and (ix) nonfinancial private sector. The nonfinancial private sector, in turn, includes the following subsectors: (i) nonfinancial corporations, (ii) households, and (iii) nonprofit institutions serving households.

In the case of the depository corporations survey, the nonbanking sector is included in the private sector, i.e. the private sector combine financial and nonfinancial institutional units, which is not in line with the MFSM. Nevertheless, data on nonbanking and nonfinancial 
private sectors are available to allow presentation of a depositary corporations survey consistent with the recommendations of the MFSM.

The principles underlying the classification of financial instruments in the monetary statistics are broadly consistent with the MFSM recommendations. Assets and liabilities are classified according to the institutional sector of the counterparts. This classification distinguishes the following broad categories: (i) monetary gold and SDRs, (ii) currency and deposits, (iii) securities other than shares, (iv) loans, (v) shares and other equity, (vi) other accounts receivable/payable, and (vii) nonfinancial assets. Due to their relative small size, data on financial derivatives and insurance technical reserves are identified but not fully sectorized.

\section{$2.4 \quad$ Basis for recording}

\subsubsection{Market prices are used to value flows and stocks}

The general recommendation in the MFSM is that the valuation of financial assets and liabilities be done on the basis of market prices or market-price equivalents (fair values). The valuation of loans is an exception to this principle. However, in the sectoral balance sheets for the depository corporations, assets and liabilities are not always valued at market prices or market-price equivalents.

Financial corporations record securities in line with the following procedures: (1) securities held to maturity are recorded at face value and are provisioned only if the credit capacity of the issuer decreases; (2) capital and debt securities held for trading are valued at market prices; and (3) capital and debt securities held for sale are valued at the lowest of face value or market value. In the case of the CRBP, securities are valued at purchase prices. However, if the purchase price is higher than the market value, the lowest (market value) is chosen. The MSD neither estimates fair values for those securities not valued at market prices, nor requests this information to the reporting financial institutions. The same situation applies to shares and other equity.

Consistent with the recommendations of the MFSM, the loan portfolio and deposits on the balance sheets of the banks are valued at book value, and loan valuation is not adjusted for expected loan losses. Provisions for expected loan losses are recorded as separate entries on the liability side of the balance sheet.

According to the MFSM, all stocks and flows denominated in foreign currency should be converted to domestic currency values at the market exchange rate prevailing at the point in time to which the balance sheet applies. The MSD uses the midpoint between the buying and the selling exchange rate of the interbank exchange market calculated by the SBIC.

The MFSM recommends that data be compiled on stocks and on each of the three flows components: transactions, revaluations, and other changes in the volume of assets. In the case of Peru, banks do not provide financial information on flows, and the CRBP does not derive transactions from stock data. 


\subsubsection{Recording is done on an accrual basis}

The accrual accounting principle recommended in the MFSM establishes that interest due but not paid on financial instruments be incorporated into the outstanding amount of the financial asset/liability, rather than being treated as part of other accounts receivable/payable. Even though the balance sheets of depository corporations provide for the allocation of accrued interest into the outstanding amount of the financial asset/liability of origin, the depositary corporations survey records accrued interest in other accounts receivable/payable.

\subsubsection{Grossing/netting procedures are broadly consistent with internationally accepted standards, guidelines, or good practices}

In line with the general principle of the MFSM, assets and liabilities of the financial corporations are collected and compiled on a gross basis. In addition, claims on particular transactors are not netted against liabilities to those transactors. However, for purposes of presentation in the depository corporations survey, they are netted out for all sectors except for the private sector.

\section{Accuracy and reliability}

\subsection{Source data}

\subsubsection{Source data are collected from comprehensive data collection programs that take into account country-specific conditions}

The source data for compiling the central bank survey are the accounting records (balance sheets) of the CRBP prepared by the ASD on a daily basis. These reports are generated by an electronic general ledger system based on complete reporting.

The source data for the other depository corporations survey are the "Forma E" Report and the Sectoral Report. These reports are transmitted to the MSD both as an electronic text-file and as a printed copy. The "Forma E" Report is prepared on a weekly basis and comprises the following statements and appendix: a balance sheet, a profits and losses account (only on a monthly basis), and an appendix of the main financial instruments (accounts) sectorized by economic sectors. The Sectoral Report is submitted on a monthly basis and contains complete information of the balance sheet sectorized by financial instruments and economic sectors. The preliminary monetary statistics are based on the "Forma E" Report, while definite data are compiled using the Sectoral Report. The local branches of financial corporations send information to their headquarters, which prepare the consolidated statements and submit them to the MSD. 
The financial press is monitored for information on developments in financial markets that may be of relevance for the compilation of monetary statistics. In this context, reports may be prepared by the staff based on information on financial instruments and markets.

\subsubsection{Source data reasonably approximate the definitions, scope, classifications, valuation and time of recording required}

There are ongoing efforts at the CRBP to use source data that reasonably approximate the definitions, scope, classifications, time of recording, and valuation required to compile sound monetary statistics. The structure of the balance sheet of the CRBP facilitates the adoption of the sectorization system recommended by the MFSM.

Transactions of other depository corporations with counterparties that cannot be reasonably approximated or allocated to specific instruments or sectors are recorded in "other assets" and "other liabilities".

Although the "Forma E" Report and the Sectoral Report are the principal source of data for the financial corporations, the CRBP is aware of possible discrepancies with secondary sources of data, such as financial market data and data reported from the bank's counterparties. The CRBP continuously strives to identify the differences and reconcile the data obtained from different sources. For instance, some adjustments to the primary source data are performed using nonfinancial public sector information and the appendix of banks' investment in securities (Appendix 1 of the "Forma A" required by the SBIC on a monthly basis).

\subsubsection{Source data are timely}

The data collection system allows timely compilation of monetary statistics, which are released in the Weekly Bulletin. The MSD collects the sectoral balance sheets for the CRBP on a daily basis by e-mail, and for the remaining depository corporations on a weekly basis. The other depository corporations are required to send their weekly "Forma E" Report to the CRBP within the first eight business days following the end of the reference week. In addition, the Sectoral Report must be sent within the first thirty calendar days following the balance sheet cut-off date.

The CRBP monitors reception on the data and is constantly in touch with respondents to ensure that they meet the deadline. This has contributed to an increasing response rate of the financial corporations.

\subsection{Statistical techniques}

\subsubsection{Data compilation employs sound statistical techniques}

Reporting forms are easy to complete for the respondents (using MS Excel spreadsheets), and they include several checks within the tables. New reporting forms are always pilot-tested 
with several respondents prior to their implementation. The statistical techniques used to compile monetary statistics are automated. To avoid errors in processing source data, computerized files that incorporate designed programs (i.e., macros) are used. Procedures for data management are documented.

\subsubsection{Other statistical procedures (e.g., data adjustments and transformations and statistical analysis) are also based on sound statistical techniques}

In case of late returns from financial corporations, which rarely occurs, the latest reported data are carried forward to compile preliminary monetary statistics, until a new return has been officially received and processed. Adjustments for missing data are documented. The CRBP calculates and disseminates seasonally adjusted series of currency in circulation and monetary base.

\subsection{Assessment and validation of source data}

3.3.1 Source data-including censuses, sample surveys and administrative records-are routinely assessed, e.g., for coverage, sample error, response error and nonsampling error; the results of the assessments are monitored and made available to guide planning

The process for assessing and validating source data is automated. In the case of the CRBP balance sheet, data are based on detailed accounting records and a variety of comparison and revision tools are used to ensure that errors are minimal.

Submitted data of other depository corporations are subject to automated control checks through the application of validation techniques and accounting consistency verification. For instance, each financial corporation has a validation program based on accounting consistency tools provided by the MSD, to ensure the quality of the data delivered to the CRBP.

Source data are scrutinized for omissions or reporting errors. When the figures reported by the financial corporations indicate major shifts, the information is crosschecked with secondary data sources.

The CRBP and other depository corporations are in constant contact, which allows investigation of doubts about the figures directly with the reporting corporation. They are asked to provide explanations and, when needed, to resubmit reports with corrections.

\subsection{Assessment and validation of intermediate and final output data}

\subsubsection{Main intermediate results are validated against other information where applicable}

If deemed necessary, the accuracy of the sectoral balance sheets submitted by other depository corporations is checked against secondary data sources, such as the statistical 
information published by the SBIC. In general, queries concerning monetary statistics are resolved directly with banks by phone or e-mail.

Validation procedures for assessing the plausibility or reasonableness of compiled data are undertaken both automatically and visually, on a bank-by-bank basis. A main tool for this purpose is the analysis of variations in the accounts.

\subsubsection{Statistical discrepancies in the intermediate data are assessed and investigated}

Whenever statistical discrepancies are detected in the intermediate data, the staff investigates their nature and origin.

\subsubsection{Statistical discrepancies and other indicators of potential problems with other output data are investigated}

When significant fluctuations are observed, the staff investigates directly with the reporting financial corporations and cross-check information with other institutions and sources.

\subsection{Studies of revisions}

\subsubsection{Studies and analyses of revisions are carried out routinely and used to improve statistical processes}

The MSD routinely analyzes and compares preliminary and final data. The findings are documented and reported to the manager of the MSD. When necessary, the financial corporations are asked to report revisions of their preliminary data. The CRBP and the reporting institutions communicate regularly with one another in order to pinpoint discrepancies between the data. The findings of those investigations are taken into account in the compilation of data for subsequent periods.

\section{Serviceability}

\subsection{Relevance}

\subsubsection{The relevance and practical utility of the statistics in meeting users' needs are monitored}

There is no formally established procedure of consultation with policy departments within the CRBP, ministries, or representatives from the private sector or academia. Nonetheless, the MSD conducts informal, periodic reviews with users through e-mail, telephone, and facsimile. The staff of the MSD regularly participates in international statistical meetings and seminars organized by international and regional organizations. 


\subsection{Timeliness and periodicity}

\subsubsection{Timeliness follows dissemination standards}

The central bank survey is disseminated one week after the end of the reference week. The depository corporations survey is disseminated within three to four weeks after the end of the reference week. Preliminary data becomes final and are disseminated within three to four months after the end of the reference month. This practice is consistent with the specifications of the SDDS.

\subsubsection{Periodicity follows dissemination standards}

The central bank and depository corporations surveys are disseminated on a weekly basis, exceeding the specifications of the SDDS.

\subsection{Consistency}

\subsubsection{Statistics are internally consistent within the dataset (e.g., accounting identities are observed)}

The CRBP and other depository corporations records of claims on, and liabilities to, each other show discrepancies because of differences in the time of recording of financial transactions. However, discrepancies are not significant. The reconciliation of stock and flow data is not possible because flow data are not compiled for monetary statistics.

\subsubsection{Statistics are consistent or reconcilable over a reasonable period of time}

The CRBP and the other depository corporations surveys are consistent over time. Time series are available in electronic format on the CRBP website, on a weekly, monthly, and annual basis. Main breaks and discontinuities in time series are explained in detail in attached notes/footnotes. Unusual changes in economic trends are explained by the ESD in the Weekly Bulletin.

\subsubsection{Statistics are consistent or reconcilable with those obtained from other data sources or statistical frameworks}

The monetary statistics are reconcilable with balance of payments and government finance statistics. The transactions and sectorization of foreign assets found in the monetary statistics are compatible with those of the balance of payments. Consistency checks and reconciliation between government finance statistics and monetary statistics are conducted on a monthly basis, prior to the dissemination of the depository corporations survey of the last week of every month. 


\subsection{Revision policy and practice}

\subsubsection{Revisions follow a regular, well-established and transparent schedule}

Data revisions are conducted following internal procedures and disseminated regularly within three to four months after the end of the reference month. Under this arrangement, published figures remain preliminary for approximately four months, after which they become final. The contents of the statistics are reviewed on a continuous basis and any change that arises is immediately incorporated into the database. Users are notified of the changes by means of footnotes.

\subsubsection{Preliminary data are clearly identified}

Preliminary data are clearly identified by means of footnotes in the publications. Revised data are published with the same level of detail as the previous data.

\subsubsection{Studies and analyses of revisions are made public (see section 3.5.1)}

Routine consistency analyses are carried out between preliminary and final data. These analyses are not made public because revisions are generally not important. Significant revisions are notified by means of footnotes in the statistical publications.

\section{Accessibility}

\subsection{Data accessibility}

5.1.1 Statistics are presented in a way that facilitates proper interpretation and meaningful comparison (layout and clarity of text, tables and charts)

The presentation of monetary statistics facilitates the interpretation of the data and allows monitoring of monetary and financial developments. The Weekly Bulletin contains tables presenting data in a clear and user friendly layout.

\subsubsection{Dissemination media and formats are adequate}

The media and formats used in the dissemination of data are adequate, particularly for users who have Internet access, as both new data and historical time series can be accessed on the CRBP website. The monetary statistics are available on a daily, monthly, and annual basis, and can be downloaded from the CRBP website in a MS Excel file. The CRBP also publishes the information through press releases. 


\subsubsection{Statistics are released on a pre-announced schedule}

Statistics are released on a pre-announced schedule, which is available on the Weekly Bulletin and also on the CRBP website.

\subsubsection{Statistics are made available to all users at the same time}

Weekly data are released simultaneously to all interested users on the CRBP website every Friday, following approval by the CRBP Board of Directors, and in hardcopy the following Monday.

\subsubsection{Nonpublished (but nonconfidential) subaggregates are made available upon request}

Upon request, the CRBP provides free of charge unpublished and nonconfidential data. However, the availability and the terms and conditions of this service are not made public.

\subsection{Metadata accessibility}

5.2.1 Documentation on concepts, scope, classifications, basis of recording, data sources and statistical techniques is available, and differences from internationally accepted standards, guidelines, or good practices are noted

Metadata for monetary statistics, including the concepts, classifications, data sources, characteristics, and definitions are available on the DSBB. These metadata are updated periodically, although the information provided is limited. In addition, information on the methodology of monetary statistics is given by the publication "Como Leer la Nota Semanal" (How to Read the Weekly Bulletin). This guide, which is published in Spanish, is issued on an occasional basis and is available at the CRBP's Library (Information and Documentation Center).

\subsubsection{The degree of detail is adapted to the needs of users, to ensure their satisfaction}

In addition to the publication "Como Leer la Nota Semanal," which provides summarized information on how to interpret the tables published in the Weekly Bulletin, there is a more comprehensive sources and methods document to inform analysts and other users of monetary statistics about how the data are produced. However, this document has not been updated since 1983. 


\subsection{Assistance to users}

\subsubsection{Contact person for each subject field is publicized}

Prompt and knowledgeable service and support is provided to users of statistics. The phone numbers and e-mail addresses of the CRBP contact persons can be found on the "Contact Us" section of CRBP website.

\subsubsection{Catalogues of publications, documents and other services, including information on their cost, are easily obtainable}

The CRBP has a catalogue of publications listing all available titles on monetary statistics, macroeconomic issues, and research papers. This information, which includes the advance release calendar, can be accessed on the CRBP website. All CRBP publications are free of charge for educational institutions. For private use, subscription to copies of each publication is available. 
Table 5. Peru: Data Quality Assessment Framework-Summary of Results for Monetary Statistics

(Compiling Agency: Banco Central de Reserva del Peru)

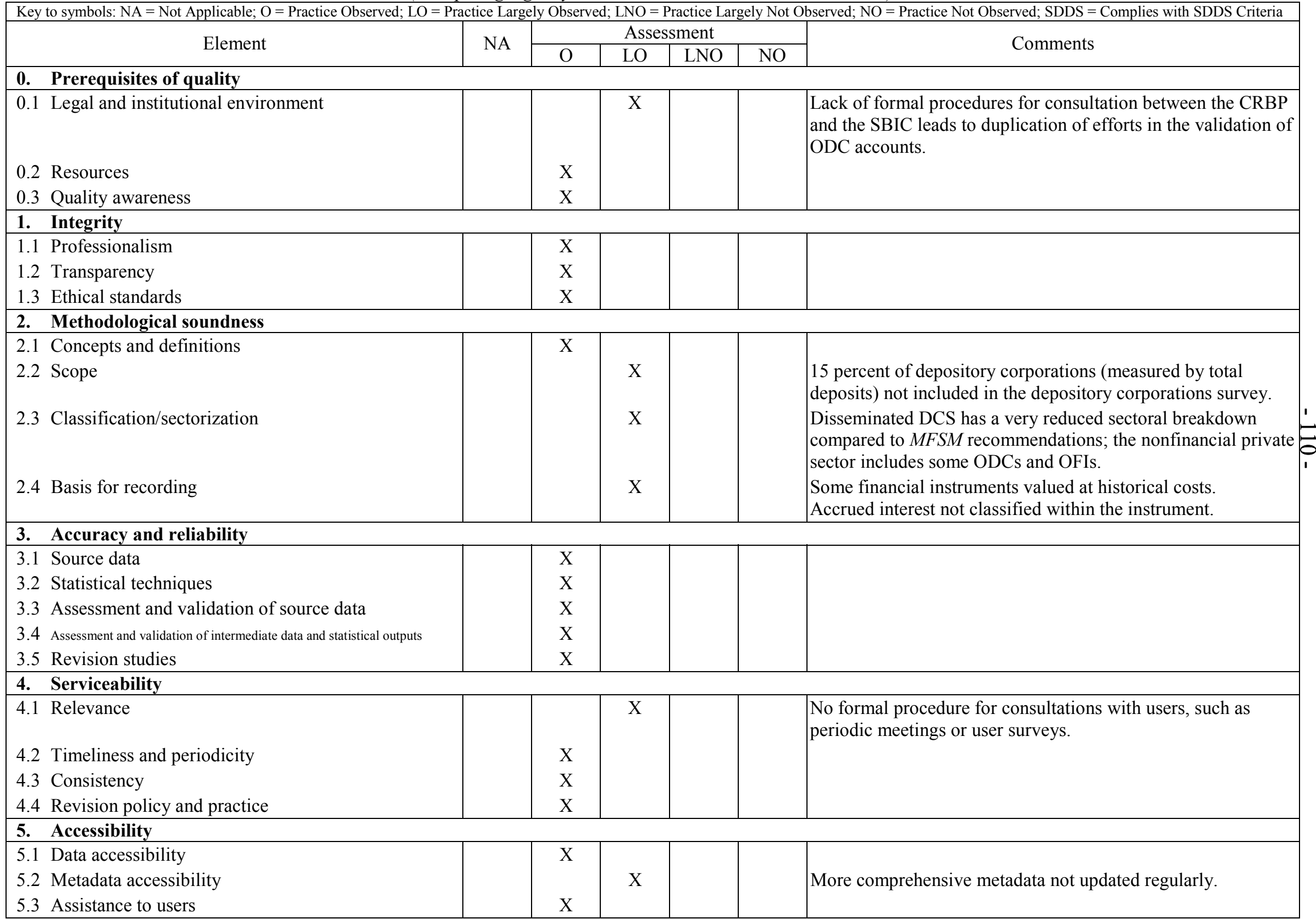

CInternational Monetary Fund. Not for Redistribution 


\section{Balance of Payments Statistics6 ${ }^{5}$}

\section{Prerequisites of quality}

\subsection{Legal and institutional environment}

\subsubsection{The responsibility for collecting, processing, and disseminating statistics is clearly specified}

Article $84^{\circ}$ of the Constitution of the Republic states that the Central Reserve Bank of Peru (CRBP) has the responsibility to release, on a regular basis, information on macroeconomic statistics. Under this responsibility, Articles 2 and 74 of the Charter of the CRBP (1993, Law $\mathrm{N}^{\circ}$ 26123) state that the CRBP should release periodically reports on the nation's finances as well as the main macroeconomics statistics. The Charter specifically assigns the CRBP the task to process and disseminate balance of payment statistics. In addition, the Ministry of Economy and Finance (MEF), entitles the CRBP, through the Ministerial Resolution No. 239-93-EF-10, to gather the necessary information from individual persons, and public and private entities. Fines and penalties in case of noncompliance or for submitting incomplete or inaccurate information (Articles 73 and 74 of the Charter) are updated by the CRBP through regular "circulars" indicating how the penalty is generated.

Working arrangements are consistent with this assignment of responsibility. The Economic Studies Division (ESD) of the CRBP through the Balance of Payments Department (BOPD) is directly responsible for the data collection, compilation, and processing of balance of payments statistics. The BOPD has the direct responsibility to compile exports and imports of goods and services, private income, non financial private external debt, and direct investment. The External Debt Department (EDD), which is part of the ESD, compiles the disbursements, repayments, and income debits of the public sector. The Monetary Sector of the ESD compiles the private short and long term debt as well as international reserves.

More than one agency is involved in producing inputs for balance of payments statistics, and arrangements are in place to ensure exchange of data and consistency of methods and results. The methodology used for compilation in other agencies is coordinated by the CRBP to comply with the fifth edition of the Balance of Payments Manual (BPM5). The BOPD collects data from public entities, private companies, individuals, and other departments of the CRBP.

\subsubsection{Data sharing and coordination among data-producing agencies are adequate}

\footnotetext{
5 As noted in the ROSC, in view of the recent enhancements to the SDDS, the mission took the opportunity to discuss with the authorities the data provided under the Data Template on International Reserves and Foreign Currency Liquidity (Data Template). The mission's findings are discussed in the corresponding sections of this DQAF, namely 2.1.1, 2.4.2, and 4.2.1.
} 
Arrangements are in place to ensure the efficient and timely flow of source data between other agencies and the CRBP. The Customs Office provides basic data on exports and imports. Export data are supplemented with the gross value of marine resources taken by nonresident vessels operating with fishing licenses and the value of fuel and foodstuff sold to nonresident transport enterprises, as well as the repair of capital goods. Import data are supplemented with data from imports in the Tacna Special Processing Area, data on defense purchases provided by the National Bank (Banco de la Nación), purchases of goods abroad by resident transport companies, and repairs in Peru of non resident vessels. There is institutional coordination among all data producing agencies in order to count with the information on time.

Data on services are mostly based on the CRBP quarterly surveys reported by resident operators (e.g. transporters, insurance companies, telecommunications, and construction) in forms designed by the BOPD for compilation purposes. Tourism surveys (inward and outward) are also designed by the CRBP and conducted with its close supervision. Data on other services is mostly based on the annual Services, Foreign Investment, and External Debt Survey (SFIED) in forms designed by the CRBP and conducted with its close supervision. Regarding data for the income account, the CRBP mostly relies on the quarterly Foreign Investment and External Debt Survey (QFIED) in forms designed by the BOPD; it is directly conducted by it. This survey also provides information used to calculate direct investment, transactions of portfolio investment, other private nonfinancial investment, and equity capital of the financial sector. In addition, the register of portfolio investment liabilities is completed with the information from the Lima Stock Exchange (BVL). Other capital of the financial sector are calculated from quarter positions data reports on commercial bank transactions with non resident correspondents, and from the CRBP. Data on short term loans to the private sector are provided by financial institutions in forms designed by the BOPD. Information for the financial account of the private sector and income account is supplemented with the annual SFIED. Investment stocks are provided monthly by the National Commission on Investment and Foreign Technologies (CONITE). MEF provides information on general government and external debt (disbursements, repayments and interest payments). This information is supplemented with data from the Nations Bank and the financial public sector statistics (mainly COFIDE).

Contacts are maintained with other agencies to ensure proper understanding of data requirements, to avoid duplication of effort, and to take into account the respondent's burden. There are meetings, as needed, among Customs, CRBP, National Institute of Statistics and Informatics (NISI), and Tacna Special Processing Area, to address the statistical requirements of the Andean Community. 


\subsubsection{Respondents' data are to be kept confidential and used for statistical purposes only}

The Charter of the CRBP and the corresponding regulations on confidentiality clearly state that individual responses are to be treated as confidential and shall not be disclosed or used for other than statistical purposes. The Charter of the Central Bank states in its Article $41^{\circ}$ that no person at the Bank's service shall disclose to others any confidential information pertaining to or managed by the Bank. Offenders shall be liable to removal from office, in the case of managers, or dismissal, in the case of Bank employees. The Regulation about Institutional Representation, Confidentiality, and Interest Conflict approved by the Board of Directors on December 26, 2002 specifies the definition of confidential information. The Ethics Code, approved by the Board of Director on August 4, 1999 regulates the behavior of the workers. The CRBP is part of the National System of Statistics and Informatics governed by INEI; Legislative Decree No. 604 sets out the norms concerning compilation of the data, and stipulates that information provided to the Peruvian statistical system is confidential and cannot be disclosed individually, even by means of an administrative or judicial order.

Both in the surveys and other statistical inquiries, respondents are informed of their rights and obligations with regard to the provision of information, and they know that the information they provide will be used for the purpose of producing statistics. The letters to the private sector regarding the provision of information indicate that individual responses are confidential and that they are used, in aggregated form, for statistical purposes only.

Rules and regulations to prevent disclosure include penalties against staff who disclose confidential data. The CRBP Charter states that offenders shall be liable to removal from office, in the case of Managers, or dismissal, in the case of Bank employees. The Labor Regulation of the CRBP, approved by the Board of Directors on June 15, 1995 and modified on February 22, 1996 and on May 30, 2002, state the obligation of the employee to comply with the CRBP Charter, the Statute and other internal Regulations; it also states the fails to duties and the disciplinary penalties. The CRBP Statute, approved by the Board of Directors of the CRBP on February 10, 1994 and published on February 27, 1994, state that this obligation persists two years after the staff of the CRBP has left the institution. The Regulation about Institutional Representation, Confidentiality, and Interest Conflict, approved by the Board of Directors on December 26, 2002, specifies the definition of confidential information.

There are no special aggregation rules to ensure that residual disclosure does not occur when aggregations of survey or other confidential data are disseminated. Staff do not review all data to be disseminated for possible indirect disclosure of individual data, or design tables or outputs to prevent disclosure. Direct individual information is only published in a CRBP document when it has been made of public knowledge by the involved enterprise itself of the media.

In general, access to individual data is restricted to staff who require the information in the performance of their duties and on request from the Board of Directors. In the case of the annual SFIED, the information is obtained and verified by a private enterprise contracted by 
the CRBP through a public bid process. It is conducted under the close supervision of the CRBP staff. The contract signed by the Bank and the private enterprise states that the ownership of the information is of the CRBP. Tourism surveys (inward and outward) are anonymous and conducted by a private enterprise contracted by the CRBP also through a public bid process. It is conducted under the close supervision of the Bank staff and the processing of the information is restricted to the Bank. The QFIED is directly conducted by CRBP staff. In the case of the information on Public External Debt, the CRBP does not count with individualized information. Data from MEF would only be published when the information is previously disclosed by the MEF.

The computer systems prevent unauthorized access to individual data. Confidentiality of data is appropriately guarded during storage and during the process of the destruction of records.

\subsubsection{Statistical reporting is ensured through legal mandate and/or measures to encourage response}

The CRBP has the legal authority to collect data required to compile the balance of payments statistics. The Charter of the CRBP states on its Article $74^{\circ}$ that the CRBP is entitled to directly request information to the public, private enterprises (including financial and nonfinancial institutions), and individuals.

Conflicts or potential conflicts between the legal authority to compile the balance of payments and other laws or provisions (e.g., access to information law or bank secrecy laws) have been successfully resolved or reconciled with no major impairment to the data production.

There are penalties for noncompliance with reporting requirements, even if such provisions rarely need to be applied. The Charter of the CRBP states on its Article $74^{\circ}$ that the CRBP is entitled to determine penalties for cases of omission or inaccuracy of the information. The Circular 004-2002-EF/90 is a directive issued by CRBP to indicate how the penalty, which is indexed to a well known indicator, is defined and applied.

The CRBP considers carefully the burden on the respondents and provides assistance in completing and submitting forms. The forms for the compilation of annual and quarterly data on Services, Foreign Investment and External Debt Survey (SFIED and QFIED) include detailed instructions to the provider of information. The instructions are also provided to the enterprises that answer forms on services. The staff that conduct the tourism surveys (inward and outward) are trained by the CRBP staff. The forms of the surveys for enterprises have the name of the contact that is responsible for the information provided, so the CRBP staff can make contacts to verify the information. There is also the option of communication through e-mail, which is particularly useful when data need to be verified, so the provider of information can identify the question without doubt.

The CRBP seeks to secure the cooperation of respondents by creating goodwill. The instructions provided to the respondent are oriented to reduce the burden. The forms can be 
sent through e-mail to facilitate the response. CRBP staff inform respondents on how the information they provide is used and on the importance for macroeconomic analysis purposes.

\section{$0.2 \quad$ Resources}

\subsubsection{Staff, financial, and computing resources are commensurate with statistical programs}

Overall, the number of staff is adequate to compile, validate, and process balance of payments statistics. Six analysts are directly in charge of this task. One additional analyst has the responsibility to produce final tables and to distribute the information inside the CRBP and to other institutions. All the personnel have a professional degree at a well recognized university and the majority have been recruited through their merits in the Annual Summer Course at the CRBP. Public sector external debt data are processed in the External Debt Department, which has three persons assigned to this task, and financial data of the private sector are processed by the Monetary Sector Department of the CRBP.

Staff are qualified to perform the assigned tasks. Four of the staff of the BOPD have received training on balance of payments methodology and compilation methods at the IMF Institute. Efforts are made to ensure the retention at any point in time of a core contingent of trained balance of payments staff. Every member of the BOPD has a back-up to cover vacations, license for studies, or any other eventuality. The back-up has been properly trained in order to comply with the statistical duties. The same arrangement is in place in the External Debt Department.

Overall, adequate resources are allocated and best efforts are made to make use of the full potential of modern computing technology for compiling and disseminating statistics. The software is modern, continually updated, and well adapted to perform existing and emerging tasks. The current software used by the BOPD and the External Debt Department includes EXCEL, FoxPro (for large databases), and some specific programs for consulting purposes of external trade operations. There are also programs designed for the management of survey information. The CRBP is also using the FAME information services, particularly for the publication of the periodical statistics, and the personnel has the necessary technical support for its use. FAME is an integral software and database management system. There are plans to unify the administration of enterprises directories, to manage databases of surveys from different years, and to monitor surveys online.

Hardware is adequate to ensure efficient processing of data and management of the databases. Each member of the BOPD and the External Debt Department staff has assigned a $\mathrm{PC}$ that is connected to the network.

Overall financial resources for compiling balance of payments statistics are adequate to perform required tasks and commensurate with the overall resource allocation of the CRBP. The BOPD and the External Debt Department have the necessary computing resources and communications services (telephone, fax service, and e-mail that facilitate communications 
with enterprises and other public institutions). In terms of training of the staff, there is a budgetary assignment for relevant seminars and short courses as well as for language training. There are also budgetary assignments for office materials, surveys forms printing, courier services, and local transportation to enterprises in case of direct interviews. The budget of the CRBP considers, as well, resources for the annual compilation of services, SFIED, and tourism surveys in the local airport and in the borders of Tacna and Puno Departments. Currently, the amounts assigned to these tasks have been sufficient. There are no plans in the near future to allocate budgetary resources to future statistical development.

\subsubsection{Measures to ensure efficient use of resources are implemented}

CRBP managers promote a vision and sense of direction that are shared with the staff. Each year, the Economic Studies Division develops a project with the objectives and plans for each Department that includes statistical projects as well as studies related with the topics of the Department. The staff are aware of the objectives of the Division.

Efficiency is sought by encouraging consistent concepts and methodologies across the different units within the Economic Studies Division. There are clear responsibilities assigned among different areas, so that there is only one producer of accounts or subaccounts who shares the information with any user within the Division. There is a Manual that states the duties of every analyst in the Economic Studies Division. However, there are no procedural manuals documenting management.

Procedures are used to minimize processing errors, such as coding, editing, and tabulation errors in the data. Particularly in the case of large databases, there is a process to verify internal consistency before the data are finally processed. Usually, the final reports for internal use consider aggregation and sorting of the data at different levels, that allows the identification of any inconsistency before the data are released to the public. Enterprises are in general identified by the RUC (Unique Register of the Taxpayer) code.

Several departments of the CRBP are involved in the compilation of the balance of payments: the BOPD has the direct responsibility to compile exports and imports of goods and services, private income, nonfinancial private external debt, and direct investment; the External Debt Department compiles the disbursements and repayments and income debits of the public sector; and the Monetary Sector compiles the financial private short and long-term debt as well as the international reserves. However, there are no specific internal processes to measure resources used to compile the balance of payments statistics and to compare the resource usage of the BOP program vis-à-vis other statistical programs. Periodic reviews of working processes are undertaken, nevertheless, to ensure that scarce resources are best employed in addressing major data problems or meeting new data priorities. Each year, working processes are reviewed considering the results of the previous year. This revision may consider the inclusion or exclusion of questions or other details of the survey forms, the review of the instructions according to the responses received by the BOPD, or the revision of the considerations for the bid process, mainly in order to avoid delays. 
The CRBP strives to make the best use of newly emerging opportunities, such as computing technology for data processing/dissemination, to achieve savings of resources. If necessary, the CRBP seeks outside expert assistance to evaluate statistical methodologies and compilation systems. The BOPD is continuously reviewing the programs to process data in order to adopt more efficient technologies according to the requirements of the Division, and to reduce the time for processing data and improving their timeliness. When considered necessary, the BOPD seeks outside assistance to evaluate statistical methodologies and compilation systems. That is the case of the acquisition of the FAME program with the objective to provide a better administration of databases. Other example is the remittances of Peruvian living abroad. In 1997 the CRBP contacted an outside enterprise through a biding process to estimate these remittances. The methodology proposed was consulted with the IMF. The study showed that the series had been underestimated and, as a result, the series of current transfers were reviewed.

\subsection{Quality awareness}

\subsubsection{Processes are in place to focus on quality}

Managers are sensitive to all dimensions of data quality. The CRBP has implemented some processes that focus on quality. The data are externally audited each year and the results are presented in the Annual Report. The IMF has provided assistance in the area of accounting of Fund transactions. The CRBP does not provide an specific infrastructure for quality awareness of the economies of scale, nor regarding interrelationships between datasets.

\subsubsection{Processes are in place to monitor the quality of the collection, processing, and dissemination of statistics}

Reviews are undertaken to identify problems at the various stages of collecting, processing, and disseminating data. In the case of large databases, there is a process of internal consistency before the data are finally processed. Internal reports review aggregation and sorting of the data at different levels, allowing for identification of inconsistencies before the data are released to the public.

The CRBP does not have a body distinct from the data producing unit that provides guidance on the quality of balance of payments statistics and on strategies for improving data production. Nevertheless, the BOPD participates actively in international surveys on methodology conducted by the IMF, such as the recent Foreign Direct Investment Survey.

There are no periodic users' surveys or other processes to obtain feedback from users of statistics on data quality issues. Nevertheless, the BOPD is aware of any comments to the statistics published in the media and responds to any requirements from the Congress or other institutions. 


\subsubsection{Processes are in place to deal with quality considerations, including tradeoffs within quality, and to guide planning for existing and emerging needs}

There is recognition by CRBP management of the tradeoffs among the dimensions of data quality. Balance of payments statistics are published quarterly with the information available at that time. Nevertheless, the publication clearly states that the information is preliminary. Significant changes in methodology are informed in the Annual Report. The significance of the tradeoffs among the dimensions of quality is communicated to users of statistics. Improvement of data quality is taken into account in planning the forward work program.

There are no periodic meetings convened with policy makers and other data users to review balance of payments statistics and to identify any emerging data requirements. Nevertheless, comments from the Balance of Payments Division of the IMF's Statistics Department, policy makers, and other data users are taken into account to review existing balance of payments statistics, and to identify emerging data requirements. Users' feedback on balance of payments statistics is not encouraged but is considered. The presentation of statistics is adjusted to meet users' needs.

\section{Integrity}

\subsection{Professionalism}

\subsubsection{Statistics are compiled on an impartial basis}

The CRBP Charter states that the Central Bank formulates exclusively the balance of payments and the monetary accounts. Therefore, the methodology applied is the exclusive responsibility of balance of payments compilers. The legislation also requires that the CRBP inform periodically about the situation of the national finances and publish the main national macroeconomic statistics. Article 3 of the CRBP Charter indicates that CRBP is an autonomous institution.

Professional competency plays a key role in recruitment and promotion policies. Professionalism is promoted by the publication of methodological papers and by organizing meetings of professional groups. The CRBP encourages the participation of professional staff in the Annual Economists Meeting organized by the CRBP, where papers are presented to debate. The staff participate in internal and external courses and conferences. Staff performance is assessed each semester.

Research and analysis for publication are subject to internal review and other processes to maintain the CRBP reputation for professionalism. Previous to the Annual Economists Meeting, there are also internal reviews through working groups in order to maintain the agency's reputation for professionalism. 


\subsubsection{Choices of sources and statistical techniques are based solely on statistical considerations}

Choices of data sources (e.g., among surveys) and statistical techniques (e.g., processing and validation techniques) are based solely on statistical considerations. The surveys conducted by the BOPD are used to obtain information for the private nonfinancial account and the other services account of the balance of payments. Tourism surveys consistent with the methodology of balance of payments are only conducted by the CRBP. There are other data sources that are unique, such as trade and external public debt statistics.

\subsubsection{The appropriate statistical entity is entitled to comment on erroneous interpretation and misuse of statistics}

The CRBP does not comment publicly on erroneous interpretations or misuse of BOP statistics in the media or other fora. Nevertheless, the CRBP keeps track of any comments on balance of payments data and, if needed, a report is prepared for the Management or for the Board of Directors. When there are questions directed to the CRBP by the Congress, there are responses sent by the President or the General Manager to clarify the doubts. The CRBP seeks to prevent misinterpretation or misuse of statistics by providing explanatory materials on its website or through publications.

\subsection{Transparency}

\subsubsection{The terms and conditions under which statistics are collected, processed, and disseminated are available to the public}

The terms and conditions under which official statistics are compiled and disseminated are available in the CRBP publications and website. The CRBP website disseminates the CRBP Charter, which states the responsibility of the CRBP to produce balance of payments statistics. It also states the terms and conditions under which the information can be required from the public. The CRBP Statute and the Regulation about Institutional Representation, Confidentiality, and Interest Conflict is also posted on the website. These documents describe the confidentiality obligations of the staff and define confidential information.

\subsubsection{Internal governmental access to statistics prior to their release is publicly identified}

Only the General Manager and the Board of Directors of the CRBP have access to balance of payments statistics prior to their release. The public is made aware that the approval process for the publication of balance of payments statistics rests entirely on the Board of Directors. This information is posted on the CRBP website. 


\subsubsection{Products of statistical agencies/units are clearly identified as such}

Data released to the public are clearly identified in the CRBP publications and website. Sources of information are stated on each table. The CRBP does not have joint publications.

\subsubsection{Advance notice is given of major changes in methodology, source data, and statistical techniques}

There is no advance notice given when major changes in methodology, sources, or statistical techniques are introduced. These changes are announced to the public at the moment of release.

\subsection{Ethical standards}

\subsubsection{Guidelines for staff behavior are in place and are well known to the staff}

There are clear guidelines outlining correct behavior when the staff is confronted with potential conflict of interest situations. A Code of Ethics was approved by CRBP management on August 4, 1999. In addition, the Charter of the CRBP, the Statute, the Labor Regulation of the CRBP, and the Internal Regulation about Institutional Representation, Confidentiality, and Interest Conflict specifically refer to confidentiality.

The reputation of CRBP management for the maintenance of ethical standards assures autonomy from political interference. According to the last Opinion Report (September 2002) by the private enterprise Apoyo regarding the level of confidence on institutions, 44 percent of the population trusted the CRBP as an institution.

Management acknowledges its status as role model and is vigilant in following the ethical guidelines. New staff are made aware of the guidelines when they join the organization and are reminded periodically of these guidelines.

\section{Methodological soundness}

\subsection{Concepts and definitions}

\subsubsection{The overall structure in terms of concepts and definitions follows internationally accepted standards, guidelines, or good practices}

With a few exceptions, key concepts and definitions follow the guidelines of the BPM5. Some of the exceptions are: a) the valuation procedures used in the compilation of the international investment position do not permit the separation of price and exchange rate effects; b) the gross value of marine resources taken by nonresident vessels operating with fishing licenses are still included in the exports of goods; c) on the flows side, there is a limited register of short term assets of non financial residents (BIS statistics are taken into account, as well as particular operations declared by enterprises in the SFIED); d) lack of 
surveys to individuals on financial account operations, such as acquisition of land and buildings; and e) the BOPD does not have the necessary information for an accurate distinction between claims on direct investors or assets on portfolio investment (for an operation between a direct investment enterprise and its direct investor). However, deviations from the above concepts and definitions are kept under review.

Regarding the Data Template on International Reserves an Foreign Currency Liquidity, the CRBP includes the full amount of the liquidity requirements in the reserve template under official reserves assets, and does not register the contingent net drain, as specified in Section III of the Data Template.

\subsection{Scope}

\subsubsection{The scope is broadly consistent with internationally accepted standards, guidelines, or good practices}

Most resident-nonresident transactions as specified in the BPM5 are covered in the balance of payments statistics. However, there are exceptions due to the lack of surveys to individuals regarding financial account operations, and the movement of deposits of individuals abroad. Resident institutional units are defined in conformity with the BPM5 and relate to those that have a center of economic interest in the country/territory. In principle, all resident institutional units engaged in transactions with nonresidents are covered, which is in conformity with the BPM5.

\subsection{Classification/sectorization}

\subsubsection{Classification/ sectorization systems used are broadly consistent with internationally accepted standards, guidelines, or good practices}

In general, institutional units and transactions are classified according to the BPM5.

Deviations, which are kept under review, include (a) the inclusion within exports of the gross value of marine resources taken by nonresident vessels operating with fishing licenses (limited to fisheries of giant squid), and (b) the use of BIS data to register the assets held abroad by residents of Peru.

\subsection{Basis for recording}

\subsubsection{Market prices are used to value flows and stocks}

The principle of market valuation specified in the BPM5 is not used in all cases to value transactions. End-month stocks data on public and private external debt are recorded at nominal value. Data from the stock market is valued at market prices at the end of period.

Balance of payments statistics are compiled in U.S. dollars. Trade transactions are mostly collected in US dollars. Other transactions are also reported in U.S. dollars. If the enterprise 
registers the data in soles, the form indicates the exchange rate that must be used, which corresponds to the average exchange rate for the shortest applicable period. Transactions collected in local currency, such as portfolio investment, are converted into U.S. dollars at the daily average exchange rate. Where transaction estimates are derived from stock data, the conversion of stocks is made at the exchange rate for the end of period.

\subsubsection{Recording is done on an accrual basis}

In general, change of ownership as specified in BPM5 is the principle governing the recognition of transactions and their time of recording. Where possible, the accounting of balance of payments is made on an accrual basis. Exports are recorded when the merchandise is shipped, and imports are recorded on the date on which Customs documents are numbered. Income on equity and debt, and the public financial account are registered on an accrual basis, but private financial account flows and services are registered on a cash basis. If data on accrual basis are not available, no adjustments are made to data on a cash basis to approximate accrued values.

With respect to the Data Template, the basis for recording of interest for official reserve assets does not follow the accrual principle recommended by BPM5 and the Operational Guidelines.

\subsubsection{Grossing/netting procedures are broadly consistent with internationally accepted standards, guidelines, or good practices}

In line with the recommendations of the BPM5, current and capital account transactions are recorded on a gross basis while financial account transactions are recorded on a net basis, when possible separately for the individual asset and liability components.

\section{Accuracy and reliability}

\subsection{Source data}

\subsubsection{Source data are collected from comprehensive data collection programs that take into account country-specific conditions}

Data sources are kept under continuous review to ensure that the data collection program remains comprehensive. There is coordination with appropriate institutions when there is a review of the Customs Nomenclature. The last revision was made in January 2002, to properly classify tariff items for analysis of exports and imports. Directories are reviewed to incorporate new enterprises or new projects with external financing.

The primary data sources are broadly sufficient to compile the balance of payments statistics. Nevertheless there are a few topics under review: a) on the flows side, there is an limited register of short-term assets of non financial residents abroad; and b) the valuation at market prices of the international investment position. 
Data from primary sources are supplemented with information from secondary data, as follows:

- International merchandise trade statistics, which are based on Customs data, are used to compile data on goods. This information is supplemented with exports by the gross value of marine resources taken by nonresident vessels operating with fishing licenses. In addition, the acquisition of fuel and foodstuff to foreign crafts and repairs on capital goods are included. In the case of imports, Customs data are supplemented with data on imports into the Tacna Special Processing Area, the acquisition of fuel and foodstuff abroad by Peruvian resident crafts, and repairs of capital goods abroad.

- Monetary and financial statistics on the external positions of resident units are used to derive the financial transactions for these units.

- Data on reserve assets are provided by the CRBP with flows distinguished from valuation changes or with sufficient detail to enable derivation of flow measures that exclude valuation changes.

- The External Debt Department provides information on the government's external long-term debt transactions. This information comes originally from the MEF, the National Bank, and COFIDE.

There are registers that have comprehensive coverage of units engaged in balance of payments transactions. Surveys are applied to enterprises for services (transport, communications, insurance, and other services) and for the financial account and its associated income. In the case of services, the surveys are applied to the universe of enterprises. In the case of the annual SFIED survey, the directory of enterprises covers the universe of the enterprises that have financial transactions with non residents. For the QFIED survey, there is a sample of enterprises (around 180) that covers between 60 and 70 percent of each corresponding item of the balance of payments. These directories are reviewed regularly.

There are established procedures for integrating new units into the register on a regular basis. The communication with the enterprises involved is very fluent and there is complete information of mergers, cessation of operations, and any other operation. Where sampling is used, the samples are derived by scientific random sampling techniques. Sampling is used for travel surveys. The technique used is the stratified random sampling.

There is no International Transactions Reporting System (ITRS) in place. Financial institutions report to the CRBP for monetary accounts purposes. The coverage of reporting banks is integrated with the bank register maintained by the bank supervisory authorities. The information from the monetary sector for BOP purposes corresponds to short and long-term financial transactions (assets and liabilities) with non residents. In the case of financial institutions with foreign participation, it is not possible to distinguish transactions with its 
direct investment bank abroad. That information is cross checked with the QFIED survey. Also:

- $\quad$ The directory for the QFIED survey includes a sample of banks to classify transactions across the balance of payments components when needed.

- $\quad$ Transactions are not reported to an ITRS. The information comes from the QFIED survey or through direct consultation to the enterprise.

- Data on loans in foreign direct investment have limitations derived from the information obtained from the QFIED.

- $\quad$ Revisions incorporate all material changes from available up-to-date data.

- The financial press is monitored regarding information on international transactions for its integration into statistics/registers.

- $\quad$ Periodic meetings are held with financial market participants and with the business community to identify new developments that need to be taken into account in the balance of payments compilation system.

3.1.2 Source data reasonably approximate the definitions, scope, classifications, valuation, and time of recording required

Specific procedures have been developed to adjust data from various sources so that coverage, classification, and valuation systems conform top the guidelines set out in BPM5:

- In order to improve the coverage of exports, Customs statistics are supplemented by the gross value of marine resources taken by non resident vessels operating with fishing licenses, the sale of fuel and foodstuff to foreign crafts, and the repair of capital goods.

- Tin sales through consignment contracts are included in the statistics as the regularization of these sales are done, with a delay of three-five months.

- $\quad$ To improve the coverage of imports, Customs statistics are supplemented with imports into the Tacna Special Processing Area, the acquisition of fuel and foodstuff by resident vessels abroad, as well as the debit side of the repair of capital goods.

- $\quad$ Customs import and export data are compiled on a f.o.b. basis.

- $\quad$ There are not withholding taxes applied to income and service payments.

- Data in telecommunications services are reported on a gross basis. 
- Source data on securities transactions in secondary markets, which are reported net of fees and commissions, are not adjusted to a gross basis but recorded on the basis of information on average commission rates obtained from a sample of securities dealers.

Compilers are aware of the differences in practices regarding source data for the balance of payments statistics. All tables include notes that explain the methodology employed. In the case of the flow of foreign investment, the registry in ProInversión (official agency in charge of promoting investment) has discrepancies related to the time of recording. Supplementary information is carefully evaluated before it is incorporated in the balance of payments.

Information on public external debt obtained from the MEF is broadly in line with the recommendations of the BPM5. Information on private debt is collected in CRBP forms designed specifically for balance of payments needs.

\subsubsection{Source data are timely}

Respondents are made aware of the deadlines set for reporting. If the response to the survey has not been returned to the CRBP after four weeks, BOPD staff follow up by telephone with the respondent to ensure the timely receipt of respondents' data.

\subsection{Statistical techniques}

\subsubsection{Data compilation employs sound statistical techniques}

Data compilation procedures minimize processing errors such as coding, editing, and tabulation errors:

- $\quad$ Product average prices are used to detect possible coding, editing, or tabulation errors.

- Data analysis through different classifications allow to identify possible errors.

- $\quad$ Enterprise survey data focused on the private financial account include additional information, such as net worth, which allows to implement internal consistency between earnings, new equity, and worth.

The report forms are designed in a way that makes them easy to complete and appropriate for computer processing. The surveys have their own instructions set to guide the enterprises to fill the formats. 


\subsubsection{Other statistical procedures (e.g., data adjustments and transformations, and statistical analysis) employ sound statistical techniques}

Imports are reported on a FOB basis. There are not estimates of shuttle trade based on information from periodic surveys conducted at major border points on goods carried by organized and nonorganized traders. There are not adjustments for the underestimation of exports made on the basis of partner country import data. Estimation techniques are not employed to adjust data for missing observations in statistical collections.

\subsection{Assessment and validation of source data}

3.3.1 Source data-including censuses, sample surveys and administrative records-are routinely assessed, e.g., for coverage, sample error, response error, and nonsampling error; the results of the assessments are monitored and made available to guide planning

Information on sampling errors regarding the survey for travel service is available and is reviewed regularly. Other surveys are applied to the universe of the enterprises involved. Information on nonsampling errors, such as over/under-coverage, misclassification, measurement, and nonresponse is also available. High-value transactions are confirmed with respondents. Accuracy of the data from enterprise surveys is routinely assessed. High-value transactions are first confirmed with individual respondents. The staff have preliminary and previous information reported for the most important transactions.

The source data are analyzed to verify for underreporting/misreporting. For trade data, the Customs database is evaluated using average prices for the main products. For the financial account registers, large fluctuations in data from banking enterprises are continuously evaluated. Source data are analyzed in the context of revisions.

Sample selection is adjusted occasionally, when sampling errors become large. For travel survey samples, sample selection is evaluated considering the sampling errors and the time and cost of the surveys involved. Other surveys consider the universe of enterprises involved.

The consistency of the source data with the balance of payments is checked, in particular concerning definitions, valuation, reference periods, and classifications.

\subsection{Assessment and validation of intermediate data and statistical outputs}

\subsubsection{Main intermediate data are validated against other information where applicable}

Survey data are checked with other data sources. For example:

- In the case of travel services, the BOPD compares the results with other surveys that focus on the average expenditure in Peru of non residents; and 
- $\quad$ information reported in the financial press is used to verify high-value direct investment and other transactions. The sources of information for foreign investment and loans are the surveys designed by the CRBP, specialized publications, and other institutions. All this information is cross-checked with information provided by enterprises.

\subsubsection{Statistical discrepancies in intermediate data are assessed and investigated}

The behavior of data series is routinely assessed against related series. For instance:

- $\quad$ reported data on investment income payments and receipts are regularly assessed at enterprise level in relation to the others flows that explain changes in assets;

- data on freight earnings are regularly assessed in relation to the value/volume of the trade flows;

- data on travel-related transactions are analyzed in relation to information compiled by immigration authorities on the numbers of international travelers entering/leaving the country; and

- the reported financial flow data are reconciled with changes in the corresponding stock data collected for external debt and for other elements of the international investment position.

\subsubsection{Statistical discrepancies and other potential indicators of problems in statistical outputs are investigated}

BOPD staff monitor and analyze developments in the errors and omissions item, e.g., by crosschecking between entries in the current, capital, and financial accounts.

No bilateral data reconciliation is conducted for selected trade, other current, and financial account items with trading partners.

Data on selected external debt transactions are compared with the Joint BIS-IMF-OECDWorld Bank Statistics on External Debt and the BIS international banking statistics.

\subsection{Revision studies}

\subsubsection{Studies and analyses of revisions are carried out routinely and used to inform statistical processes (see also 4.4.3)}

The direction and magnitude of revisions for preliminary and final data are investigated. Routine validations are part of internal quality control exercises. The public is informed at the time of the Annual Report of the CRBP when revisions are significant. Some revisions may be related to methodological aspects, although the most common refer to data reviews at 
the time of the publications. The adjustments made in the statistical processes are taken into account in compiling the data for the subsequent periods.

\section{Serviceability}

\subsection{Relevance}

\subsubsection{The relevance and practical utility of existing statistics in meeting users' needs are monitored}

There are no established formal processes of periodic consultation with policy makers, representatives of the private sector and academia, and other users of statistics. Nevertheless, the presentation of the balance of payments statistics is continuously reviewed in order to evaluate its relevance, consistency, and practical utility.

The CRBP participates, as needed, in international statistical meetings and seminars organized by international and regional organizations.

\subsection{Timeliness and periodicity}

\subsubsection{Timeliness follows dissemination standards}

Quarterly balance of payments statistics are disseminated 8 weeks after the end of the reference quarter, thus exceeding SDDS requirements for timeliness.

The Data Template, as compiled and disseminated, exceeds the periodicity and timeliness prescribed by the SDDS; however, Sections II and III of the data template on predetermined and contingent net flows are not updated for the last three weeks of the month.

\subsection{Consistency}

\subsubsection{Statistics are consistent within the dataset}

Concepts, definitions, and classifications for producing quarterly and annual statistics are the same. Over the long run, the item of net errors and omissions has been variable. Recent studies have been prepared on smuggling and/or drug trafficking.

\subsubsection{Statistics are consistent or reconcilable over a reasonable period of time}

Consistent time series are available for at least ten years. When changes in source data, methodology, or techniques are introduced, historical series are reconstructed as far back as possible. The BOPD tries to avoid breaks in the balance of payments time series. Efforts to reconstruct the data as far back as possible are made at least in the periods covered in the Annual Report, which usually includes ten years and provides detailed explanations of the changes. 
Any unusual change in economic trends is explained in the analytical text included in the balance of payments publication and in the database accessible by users. Usually, an analytical report on the most important variables is included in the quarterly and annual publications.

\subsubsection{Statistics are consistent or reconcilable with those obtained through other data sources and/or statistical frameworks}

The item of goods is reconciled, to a large extent, with trade data. The inclusion of the gross value of marine resources taken by nonresident vessels operating with fishing licenses is under review because is not consistent with the methodology used in national accounts. However, the balance of payments statistics are generally consistent with national accounts statistics.

The banking sector transactions in the balance of payments statistics are consistent with the monetary and financial statistics. Monetary accounts related to international transactions are identified (international assets and liabilities). Transactions for the balance of payments are registered on stocks basis. International positions are valued on a nominal basis.

\subsection{Revision policy and practice}

\subsubsection{Revisions follow a regular, well-established and transparent schedule}

The implicit revision cycle is predetermined and reasonably stable from year to year. Quarterly statistics are reviewed each closing quarter. The complete year is reviewed for the publication of the Annual Report. Adequate documentation of revisions is included in the publication of the statistical series and in the database accessible to users. New source data are incorporated after evaluating its characteristics and compatibility with balance of payments needs. The revision schedule takes into account the timing for producing important official economic policy documents.

\subsubsection{Preliminary data are clearly identified}

Users are alerted that the initially published data are preliminary and subject to revision. The revised data are disseminated with the same level of detail as previously published.

\subsubsection{Studies and analyses of revisions are made public (see also 3.5.1)}

Revisions are assessed and explained in the balance of payments publication and in the database accessible by users. Analysis of preliminary versus revised data is not regularly published for major aggregates to allow an assessment of the reliability of the preliminary data. Nevertheless, this analysis is used internally to explain differences. The revisions made are well documented and published in the Annual Report. 


\section{Accessibility}

\subsection{Data accessibility}

\subsubsection{Statistics are presented in a way that facilitates proper interpretation and meaningful comparisons (layout and clarity of text, tables, and charts)}

The balance of payments statistics are published in a clear format and charts and tables are disseminated with the data to facilitate analysis. Datasets are published with various levels of detail and analysis of current-period developments is included in each publication.

The balance of payments statistics are published according to the standard components of the BPM5 and with time series. Some additional series are published to meet users' needs. There are no balance of payments series published in a seasonally adjusted form.

\subsubsection{Dissemination media and formats are adequate}

Trade balances are first released through the Weekly Bulletin in hard copy and on the CRBP website. Its release is followed by the release of the balance of payments. Recently released data and longer time series can be accessed without a fee on the CRBP website.

\subsubsection{Statistics are released on the pre-announced schedule}

The balance of payments statistics are released according to a pre-announced schedule.

\subsubsection{Statistics are made available to all users at the same time}

The data are released simultaneously to all interested users on the date and/or time specified in the pre-announced schedule.

\subsubsection{Nonpublished (but nonconfidential) sub-aggregates are made available upon request}

In addition to the balance of payments statistics that are published in the Weekly Bulletin, unpublished (but nonconfidential) specialized tabulations can be provided. However, the availability of nonpublished statistics and the terms and conditions on which they are made available are not publicized. 


\subsection{Metadata accessibility}

5.2.1 Documentation on concepts, scope, classifications, basis of recording, data sources, and statistical techniques is available, and differences from internationally accepted standards, guidelines, or good practices are annotated

Metadata on concepts, definitions, classification, and other methodology, data sources, and statistical techniques are prepared and disseminated to the public on the IMF's DSBB. The same metadata is translated to Spanish and included on the CRBP website.

\subsubsection{Levels of detail are adapted to the needs of the intended audience}

A brochure is available to inform users about the balance of payments and other external sector statistics. A comprehensive sources and methods document is produced to inform analysts and other users of statistics on the balance of payments compilation methods and techniques. This document is updated regularly.

\subsection{Assistance to users}

\subsubsection{Contact person for each subject field is publicized}

Prompt and knowledgeable service and support is available to users of statistics. All statistical releases identify specific individuals who may be contacted by mail, telephone, facsimile, or e-mail. Documentation is available in brochures to educate users of macroeconomic statistics.

5.3.2 Catalogues of publications, documents, and other services, including information on any charges, are widely available

A catalog of publications, documents, and other services to users is available and updated each year on the CRBP website. 
Table 6. Peru: Data Quality Assessment Framework-Summary of Results for Balance of Payments Statistics

(Compiling Agency: Central Reserve Bank of Peru)

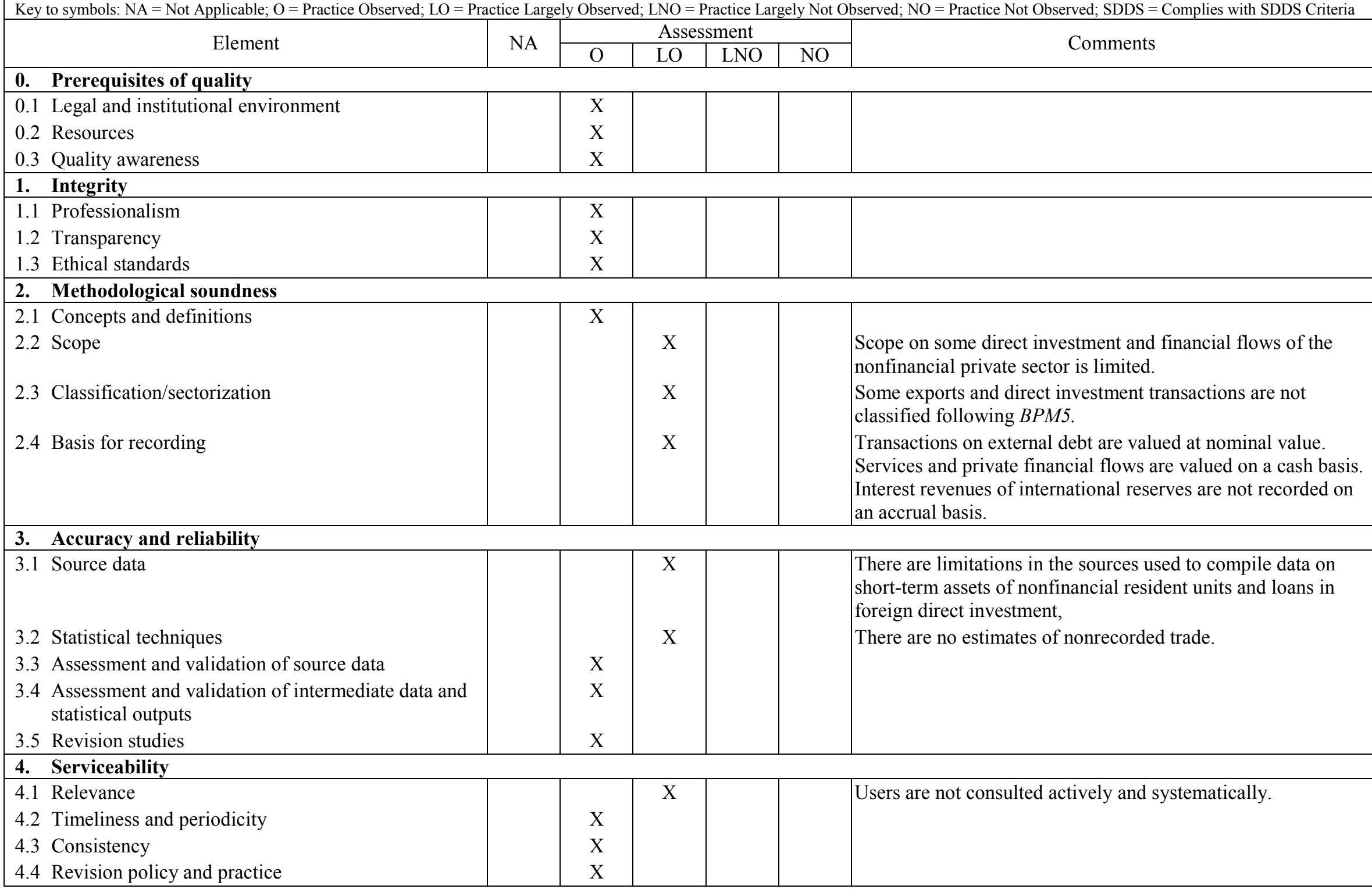


Table 6. Peru: Data Quality Assessment Framework-Summary of Results for Balance of Payments Statistics (Compiling Agency: Central Reserve Bank of Peru)

\begin{tabular}{|c|c|c|c|c|c|c|}
\hline \multirow[b]{2}{*}{ Element } & \multirow[b]{2}{*}{ NA } & \multicolumn{4}{|c|}{ Assessment } & \multirow{2}{*}{ Comments } \\
\hline & & $\mathrm{O}$ & LO & LNO & $\mathrm{NO}$ & \\
\hline \multicolumn{7}{|l|}{$\begin{array}{ll}\text { 5. } & \text { Accessibility }\end{array}$} \\
\hline 5.1 Data accessibility & & $\mathrm{X}$ & & & & \\
\hline
\end{tabular}




\section{Summary of the Special Data Dissemination Standard}

The SDDS prescribes the following practices under each of the identified dimensions:

Data dimension (coverage, periodicity, and timeliness)

- The dissemination of 18 data categories, including component detail, covering the four main sectors of the economy, with prescribed periodicity and timeliness.

\section{Access dimension}

- $\quad$ The dissemination of advance release calendars providing at least one-quarter advance notice of approximate release dates, and at least a one-week advance notice of the precise release dates; and

- the simultaneous release of data to all users.

\section{Integrity dimension}

- The dissemination of the terms and conditions under which official statistics are produced and disseminated;

- the identification of internal government access to data before release;

- the identification of ministerial commentary on the occasion of statistical release; and

- the provision of information about revision and advance notice of major changes in methodology.

\section{Quality dimension}

- $\quad$ The dissemination of documentation on statistical methodology and sources used in preparing statistics; and

- dissemination of component detail and/or additional data series that make possible cross-checks and checks of reasonableness.

SDDS subscribers are required to:

- $\quad$ Post descriptions of their data dissemination practices (metadata) on the IMF's Dissemination Standards Bulletin Board (DSBB). Summary methodologies, which describe data compilation practices in some detail are also required to be disseminated on the DSBB. 
- $\quad$ Maintain an Internet website, referred to as the National Summary Data Page (NSDP), which contains the actual data described in the metadata and to which the DSBB is electronically linked.

At the March 29, 2000 meeting of the IMF's Executive Board, Directors approved the incorporation of a new SDDS data category on external debt. The transition period for implementing this data category expires in March 2003.

As a result of the IMF Executive Board's Third Review of the SDDS in March 2000, the IMF staff began monitoring observance of the Standard through NSDPs maintained on the Internet. Monitoring commenced at the beginning of July 2000, and is limited to the coverage, periodicity, and timeliness of the data and to the dissemination of advance release calendars.

Source: Guide to the SDDS. 
Data Quality Assessment Framework-Generic Framework

(July 2001 Vintage)

\begin{tabular}{|c|c|c|}
\hline Quality Dimensions & Elements & Indicators \\
\hline $\begin{array}{l}\text { Prerequisites of } \\
\text { quality }^{1}\end{array}$ & $\begin{array}{l}\text { 0.1 Legal and institutional } \\
\text { environment-The environment is } \\
\text { supportive of statistics. } \\
\text { 0.2 Resources-Resources are } \\
\text { commensurate with needs of } \\
\text { statistical programs. } \\
\text { 0.3 Quality awareness-Quality } \\
\text { is a cornerstone of statistical work. }\end{array}$ & $\begin{array}{l}\text { 0.1.1 The responsibility for collecting, processing, } \\
\text { and disseminating statistics is clearly specified. } \\
\text { 0.1.2 Data sharing and coordination among data } \\
\text { producing agencies are adequate. } \\
\text { 0.1.3 Respondents' data are to be kept confidential } \\
\text { and used for statistical purposes only. } \\
\text { 0.1.4 Statistical reporting is ensured through legal } \\
\text { mandate and/or measures to encourage response. } \\
\text { 0.2.1 Staff, financial, and computing resources are } \\
\text { commensurate with statistical programs. } \\
0.2 .2 \text { Measures to ensure efficient use of } \\
\text { resources are implemented. } \\
\text { 0.3.1 Processes are in place to focus on quality. } \\
0.3 .2 \text { Processes are in place to monitor the quality } \\
\text { of the collection, processing, and dissemination of } \\
\text { statistics. } \\
\text { 0.3.3 Processes are in place to deal with quality } \\
\text { considerations, including tradeoffs within quality, } \\
\text { and to guide planning for existing and emerging } \\
\text { needs. }\end{array}$ \\
\hline $\begin{array}{l}\text { 1. Integrity } \\
\text { The principle of } \\
\text { objectivity in the } \\
\text { collection, } \\
\text { processing, and } \\
\text { dissemination of } \\
\text { statistics is firmly } \\
\text { adhered to. }\end{array}$ & $\begin{array}{l}\text { 1.1 Professionalism-Statistical } \\
\text { policies and practices are guided } \\
\text { by professional principles. } \\
\text { 1.2 Transparency—Statistical } \\
\text { policies and practices are } \\
\text { transparent. } \\
\text { 1.3 Ethical standards-Policies } \\
\text { and practices are guided by ethical } \\
\text { standards. }\end{array}$ & $\begin{array}{l}\text { 1.1.1 Statistics are compiled on an impartial basis. } \\
\text { 1.1.2 Choices of sources and statistical techniques } \\
\text { are informed solely by statistical considerations. } \\
\text { 1.1.3 The appropriate statistical entity is entitled } \\
\text { to comment on erroneous interpretation and } \\
\text { misuse of statistics. } \\
\text { 1.2.1 The terms and conditions under which } \\
\text { statistics are collected, processed, and } \\
\text { disseminated are available to the public. } \\
\text { 1.2.2 Internal governmental access to statistics } \\
\text { prior to their release is publicly identified. } \\
\text { 1.2.3 Products of statistical agencies/units are } \\
\text { clearly identified as such. } \\
\text { 1.2.4 Advance notice is given of major changes in } \\
\text { methodology, source data, and statistical } \\
\text { techniques. } \\
\text { 1.3.1 Guidelines for staff behavior are in place } \\
\text { and are well known to the staff. }\end{array}$ \\
\hline
\end{tabular}


Data Quality Assessment Framework-Generic Framework (continued) (July 2001 Vintage)

\begin{tabular}{|c|c|c|}
\hline Quality Dimensions & Elements & Indicators \\
\hline $\begin{array}{l}\text { 2. Methodological } \\
\text { soundness } \\
\text { The methodological } \\
\text { basis for the } \\
\text { statistics follows } \\
\text { internationally } \\
\text { accepted standards, } \\
\text { guidelines, or good } \\
\text { practices. }\end{array}$ & $\begin{array}{l}\text { 2.1 Concepts and definitions- } \\
\text { Concepts and definitions used are } \\
\text { in accord with internationally } \\
\text { accepted statistical frameworks. } \\
\text { 2.2 Scope-The scope is in accord } \\
\text { with internationally accepted } \\
\text { standards, guidelines, or good } \\
\text { practices. } \\
\text { 2.3 Classification/sectorization- } \\
\text { Classification and sectorization } \\
\text { systems are in accord with } \\
\text { internationally accepted standards, } \\
\text { guidelines, or good practices. } \\
\text { 2.4 Basis for recording-Flows } \\
\text { and stocks are valued and } \\
\text { recorded according to } \\
\text { internationally accepted standards, } \\
\text { guidelines, or good practices. }\end{array}$ & $\begin{array}{l}\text { 2.1.1 The overall structure in terms of concepts } \\
\text { and definitions follows internationally accepted } \\
\text { standards, guidelines, or good practices: see } \\
\text { dataset-specific framework } \\
\text { 2.2.1 The scope is broadly consistent with } \\
\text { internationally accepted standards, guidelines, or } \\
\text { good practices: see dataset-specific framework. } \\
\text { 2.3.1 Classification/sectorization systems used are } \\
\text { broadly consistent with internationally accepted } \\
\text { standards, guidelines, or good practices: see } \\
\text { dataset-specific framework. } \\
\text { 2.4.1 Market prices are used to value flows and } \\
\text { stocks. } \\
\text { 2.4.2. Recording is done on an accrual basis. } \\
\text { 2.4.3 Grossing/netting procedures are broadly } \\
\text { consistent with internationally accepted standards, } \\
\text { guidelines, or good practices. }\end{array}$ \\
\hline
\end{tabular}


Data Quality Assessment Framework-Generic Framework (continued) (July 2001 Vintage)

\begin{tabular}{|c|c|c|}
\hline Quality Dimensions & Elements & Indicators \\
\hline $\begin{array}{l}\text { 3. Accuracy and } \\
\text { reliability } \\
\text { Source data and } \\
\text { statistical techniques } \\
\text { are sound and } \\
\text { statistical outputs } \\
\text { sufficiently portray } \\
\text { reality. }\end{array}$ & $\begin{array}{l}\text { 3.4 Assessment and validation of } \\
\text { intermediate data and statistical } \\
\text { outputs_Intermediate results and } \\
\text { statistical outputs are regularly } \\
\text { assessed and validated. } \\
\text { 3.5 Revision studies_Revisions, } \\
\text { as a gauge of reliability, are } \\
\text { tracked and mined for the } \\
\text { information they may provide. }\end{array}$ & $\begin{array}{l}\text { 3.1.1 Source data are collected from } \\
\text { comprehensive data collection programs that take } \\
\text { into account country-specific conditions. } \\
\text { 3.1.2 Source data reasonably approximate the } \\
\text { definitions, scope, classifications, valuation, and } \\
\text { time of recording required. } \\
\text { 3.1.3 Source data are timely. } \\
\text { 3.2.1 Data compilation employs sound statistical } \\
\text { techniques. } \\
\text { 3.2.2 Other statistical procedures (e.g., data } \\
\text { adjustments and transformations, and statistical } \\
\text { analysis) employ sound statistical techniques. } \\
\text { 3.3.1 Source data-including censuses, sample } \\
\text { surveys and administrative records-are routinely } \\
\text { assessed, e.g., for coverage, sample error, } \\
\text { response error, and nonsampling error; the results } \\
\text { of the assessments are monitored and made } \\
\text { available to guide planning. } \\
\text { 3.4.1 Main intermediate data are validated against } \\
\text { other information where applicable. } \\
\text { 3.4.2 Statistical discrepancies in intermediate data } \\
\text { are assessed and investigated. } \\
\text { 3.4.3 Statistical discrepancies and other potential } \\
\text { indicators of problems in statistical outputs are } \\
\text { investigated. } \\
\text { 3. } 5.1 \text { Studies and analyses of revisions are } \\
\text { carried out routinely and used to inform statistical } \\
\text { processes. }\end{array}$ \\
\hline
\end{tabular}


Data Quality Assessment Framework - Generic Framework (continued) (July 2001 Vintage)

\begin{tabular}{|c|c|c|}
\hline Quality Dimensions & Elements & Indicators \\
\hline $\begin{array}{l}\text { 4. Serviceability } \\
\text { Statistics are } \\
\text { relevant, timely, } \\
\text { consistent, and } \\
\text { follow a predictable } \\
\text { revisions policy. }\end{array}$ & $\begin{array}{l}\text { 4.1 Relevance-Statistics cover } \\
\text { relevant information on the subject } \\
\text { field. } \\
\text { 4.2 Timeliness and periodicity - } \\
\text { Timeliness and periodicity follow } \\
\text { internationally accepted } \\
\text { dissemination standards. } \\
\text { 4.3 Consistency_Statistics are } \\
\text { consistent within the dataset, over } \\
\text { time, and with major datasets. } \\
\\
\text { 4.4 Revision policy and } \\
\text { practice-Data revisions follow a } \\
\text { regular and publicized procedure. }\end{array}$ & $\begin{array}{l}\text { 4.3.1 Statistics are consistent within the dataset } \\
\text { (e.g., accounting identities observed). } \\
\text { 4.3.2 Statistics are consistent or reconcilable over } \\
\text { a reasonable period of time. } \\
\text { 4.3.3 Statistics are consistent or reconcilable with } \\
\text { those obtained through other data sources and/or } \\
\text { statistical frameworks. } \\
\text { 4.4.1 Revisions follow a regular, well-established } \\
\text { and transparent schedule. } \\
\text { 4.4.2 Preliminary data are clearly identified. } \\
\text { 4.4.3 Studies and analyses of revisions are made } \\
\text { public. }\end{array}$ \\
\hline
\end{tabular}


Data Quality Assessment Framework-Generic Framework (concluded) (July 2001 Vintage)

\begin{tabular}{|c|c|c|}
\hline Quality Dimensions & Elements & Indicators \\
\hline $\begin{array}{l}\text { 5. Accessibility } \\
\text { Data and metadata } \\
\text { are easily available } \\
\text { and assistance to } \\
\text { users is adequate }\end{array}$ & $\begin{array}{l}\text { 5.2 Metadata accessibility_Up- } \\
\text { to-date and pertinent metadata are } \\
\text { made available. } \\
5.3 \text { Assistance to users-Prompt } \\
\text { and knowledgeable support service } \\
\text { is available. }\end{array}$ & $\begin{array}{l}\text { 5.1.1 Statistics are presented in a way that } \\
\text { facilitates proper interpretation and meaningful } \\
\text { comparisons (layout and clarity of text, tables, } \\
\text { and charts). } \\
\text { 5.1.2 Dissemination media and formats are } \\
\text { adequate. } \\
\text { 5.1.3 Statistics are released on the pre-announced } \\
\text { schedule. } \\
\text { 5.1.4 Statistics are made available to all users at } \\
\text { the same time. } \\
\text { 5.1.5 Nonpublished (nonconfidential) } \\
\text { subaggregates are made available upon request. } \\
\text { 5.2.1 Documentation on concepts, scope, } \\
\text { classifications, basis of recording, data sources, } \\
\text { and statistical techniques is available, and } \\
\text { differences from internationally accepted } \\
\text { standards, guidelines or good practices are } \\
\text { annotated. } \\
\text { 5.2.2 Levels of detail are adapted to the needs of } \\
\text { the intended audience. } \\
\text { 5.3.1 Contact person for each subject field is } \\
\text { publicized. } \\
\text { 5.3.2 Catalogues of publications, documents, and } \\
\text { other services, including information on any } \\
\text { charges, are widely available. }\end{array}$ \\
\hline
\end{tabular}

${ }^{1}$ The elements and indicators included here bring together the pointers to quality that are applicable across the five identified dimensions of data quality. 


\section{Users' Survey}

\section{Summary of Results of Survey of Data Users}

1. With the assistance of the authorities, and to complement the Fund staff's own assessment of the quality of Peru's macroeconomic statistics, the mission that visited Lima during February 12-26, 2003 conducted an informal survey of banks, public sector agencies, academia, media, and international organizations. Public sector agencies included government agencies, autonomous institutions, and nonfinancial public corporations. The survey asked users to evaluate four specific aspects of Peruvian macroeconomic statistics — namely, (i) coverage and detail; (ii) periodicity and timeliness; (iii) other dissemination practices; and (iv) accessibility — as well as to provide an overall assessment.

2. Seventy one of a sample of 125 users responded. The response rate of 57 percent overall compares well with similar surveys conducted in other countries. Of the responses, 34 percent were submitted by the nonfinancial private sector; 27 percent by the banks; 21 percent by public policy organizations; 14 percent by academics; and 4 percent by international organizations.

3. The table below shows that these respondents' views were mostly positive: on the scale of 1 to 5, being 5 excellent, the average rate was 3.5. Private sector analysts responded above average (3.7), while academics did below average (3.2). Banks, public sector and international organizations had a very similar opinion of the overall quality of official statistics (3.5 in all cases).

4. Respondents were broadly satisfied with the coverage and the detail provided by macroeconomic statistics, the frequency and timeliness of the data, the access to the data, as well as the unbiased and accurate nature of data. They were critical of the lack of information on revisions to the data, and the quality of information on methodology used in compiling the statistics. Notwithstanding these critical assessments, most respondents considered Peru's statistics to be of about the same quality as those of the other countries in the region.

5. Many respondents took the opportunity to provide comments and suggestions on Peru's statistics; these are summarized below. Data provided by the Central Reserve Bank of Peru (CRBP) and the Superintendency of Banks and Insurance Companies (SBIC) are considered of good quality, while data of the National Institute of Statistics and Informatics (NISI) and the Ministry of Economy and Finance (MEF) are viewed of less quality. A great deal of users expressed the need to produce more disaggregated and sound national accounts and labor market statistics. Dissemination of data has become more transparent and easy to access with the use of Internet. However, methodological notes on macroeconomic statistics are not always detailed enough. Finally, timeliness is considered generally better than accuracy and reliability of the data. 
6. Selected comments are summarized and grouped into four categories below:

(i) methodological soundness; (ii) accuracy and reliability; (iii) serviceability; and

(iv) accessibility.

\section{Comments of Respondents to User Survey}

\section{Methodological soundness}

- National accounts should have better coverage.

- BOP statistics are too aggregated.

- CPI and WPI should provide more details.

- There is no information on GDP by regions.

- There is no information on CPI by regions.

- There is no data on imports and exports by product.

- Methodology used to calculate GDP is not adequate.

\section{Accuracy and reliability}

- The CRBP should publish its projections on major macroeconomic indicators.

- National accounts do not follow a pre-announced schedule of publication.

- GDP figures are not timely (frequently mentioned by users).

- Timeliness is better than accuracy and reliability of the data.

\section{Serviceability}

- The methodology for revisions on monetary statistics is not known to users.

- Even when revisions are important, the CRBP and INEI do not comment on the reasons for such changes.

- There is no dissemination of revisions in the historical series, being therefore difficult for the user to maintain homogeneous time series.

- Expected revision dates are not publicized.

\section{Accessibility}

- Data provided by the CRBP and SBIC are good, while data of the NISI and MEF are poorer and with no availability of historical series.

- The CRBP website should be improved.

- Access to historical series in the INEI website is difficult.

- Methodological notes are not always detailed enough.

- Dissemination of data has become more transparent and easy to access with the use of Internet. 
Table 1. Results of Peru's User Survey (number of responses in each category)

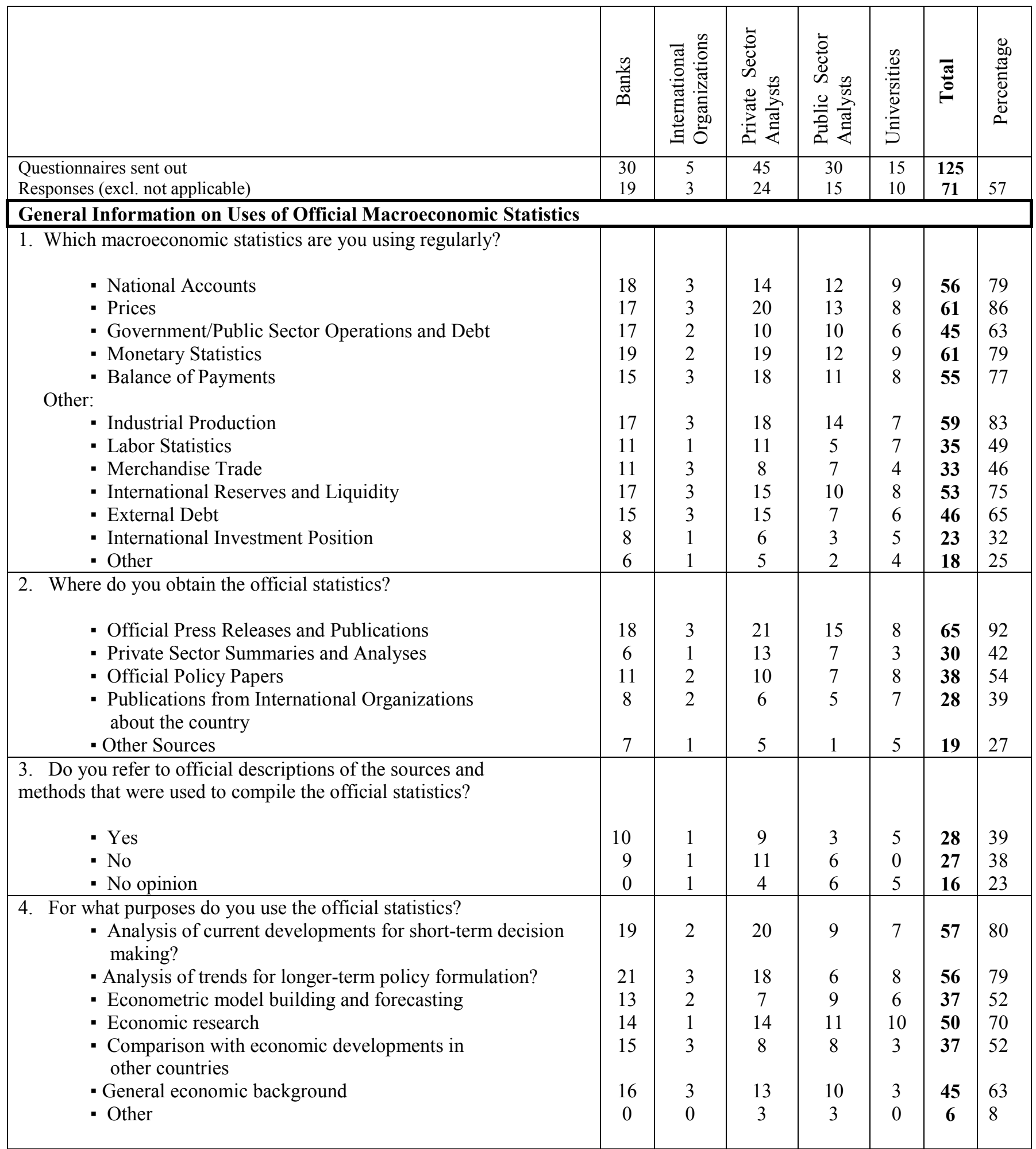




\begin{tabular}{|c|c|c|c|c|c|c|c|}
\hline & $\begin{array}{l}\tilde{y} \\
\tilde{\tilde{E}}\end{array}$ & 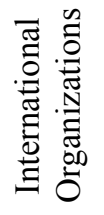 & 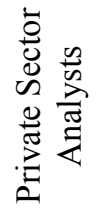 & 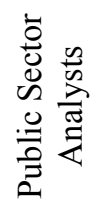 & 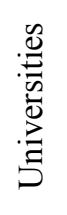 & $\stackrel{\bar{\pi}}{\stackrel{0}{\theta}}$ & 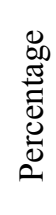 \\
\hline \multicolumn{8}{|l|}{ Quality Aspects of the Official Macroeconomic Statistics } \\
\hline $\begin{array}{l}5.1 \text { Is the coverage of these statistics satisfactory? } \\
\text { Y Yes } \\
\text { - No No opinion }\end{array}$ & $\begin{array}{c}11 \\
6 \\
3\end{array}$ & $\begin{array}{l}1 \\
2 \\
0\end{array}$ & $\begin{array}{c}17 \\
5 \\
2 \\
\end{array}$ & $\begin{array}{c}10 \\
4 \\
1\end{array}$ & $\begin{array}{l}4 \\
5 \\
0\end{array}$ & $\begin{array}{c}43 \\
22 \\
6\end{array}$ & $\begin{array}{l}61 \\
31 \\
8\end{array}$ \\
\hline $\begin{array}{l}5.2 \text { Is the detail provided by these statistics satisfactory? } \\
\text { - Yes } \\
\text { - No } \\
\text { - No opinion }\end{array}$ & $\begin{array}{c}10 \\
6 \\
3\end{array}$ & $\begin{array}{l}2 \\
1 \\
0\end{array}$ & $\begin{array}{c}17 \\
7 \\
0\end{array}$ & $\begin{array}{l}8 \\
6 \\
1\end{array}$ & $\begin{array}{l}7 \\
3 \\
0\end{array}$ & $\begin{array}{c}44 \\
23 \\
4\end{array}$ & $\begin{array}{l}62 \\
32 \\
6\end{array}$ \\
\hline $\begin{array}{l}\text { 6.1 Is the frequency (e.g. weekly, monthly, quarterly, annual } \\
\text { compilation) of these statistics satisfactory? } \\
\text { - Yes } \\
\text { - No } \\
\text { - No opinion }\end{array}$ & $\begin{array}{c}16 \\
2 \\
1 \\
\end{array}$ & $\begin{array}{l}3 \\
0 \\
0 \\
\end{array}$ & $\begin{array}{c}19 \\
3 \\
2 \\
\end{array}$ & $\begin{array}{c}10 \\
5 \\
0 \\
\end{array}$ & $\begin{array}{l}8 \\
2 \\
0 \\
\end{array}$ & $\begin{array}{c}56 \\
12 \\
3 \\
\end{array}$ & $\begin{array}{l}79 \\
17 \\
4 \\
\end{array}$ \\
\hline $\begin{array}{l}\text { 6.2 Is the timeliness (the delay of publication) of these } \\
\text { statistics satisfactory? } \\
\text { - Yes } \\
\text { - No } \\
\text { - No opinion }\end{array}$ & $\begin{array}{c}10 \\
7 \\
2\end{array}$ & $\begin{array}{l}3 \\
0 \\
0\end{array}$ & $\begin{array}{c}12 \\
10 \\
2\end{array}$ & $\begin{array}{l}8 \\
5 \\
2 \\
\end{array}$ & $\begin{array}{l}8 \\
2 \\
0\end{array}$ & $\begin{array}{c}41 \\
24 \\
6\end{array}$ & $\begin{array}{l}58 \\
34 \\
8\end{array}$ \\
\hline $\begin{array}{l}\text { 7.1 Do you know if there is a publicly disseminated } \\
\text { calendar that announces the dissemination of the various } \\
\text { - Yes } \\
\text { - No } \\
\text { - No opinion }\end{array}$ & $\begin{array}{c}14 \\
4 \\
1\end{array}$ & $\begin{array}{l}2 \\
1 \\
0\end{array}$ & $\begin{array}{c}7 \\
16 \\
1\end{array}$ & $\begin{array}{l}9 \\
5 \\
1\end{array}$ & $\begin{array}{l}5 \\
5 \\
0\end{array}$ & $\begin{array}{c}\mathbf{3 7} \\
\mathbf{3 1} \\
\mathbf{3}\end{array}$ & $\begin{array}{l}52 \\
44 \\
4\end{array}$ \\
\hline $\begin{array}{l}\text { 7.2 If there is a calendar of release dates, are the official } \\
\text { statistics released on the dates announced? } \\
\text { - Yes } \\
\text { - No } \\
\text { - No opinion }\end{array}$ & $\begin{array}{c}11 \\
5 \\
3\end{array}$ & $\begin{array}{l}1 \\
0 \\
2\end{array}$ & $\begin{array}{c}5 \\
7 \\
12 \\
\end{array}$ & $\begin{array}{c}10 \\
0 \\
5\end{array}$ & $\begin{array}{l}3 \\
1 \\
6\end{array}$ & $\begin{array}{l}30 \\
13 \\
28\end{array}$ & $\begin{array}{l}42 \\
18 \\
39\end{array}$ \\
\hline $\begin{array}{l}\text { 7.3 Is there enough information about revisions to } \\
\text { official statistics to satisfy your needs? } \\
\text { - Yes } \\
\text { - No } \\
\text { - No opinion }\end{array}$ & $\begin{array}{l}9 \\
7 \\
3\end{array}$ & $\begin{array}{l}3 \\
0 \\
0\end{array}$ & $\begin{array}{c}8 \\
10 \\
6\end{array}$ & $\begin{array}{l}6 \\
6 \\
3\end{array}$ & $\begin{array}{l}5 \\
4 \\
1\end{array}$ & $\begin{array}{l}31 \\
27 \\
13\end{array}$ & $\begin{array}{l}44 \\
38 \\
18\end{array}$ \\
\hline $\begin{array}{l}\text { 8.1 Are the official statistics referred in item } 1 \text { easily } \\
\text { accessible to you? } \\
\text { - Yes } \\
\text { - No } \\
\text { - No opinion }\end{array}$ & $\begin{array}{c}16 \\
2 \\
1\end{array}$ & $\begin{array}{l}3 \\
0 \\
0\end{array}$ & $\begin{array}{c}20 \\
1 \\
3\end{array}$ & $\begin{array}{c}12 \\
1 \\
2\end{array}$ & $\begin{array}{l}8 \\
1 \\
1\end{array}$ & $\begin{array}{c}\mathbf{5 9} \\
\mathbf{5} \\
\mathbf{7}\end{array}$ & $\begin{array}{l}83 \\
7 \\
10\end{array}$ \\
\hline $\begin{array}{l}\text { 8.2 Can you get easy access to information pertaining to official } \\
\text { statistics you use (explanatory notes, methodological descriptions)? } \\
\text { - Yes } \\
\text { - No } \\
\text { - No opinion }\end{array}$ & $\begin{array}{c}12 \\
5 \\
2\end{array}$ & $\begin{array}{l}3 \\
0 \\
0\end{array}$ & $\begin{array}{c}11 \\
8 \\
5\end{array}$ & $\begin{array}{l}8 \\
5 \\
2\end{array}$ & $\begin{array}{l}6 \\
2 \\
2\end{array}$ & $\begin{array}{l}40 \\
20 \\
11\end{array}$ & $\begin{array}{l}56 \\
28 \\
15\end{array}$ \\
\hline
\end{tabular}




\begin{tabular}{|c|c|c|c|c|c|c|c|}
\hline & 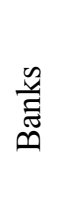 & 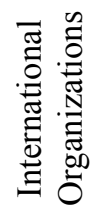 & 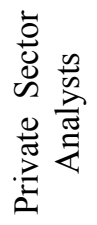 & 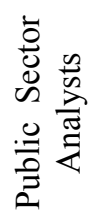 & 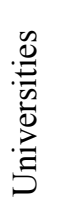 & $\stackrel{\bar{\pi}}{\theta}$ & 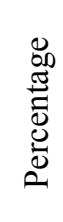 \\
\hline $\begin{array}{l}8.3 \text { Is the above information on methodology clear and adequate? } \\
\text { - Yes } \\
\text { - No } \\
\text { - No opinion }\end{array}$ & $\begin{array}{l}7 \\
5 \\
7\end{array}$ & $\begin{array}{l}1 \\
0 \\
2\end{array}$ & $\begin{array}{l}9 \\
7 \\
8\end{array}$ & $\begin{array}{l}6 \\
6 \\
3\end{array}$ & $\begin{array}{l}4 \\
3 \\
3\end{array}$ & $\begin{array}{l}27 \\
21 \\
23\end{array}$ & $\begin{array}{l}38 \\
30 \\
32\end{array}$ \\
\hline $\begin{array}{l}\text { 8.4 How do you get access to official statistics? } \\
\text { (Total responses computed) } \\
\text { - Hard copy } \\
\text { - Electronic form }\end{array}$ & $\begin{array}{l}16 \\
18\end{array}$ & $\begin{array}{l}1 \\
2\end{array}$ & $\begin{array}{l}22 \\
23\end{array}$ & $\begin{array}{l}15 \\
14\end{array}$ & $\begin{array}{l}10 \\
10\end{array}$ & $\begin{array}{l}64 \\
67\end{array}$ & $\begin{array}{l}90 \\
94\end{array}$ \\
\hline $\begin{array}{l}9.1 \text { Is the underlying methodology of official statistics } \\
\text { sound and appropriate? } \\
\text { - Yes } \\
\text { - No } \\
\text { - No opinion }\end{array}$ & $\begin{array}{c}10 \\
5 \\
4\end{array}$ & $\begin{array}{l}1 \\
0 \\
2\end{array}$ & $\begin{array}{c}10 \\
9 \\
5\end{array}$ & $\begin{array}{l}9 \\
2 \\
4\end{array}$ & $\begin{array}{l}1 \\
4 \\
5\end{array}$ & $\begin{array}{l}31 \\
20 \\
20\end{array}$ & $\begin{array}{l}44 \\
28 \\
28\end{array}$ \\
\hline $\begin{array}{l}\text { 9.2 Do you consider the official statistics to be unbiased and } \\
\text { accurate? } \\
\text { - Yes } \\
\text { - No } \\
\text { - No opinion }\end{array}$ & $\begin{array}{c}11 \\
3 \\
5 \\
\end{array}$ & $\begin{array}{l}2 \\
0 \\
1 \\
\end{array}$ & $\begin{array}{c}13 \\
5 \\
6 \\
\end{array}$ & $\begin{array}{l}8 \\
3 \\
4 \\
\end{array}$ & $\begin{array}{l}5 \\
2 \\
3 \\
\end{array}$ & $\begin{array}{l}39 \\
13 \\
19 \\
\end{array}$ & $\begin{array}{l}55 \\
18 \\
27 \\
\end{array}$ \\
\hline $\begin{array}{l}9.3 \text { How do you compare the quality of official statistics of } \\
\text { Peru with those of other countries in the region? } \\
\text { - Better } \\
\text { - Same } \\
\text { - Worse }\end{array}$ & $\begin{array}{c}1 \\
18 \\
0\end{array}$ & $\begin{array}{l}0 \\
3 \\
0\end{array}$ & $\begin{array}{c}4 \\
20 \\
0\end{array}$ & $\begin{array}{c}1 \\
14 \\
0\end{array}$ & $\begin{array}{c}0 \\
10 \\
0\end{array}$ & $\begin{array}{l}6 \\
65 \\
0\end{array}$ & $\begin{array}{l}8 \\
92 \\
0\end{array}$ \\
\hline $\begin{array}{l}9.4 \text { How do you assess the overall quality of the official statistics? } \\
\text { (Average rating from } 1 \text { to } 5 \text { ) }\end{array}$ & 3.5 & 3.5 & 3.7 & 3.5 & 3.2 & 3.5 & -- \\
\hline
\end{tabular}

